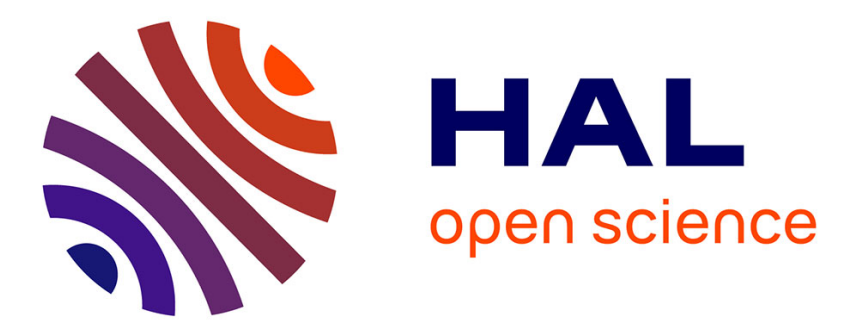

\title{
Circularly polarized luminescence in helicene and helicenoid derivatives \\ Jeanne Crassous
}

\section{To cite this version:}

Jeanne Crassous. Circularly polarized luminescence in helicene and helicenoid derivatives. Circularly Polarized Luminescence of Isolated Small Organic Molecules, Springer Singapore, pp.53-97, 2020, 9789811523090; 9789811523083. 10.1007/978-981-15-2309-0_4 . hal-02931961

\section{HAL Id: hal-02931961 \\ https://hal.science/hal-02931961}

Submitted on 23 Nov 2020

HAL is a multi-disciplinary open access archive for the deposit and dissemination of scientific research documents, whether they are published or not. The documents may come from teaching and research institutions in France or abroad, or from public or private research centers.
L'archive ouverte pluridisciplinaire HAL, est destinée au dépôt et à la diffusion de documents scientifiques de niveau recherche, publiés ou non, émanant des établissements d'enseignement et de recherche français ou étrangers, des laboratoires publics ou privés. 


\title{
Circularly polarized luminescence in helicene and helicenoid derivatives
}

\author{
Jeanne Crassous*,+ \\ ${ }^{\dagger}$ Univ Rennes, CNRS, ISCR (Institut des Sciences Chimiques de Rennes) - UMR6226, F-35000 Rennes, France \\ Email: jeanne.crassous@univ-rennes1.fr
}

Abstract In this chapter, we discuss the circularly polarized luminescence (CPL) of helicene and helicenoid derivatives. The organic helicenic derivatives are classified according to the type of atom (heteroatom or carbon) incorporated within the helical backbone. Transition-metal complexes and chiroptical devices incorporating helicene derivatives and exhibiting CPL activity are also presented. 


\section{Introduction}

Circularly polarized luminescence (CPL) is a fascinating property of many classes of chiral emissive molecules. The well-known luminescence dissymmetry factor $\left(g_{\text {lum }}\right)$ as a measure of the degree of circular polarization of emitted light is defined as $g_{\text {lum }}=2 \Delta I / I=2\left(I_{\mathrm{L}}-I_{\mathrm{R}}\right) /\left(I_{\mathrm{L}}\right.$ $+I_{\mathrm{R}}$ ), where $I_{\mathrm{L}}$ and $I_{\mathrm{R}}$ denote the left- and right-handed circularly polarized emission intensities, respectively. Various types of chiral fluorescent conjugated organic molecules exhibiting

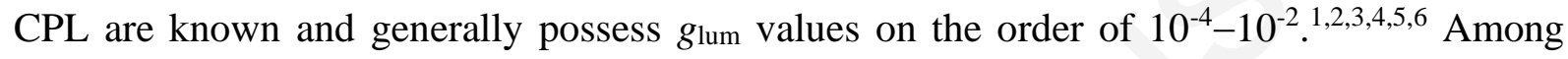
them, helicenes are a special class of chiral molecules which consist of $\mathrm{n}$ ortho-fused aromatic rings combining a helical topology with an extended $\pi$-conjugation. ${ }^{7,8,9}$ Since the first preparation of enantioenriched helicenes in $1956,{ }^{10}$ their chirality has essentially been characterized through their very large optical rotation (OR) values, and their intense and characteristic electronic circular dichroism (ECD). In more rare cases, vibrational circular dichroism (VCD) and Raman Optical Activity (ROA) of helicenes have been measured. More recently, strong interest has grown on the elucidation of the chirality-related emission properties of helicenes. Indeed, helicene derivatives can be regarded as helically-shaped polycyclic aromatic hydrocarbons (PAHs); they thus usually display organic semi-conducting behavior and are efficient chiral emitters. With the development of circularly polarized emission techniques, the CPL activity of helicenes and helicenoids is therefore being more and more investigated. In this chapter, we present the helicene derivatives that have shown to display CPL. Helically twisted acenes will not be considered here.

Theoretically, the luminescence dissymmetry factor $g_{l u m}$ for the electronic transition $i \rightarrow j$ can be expressed by the following equation: $g_{l u m}=4 \frac{\left|\boldsymbol{\mu}_{\mathrm{ij}}\right| \cdot\left|\mathbf{m}_{\mathrm{ji}}\right| \cdot \cos \theta \boldsymbol{\mu}, \mathbf{m}}{\left|\boldsymbol{\mu}_{\mathrm{ij}}\right|^{2}+\left|\mathbf{m}_{\mathrm{ji}}\right|^{2}}$, where $\boldsymbol{\mu}_{\mathrm{ij}}$ and $\mathbf{m}_{\mathrm{ij}}$ are, respectively, the electric and magnetic transition dipole moment vectors, while $\theta \boldsymbol{\mu}, \mathbf{m}$ is the angle between them. In the case of an electronic transition, the $\left|\mathbf{m}_{\mathrm{ji}}\right|$ term is usually small with respect to $\left|\boldsymbol{\mu}_{\mathrm{ij}}\right|$ so the equation becomes: $g_{\text {lum }}=4 \frac{\left|\mathbf{m}_{\mathrm{ji}}\right|}{\left|\boldsymbol{\mu}_{\mathrm{ij}}\right|} \cos \theta \boldsymbol{\mu}, \mathbf{m}$. High $g_{\text {lum }}$ values are therefore usually obtained for magnetic dipole-allowed transitions. For this reason, CPL spectroscopy is widely applied to chiral lanthanide(III) complexes: the magnetically-allowed intraconfigurational $\mathrm{f} \rightarrow \mathrm{f}$ transitions of lanthanide metal ions often provide extraordinary $g_{\text {lum }}$ values. ${ }^{11}$ In general, chiral organic $\pi$-conjugated systems display luminescence dissymmetry factors significantly lower than lanthanide(III) compounds, due to their electronic transitions with strong electric dipole-character. However, their easy processability, the wide range of emission wavelengths accessible and good quantum yields of fluorescence, together with their propensity to self-assemble into chiral supramolecules or aggregates makes chiral $\pi$ - 
conjugated molecules appealing systems for improved materials with CPL activity.4 Therefore, there is a growing interest in the investigation of the CPL properties of chiral $\pi$-conjugated systems.

In 2018, Mori et al. tried to see whether there was a correlation between excitation and emission dissymmetry factors; they examined the experimental ratio $g_{\text {lum }} / g_{\text {abs }}$ for a series of chiral organic emissive molecules among which helicenes. They found that this ratio significantly depended on the structure of the helicenic molecule and varied between 0.16 and $28 .{ }^{12}$

This chapter is structured via the different types of CPL-active helicene derivatives, i.e. the $\mathrm{N}, \mathrm{O}, \mathrm{S}, \mathrm{B}, \mathrm{Si}, \mathrm{P}$ and C-based helicenes and helicenoids, together with transition metal complexes of helicenes exhibiting CPL.

\section{CPL-active $\mathrm{N}$-containing helicenes}

\subsection{Helicenic bridged triarylamines}

In 2003, Venkataraman et al. described the preparation of helical triarylamines. These compounds were among the first helicenic structures displaying clear CPL-activity. ${ }^{13}$ The two diastereomers of $(P, S)$-1a and $(M, S)$-1b displayed identical absorption spectra (Fig. 1a and $1 \mathrm{~b}$ and Table 1) in the UV-vis region with maximum absorption and emission occurring at 434 $\mathrm{nm}$ and $453 \mathrm{~nm}$ respectively. These pseudoenantiomeric compounds showed mirror-image ECD and CPL spectra, revealing that the (1S)-camphanate substituent had no influence on the chiroptical properties. Fluorescence dissymmetry factors of \pm 0.001 were obtained in chloroform. For the longer and more $\pi$-conjugated helicenes $(P, S)-\mathbf{2 a}$ and $(M, S)-\mathbf{2 b}$, the maximum emission occured at longer wavelength, i.e. $478 \mathrm{~nm}$, and slightly smaller fluorescence dissymmetry factors $( \pm 0.0008)$ were obtained. For both compounds $\mathbf{1}$ and $\mathbf{2}$, and for the same transition, $g_{\text {abs }}$ and $g_{\text {lum }}$ have essentially the same value showing no significant geometry change upon population of the emitting state. This is corroborated by the small Stokes shifts of the emission maxima. In 2016, the CPL activity of sulfurated systems 3 and 4 was measured by Longhi et al. ${ }^{14}$ who found a $g_{\text {lum }}$ as high $0.9 \times 10^{-2}$ at $\sim 510 \mathrm{~nm}$ (positive for $(M)$ and vice versa, Table 1) for $\mathbf{4}$ while racemization was observed upon excitation of $\mathbf{3}$. Post-functionalization of heterohelicene 5 with formyl (6) and diacyanovinyl (7) groups enabled to extend the $\pi$-conjugation. ${ }^{15}$ The tails of UV/vis and ECD spectra together with emission and CPL bands in $\mathrm{CH}_{2} \mathrm{Cl}_{2}$ are highlighted in Fig. 2. These compounds are strongly emissive, with quantum yields up to 0.86 for $\mathbf{5}$ in $\mathrm{CH}_{2} \mathrm{Cl}_{2}$ (Table 1). A clear red shift of absorption and emission was observed upon increasing the conjugation. The strong charge transfer and high polarity of these molecules were evidenced experimentally through the high solvent polarity dependence of the emission properties (emission wavelength and quantum 
yield). Regarding the chiroptics, similar $g_{\text {abs }}$ and $g_{\text {lum }}$ magnitudes were found for each compound with $g_{\text {abs }} / g_{\text {lum }}$ of $+5.6 \times 10^{-3} /+4.7 \times 10^{-3}$ for $(M)-5,+2.1 \times 10^{-3} /+1.4 \times 10^{-3}$ for (M)-6, and $+0.9 \times 10^{-3} /+0.9 \times 10^{-3}$ for $(M)-7$. These properties were also compared in liquid state/solid state and in nanoparticles obtained by rapid precipitation in water. Respective $g_{\text {lum }}$ values of $4.5 \times 10^{-3}, 1.5 \times 10^{-3}$, and $2.8 \times 10^{-3}$, were measured for nanoparticles of $\mathbf{5}, \mathbf{6}$ and $\mathbf{7}$ dispersed in water, showing that CPL activity was conserved. Note that the influence of solvent polarity was studied on the quantum yields but not on the absolute CPL values.

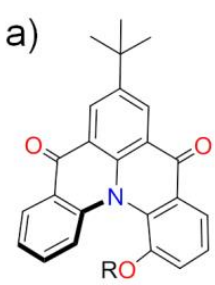

$(P, S)-1 \mathbf{a}$

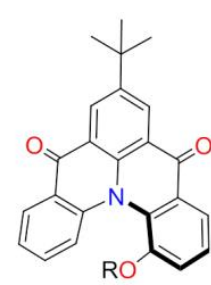

$(M, S)-1 b$

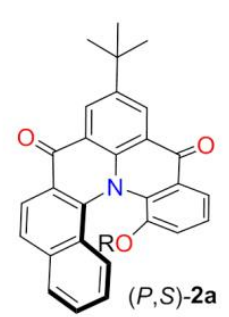

$(P, S)-2 a$
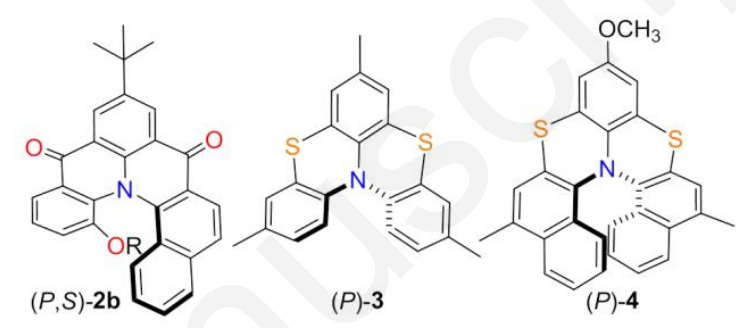

$\mathrm{R}=(\mathrm{S})$-Camphanate

b)

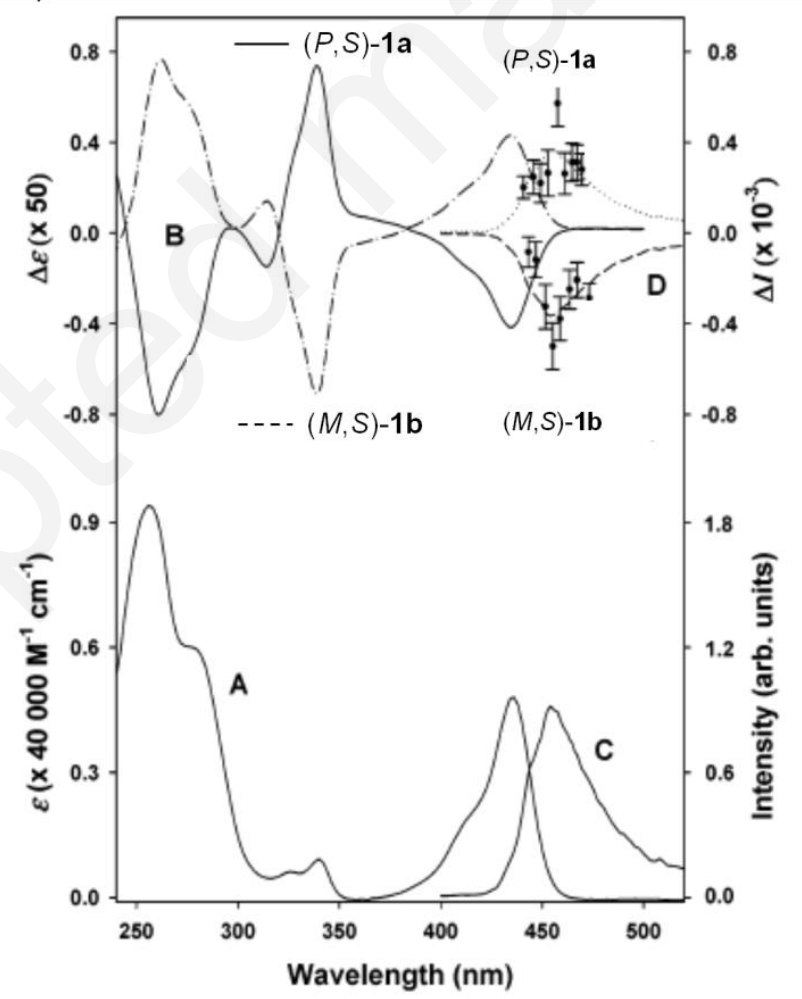

Fig. 1. a) Chemical structures of helical bridged triarylamines $\mathbf{1} \mathbf{a}, \mathbf{b}, \mathbf{2} \mathbf{a}, \mathbf{b}$ and 3-7. b) UV-vis (A), ECD (B), fluorescence (C) and CPL (D) spectra of $(P, S)$-1a and $(M, S)$-1 b in $\mathrm{CHCl}_{3}$. Reproduced with permission. ${ }^{13}$ Copyright 2003, American Chemical Society. 


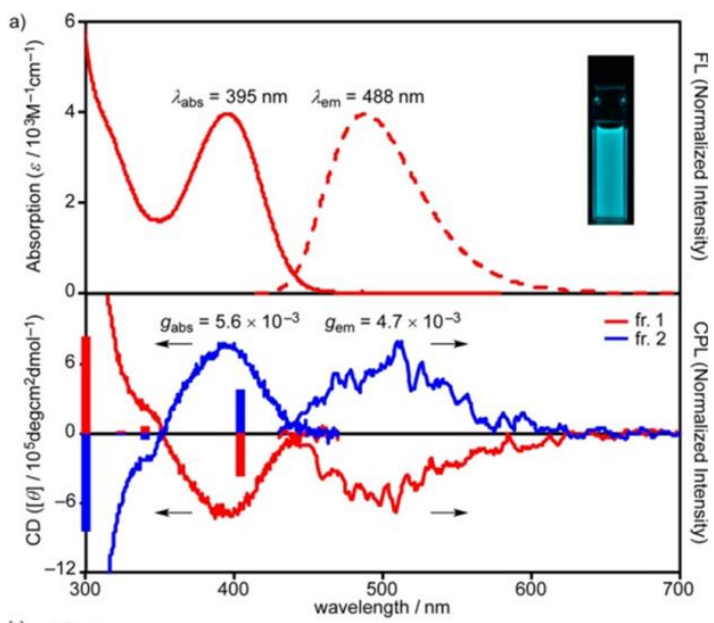<smiles>c1ccc2c(c1)Oc1cccc3c1N2c1c(ccc2ccccc12)O3</smiles>

5

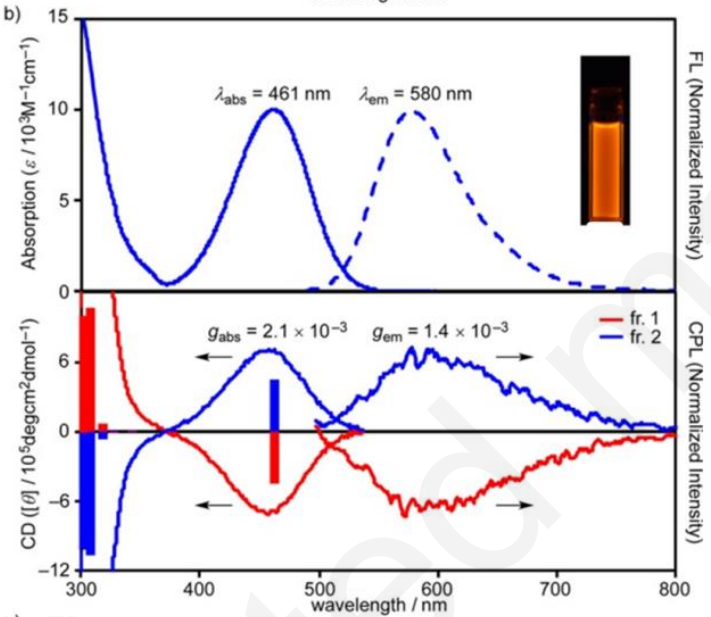<smiles>O=Cc1cc2c(c3ccccc13)[C@@H]1c3ccccc3Oc3cccc(c31)O2</smiles>

6

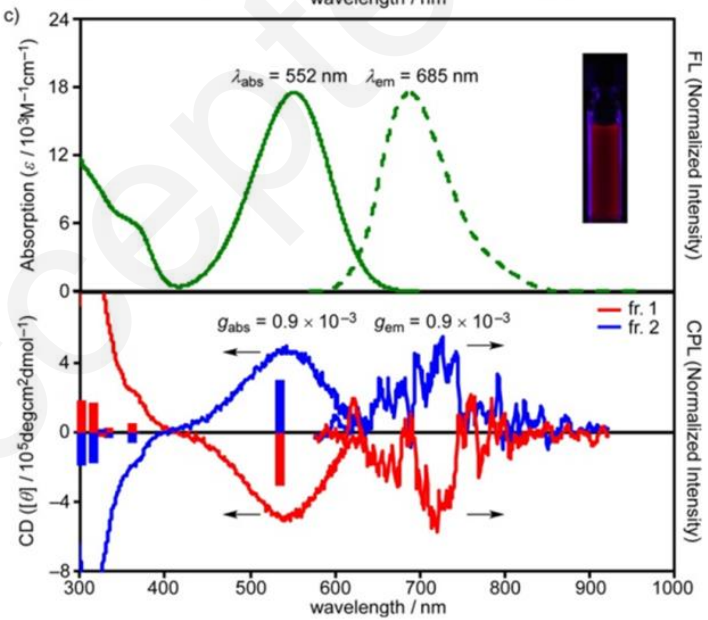<smiles>N#CC(C#N)=Cc1cc2c(c3ccccc13)[C@@H]1c3ccccc3Oc3cccc(c31)O2</smiles>

7

Fig. 2. UV-vis absorption (solid) and fluorescence (dashed) spectra (top), and $\mathrm{CD}$ and $\mathrm{CPL}$ spectra (bottom) for 5, 6, and $\mathbf{7}$ in $\mathrm{CH}_{2} \mathrm{Cl}_{2}$. The red and blue bars show the calculated ECD bands (CAM-B3LYP/6-31G(d)) for the $(P)$ - and $(M)$-helices, respectively. The transition energies have been calibrated using a factor of 0.88. Photographs show the emission of 5-7. Reproduced with permission. ${ }^{15}$ Copyright 2017, American Chemical Society. 


\subsection{Emission properties and CPL activity of azahelicenes}

In 2014, Abbate et al. reported the CPL activity of blue-fluorescent 5-aza[6]helicene (8) enantiomers in relation to their ECD spectrum (Fig. 3 and 4). ${ }^{16}$ The sign of the CPL signal was controlled by the sign of the lower energy ECD named S-type band in relation with Inoue and Mori's nomenclature. ${ }^{17}$ This effect was also shown in carbo[6]helicenes $(M)$-10 and $(M)$ 11 which exhibited positive CPL signals at $\sim 410$ and $415 \mathrm{~nm}$ respectively in $\mathrm{CHCl}_{3}$ (vide infra). ${ }^{16}$ In 2016, Longhi and Santoro reported the vibronically resolved calculated UV-vis, ECD, emission, and CPL spectra of 8. A CPL dissymmetry factor $g_{\text {lum }}$ of $+0.59 \times 10^{-3}$ at 444 $\mathrm{nm}$ was experimentally measured for $(M)-8$ in $\mathrm{CHCl}_{3}$ (Table 1) and used as a helically shaped chiral model to test the validity of advanced theoretical calculations of chiroptical techniques. ${ }^{18}$ Note that the $g_{\text {lum }}$ value of corresponding 1-aza[6] helicene 9 was evaluated to be between $10^{-4}-10^{-3}$ by Fuchter, Campbell and coworkers who used this helicene as a chiral inducer in Organic Light-Emitting Diodes (OLEDs, see paragraph 10). ${ }^{19}$

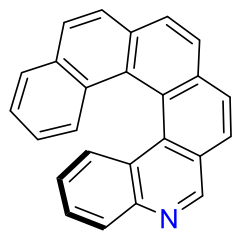

$(M)-8$

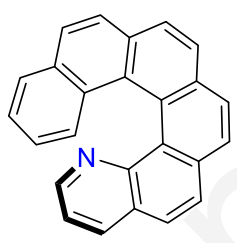

(M)-9

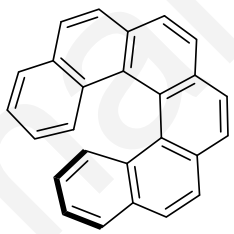

$(M)-10$

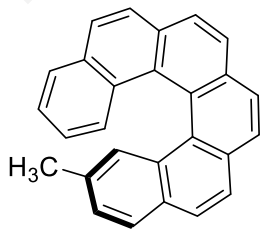

$(M)-11$

Fig. 3. Structures of aza[6] helicenes $\mathbf{8 , 9}$ and carbo[6]helicenes $\mathbf{1 0 , 1 1} \cdot{ }^{16,19}$

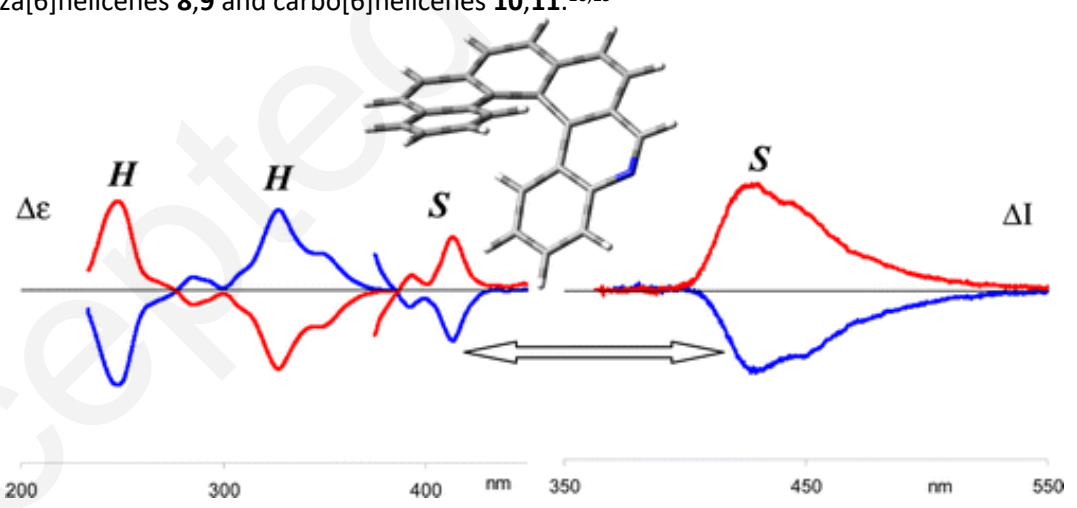

Fig. 4. ECD and CPL spectra of 8 in $\mathrm{CHCl}_{3}$. Reproduced with permission. ${ }^{16}$ Copyright 2014, American Chemical Society.

\subsection{Double vs. single azahelicenes}

In 2014 Tanaka and coworkers reported the enantioselective synthesis of azahelicenes $\mathbf{1 2}$ and 13, and of S-shaped double azahelicenes 15 and 16 (Fig. 5). ${ }^{20,21}$ Their photophysical properties are summarized in Table 1. Double azahelicenes $\mathbf{1 5}$ and $\mathbf{1 6}$ showed red shifts of absorption and emission maxima as compared with their corresponding single azahelicenes $\mathbf{1 2}$ and 13. They also showed higher quantum yields in $\mathrm{CHCl}_{3}$ solution. Interestingly, the $\mathrm{CPL}$ activity of the $\mathrm{S}$-shaped double azahelicenes was significantly higher than that of the single 
azahelicenes. Indeed, CPL measurements showed intensities for azahelicenes $\mathbf{1 2}$ and $\mathbf{1 3}$ were below their measurable limit $\left(g_{\text {lum }}<0.001\right)$ whereas double azahelicenes $\mathbf{1 5}$ and $\mathbf{1 6}$ exhibited strong CPL activities, with $g_{\text {lum }}=0.028$ at $492 \mathrm{~nm}$ for $(+)-\mathbf{1 5}$ and $g_{\text {lum }}=+0.011$ at $454 \mathrm{~nm}$ for (+)-16 in $\mathrm{CHCl}_{3} .{ }^{20}$ In 2016, (-) and (+)-aza[10]helicenes 14 were found to display $\left|g_{\text {abs }}\right|=4.5$ $\times 10^{-3}$ at $303 \mathrm{~nm}$ which correspond to a smaller value than for $S$-shaped $16\left(\left|g_{\text {abs }}\right|=6.5 \times 10^{-3}\right.$ at $331 \mathrm{~nm}$ ) but no CPL activity could be measured for $14 .^{21}$

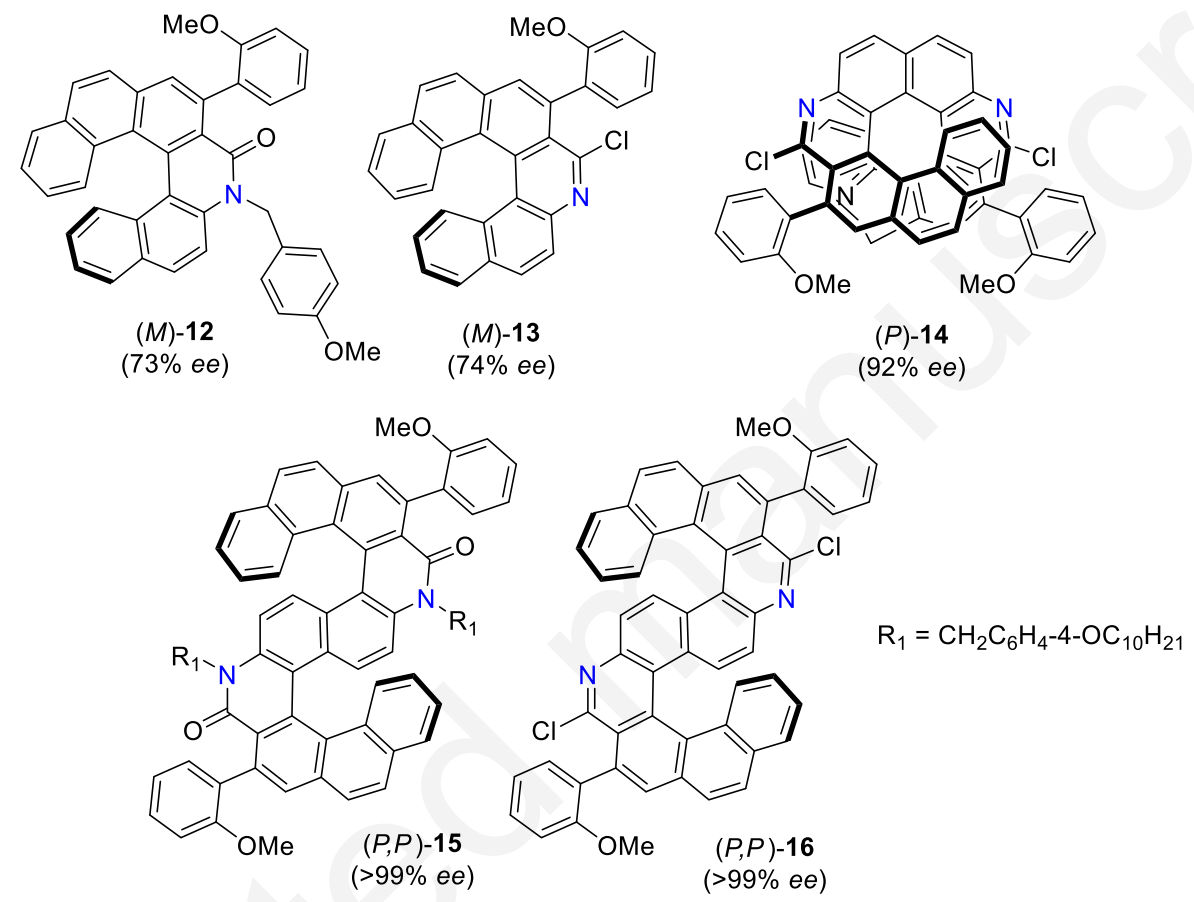

Fig. 5. Chemical structures of enantioenriched single aza[6]helicenes 12-14 and S-shaped double aza[6]helicenes 15,16. ${ }^{20,21}$

To explain the enhancement of CPL in S-shaped double helicenes, Mori et al. proposed in 2018 a protocol for rationally aligning multiple chiral units to boost the chiroptical responses, using hexahelicene $\mathbf{1 0}$ as a prototype. ${ }^{22}$ To do so, they aligned two hexahelicenes in various orientations and examined by theoretical calculations which orientation resulted in the highest chiroptical performance from X-shaped or S-shaped double hexahelicenes (see paragraph 8.2.).

\subsection{Polyaza[7]helicenes}

In 2017, Shibata et al. reported the synthesis of enantiopure polyaza[7]helicenes such as $\mathbf{1 7}$ (Fig. 6) possessing a 6-5-6-6-6-5-6 skeleton $^{23}$ which showed high fluorescence quantum yields under both neutral $\left(\Phi_{\mathrm{F}}=0.39\right)$ and acidic conditions $\left(\Phi_{\mathrm{F}}=0.80\right)$. The ECD spectrum of (+)-17 showed several positive Cotton bands in the longer wavelength region with very similar shapes for both neutral and acidic forms. These observations imply that the electronic tran- 
sitions have similar features in the ground state. Under both conditions, helicene $\mathbf{1 7}$ also

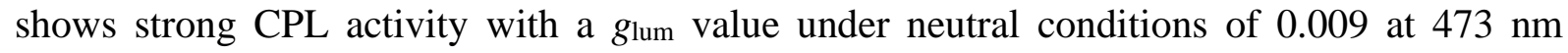
which is quite large for a heptahelicene derivative. Upon addition of 200 equivalent amounts

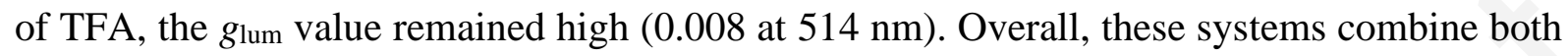
high $g_{\text {lum }}$ value with high quantum yields.
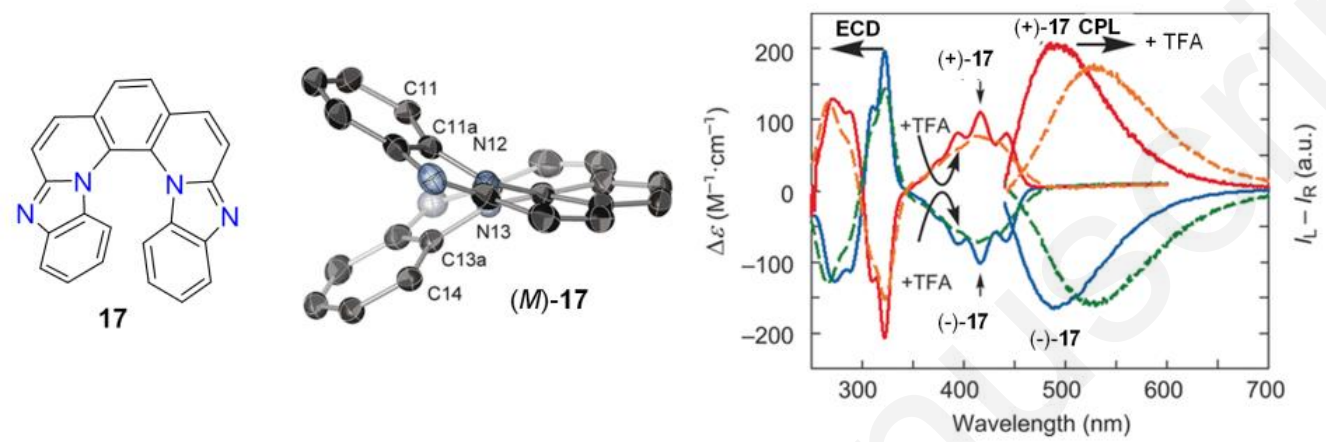

Fig. 6. Chemical structure, X-ray structure, ECD, and CPL spectra of neutral and acidic form of $\mathbf{1 7}$ enantiomers . Adapted with permission. ${ }^{23}$ Copyright 2017, Wiley.

Table 1. Photophysical data of azahelicenes.

\begin{tabular}{|c|c|c|c|c|c|c|c|}
\hline Compound & $\begin{array}{l}\lambda_{\mathrm{Abs}} \operatorname{maxa} \\
(\mathrm{nm})\end{array}$ & $\begin{array}{l}\lambda_{\mathrm{Em}} \\
(\mathrm{nm})\end{array}$ & $\Phi_{\mathrm{F}}(\%)$ & Solvent (CPL) & $10^{3} g_{\text {abs }}$ & $10^{3} \mathrm{~g}_{\mathrm{lum}}$ & Ref. \\
\hline$(P, S)-\mathbf{1 a}$ & 434 & 453 & - & $\mathrm{CHCl}_{3}$ & +1.1 & +0.9 & 13 \\
\hline$(M, S)-\mathbf{1} \mathbf{b}$ & 434 & 453 & - & $\mathrm{CHCl}_{3}$ & -1.1 & -1.1 & 13 \\
\hline$(P, S)-\mathbf{2 a}$ & 442 & 478 & - & $\mathrm{CHCl}_{3}$ & +1.0 & +0.8 & 13 \\
\hline$(M, S)-\mathbf{2 b}$ & 442 & 478 & - & $\mathrm{CHCl}_{3}$ & -1.0 & -0.7 & 13 \\
\hline (M)-4 & 400 & 510 & 1.6 & $\mathrm{CHCl}_{3}$ & $\sim 7.3^{b}$ & 9 & 14 \\
\hline$(M)-5$ & 395 & 488 & 86 & $\mathrm{CH}_{2} \mathrm{Cl}_{2}$ & +5.6 & +4.7 & 15 \\
\hline (M)-6 & 461 & 584 & 44 & $\mathrm{CH}_{2} \mathrm{Cl}_{2}$ & +2.1 & +1.4 & 15 \\
\hline (M)-7 & 552 & 685 & 9 & $\mathrm{CH}_{2} \mathrm{Cl}_{2}$ & +0.9 & +0.9 & 15 \\
\hline (M)-8 & 411 & 444 & - & $\mathrm{CHCl}_{3}$ & +5.16 & +5.9 & 18 \\
\hline$(M)-12$ & 381 & 467 & 5.1 & $\mathrm{CHCl}_{3}$ & $0.09^{b}$ & $<1$ & 20 \\
\hline$(M)-13$ & 325 & 467 & 2.1 & $\mathrm{CHCl}_{3}$ & $0.02^{b}$ & $<1$ & 20 \\
\hline$(P)-14$ & 442 & 477,509 & 1.4 & $\mathrm{CHCl}_{3}$ & 4.5 & $\sim 0$ & 21 \\
\hline$(P, P)-15$ & 448 & 471,492 & 19 & $\mathrm{CHCl}_{3}$ & $\sim 1^{b}$ & $28 \pm 2$ & 20 \\
\hline
\end{tabular}




\begin{tabular}{lccccccc}
\hline$(P, P)-16$ & 445 & 454,480 & 9.4 & $\mathrm{CHCl}_{3}$ & 6.5 & $11 \pm 2$ & 20 \\
$(+)-17$ & 416 & 473 & 39 & $\mathrm{CH}_{2} \mathrm{Cl}_{2}$ & $\sim 133^{b}$ & 9 & 23 \\
$(+)-17+$ TFA (200 eq.) & 416 & 514 & 80 & $\mathrm{CH}_{2} \mathrm{Cl}_{2}$ & - & 8 & 23 \\
\hline
\end{tabular}

${ }^{a}$ Lowest-energy absorption band. ${ }^{b}$ Taken from ref. 12.

\subsection{Azahelicenes with fused carbazole cycles (pyrrolohelicenes)}

Pyrrole-incorporating PHAs have been shown to possess remarkable physical properties such as effective hole-transporting ability and bright emission. In 2012, Hiroto, Shinokubo, et al. reported pyrrole-fused system $\mathbf{1 8}$ displaying an aza[5] helicenic structure with a stable helical conformation thanks to the presence of bulky ethynylsilylated groups (Fig. 7) ${ }^{24}$ Good fluorescence quantum yields were obtained for $18\left(\Phi_{\mathrm{F}}=0.36\right)$ with a Stokes shift of $2220 \mathrm{~cm}^{-1}$ reflecting the distorted conformation of 18; a CPL anisotropy factor $\left|g_{\text {lum }}\right|$ of $3 \times 10^{-3}$ was measured for both enantiomers. The corresponding bis-butadiyne bridged azahelicene dimer $(M, M)$ - and $(P, P)-\mathbf{2 0}$ with a figure-eight shape was prepared, and exhibited red-shifted absorption and emission, with a higher fluorescence quantum yield $\left(\Phi_{\mathrm{F}}=0.55\right)$ and higher $g_{\text {abs }}$ and $g_{\text {lum }}$ values as compared to $(M)$ - and $(P)-\mathbf{1 8}$ (with opposite signs, see Table 2). This enhancement was attributed to the rigid conformation of the dimer. ${ }^{25}$ See paragraph 3 . for the corresponding CPL-active oxygen-containing helicene derivative 19.

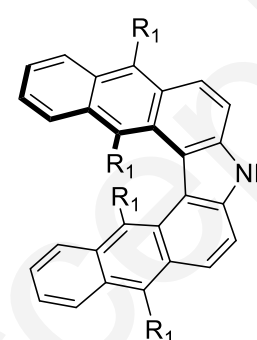

$(P)-18$

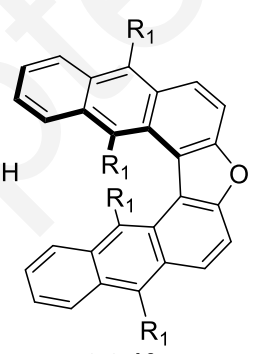

(P)-19

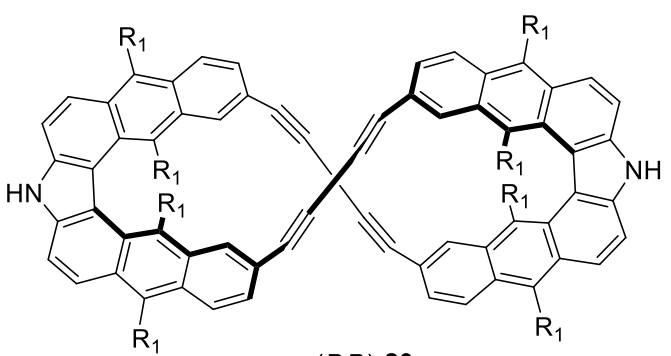

$(P, P)-20$<smiles></smiles>

(P)-21a: $\mathrm{R}_{2}=\mathrm{H}$ $(P)-21 \mathrm{~b}: \mathrm{R}_{2}=\mathrm{OMe}$
(P)-22: $\mathrm{R}_{3}=$ lone pair (P)-22. $\mathrm{H}^{+}: \mathrm{R}_{3}=\mathrm{H}^{+}$

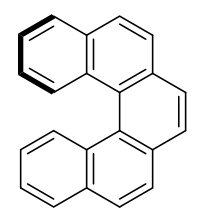

(P)-23

Fig. 7. Chemical structures of pentahelicenes incorporating a carbazole (18) together with a dimer (20) and a dibenzofurane analogue (19); pentahelicenes including imide functions (21a,b and 22, 22. $\left.\mathrm{H}^{+}\right)$together with pentacarbohelicene 23. 


\subsection{Helicene imide derivatives}

Aromatic diimides are known to display bright emission properties. In 2016, Hasobe and coworkers reported [5]carbohelicene derivatives $\mathbf{2 1 a}, \mathbf{b}$ fused with an electron-withdrawing maleimide and substituted with electron-donating methoxy groups. ${ }^{26}$ Compared to pristine [5]carbohelicene 23, the introduction of an electron-withdrawing maleimide group onto a [5]carbohelicene core contributes to the stabilization of the LUMO level in 21a whereas the energy level of HOMO level in MeO-substituted $\mathbf{2 1 b}$ increases due to the electron-donation. As a result, the HOMO-LUMO gap of $\mathbf{2 1 b}$ is smaller than that of 21a and of carbo[5]helicene 23, giving bathochromic shift of absorption and emission bands. The absolute fluorescence quantum yield of $\mathbf{2 1 a}$ was found higher (0.37) as compared to [5]carbohelicene $23(0.04)$, whereas $\Phi_{\mathrm{F}}$ of $\mathbf{2 1 b}$ was slightly smaller (0.22). The chirality of these [5]carbohelicene derivatives 21a,b was evidenced by their ECD and CPL activities. In particular, 21a and 21b gave good CPL activity with anisotropy factors $g_{\text {lum }}$ estimated to be $\pm 2.4 \times 10^{-3}$ and $\pm 2.3 \times 10^{-3}$ in THF. This example was the first observation of CPL in [5]carbohelicene derivatives which are usually thought to be configurationally unstable. Here, the authors verified that the CPL signal was stable with time in solution. Note that this negative CPL signal for the $(P)-(+)$ isomer is a S-type one (vide supra and ref. 17), i.e. corresponding to the small negative ECD signal at $435 \mathrm{~nm}$ with $g_{\text {abs }}$ values of $-4.8 /-5.7 \times 10^{-3}$ for $(P)-(+)-\mathbf{2 1 a} / \mathbf{b}$. The same authors also reported a carbo[5]helicene 22 bearing a fused benzimidazole and its protonated form $22 . \mathrm{H}^{+}$ (see Fig. 7 and Table 2). ${ }^{27}$

In 2016, Chen and coworkers reported the preparation of configurationally stable helical aromatic imides displaying full-color CPL responses. ${ }^{28}$ For this purpose, they prepared enantiomers $(P)-(-)$ - and $(M)-(+)-24 a-e$ with high $e e^{\prime}$ s (98.4-99\%). Each pair of enantiomers displayed mirror-image ECD spectra of moderate magnitude and absolute configurations opposite to those of classical heterohelicenes. (P)-(-)- and $(M)-(+)-\mathbf{2 4 a - e}$ exhibited full colour fluorescence emission (from 445 to $617 \mathrm{~nm}$ ) and mirror-image CPL signals in THF (Fig. 8). The $g_{\text {abs }}$ values of the enantiomers fell within the range of $\pm 1.5 \times 10^{-3}$ to $\pm 3.5 \times 10^{-4}$ and the

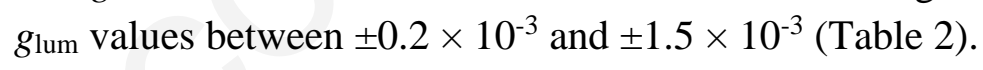


a)

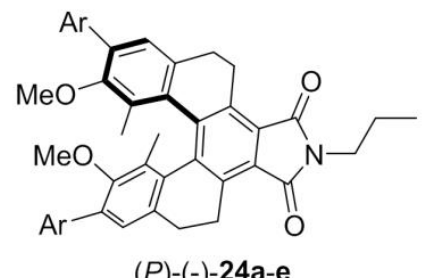

$(P)-(-)-24 a-e$

a: $\mathrm{Ar}=p-\mathrm{CF}_{3}-\mathrm{C}_{6} \mathrm{H}_{4}$

b: $\mathrm{Ar}=\mathrm{Ph}$

c: $\mathrm{Ar}=p-\mathrm{MeO}-\mathrm{C}_{6} \mathrm{H}_{4}$

d: $\mathrm{Ar}=p-\mathrm{Ph}_{2} \mathrm{~N}-\mathrm{C}_{6} \mathrm{H}_{4}$

e: $\mathrm{Ar}=5-\mathrm{Ph}_{2} \mathrm{~N}-2$-thienyl
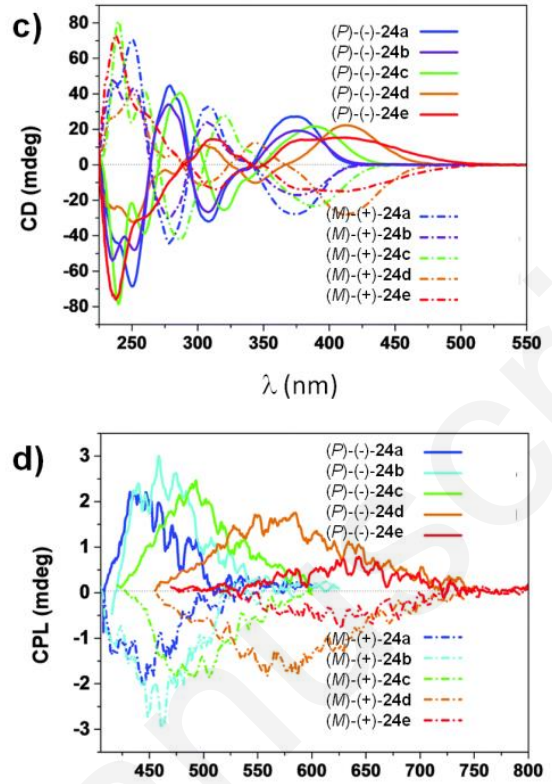

$\lambda(\mathrm{nm})$

Fig. 8. a) Chemical structure of 24a-e ((P)-(-) enantiomers); b) Emission colours panel of 24a-e. c) ECD spectra in THF of pure enantiomers. d) CPL spectra in THF of pure enantiomers. Adapted with permission. ${ }^{28}$ Copyright 2016, Royal Society of Chemistry.

Table 2. Photophysical data of helicenes fused with pyrroles or imide cycles.

\begin{tabular}{|c|c|c|c|c|c|c|c|}
\hline Compound & $\begin{array}{l}\lambda_{\mathrm{Abs}} \max \mathrm{a} \\
(\mathrm{nm})\end{array}$ & $\begin{array}{l}\lambda_{\mathrm{Em}} \\
(\mathrm{nm})\end{array}$ & $\Phi_{\mathrm{F}}(\%)$ & Solvent (CPL) & $10^{3} g_{\text {abs }}$ & $10^{3} \mathrm{glum}$ & Ref. \\
\hline$(P)-(+)-18$ & 503 & 560 & 36 & $\mathrm{CH}_{2} \mathrm{Cl}_{2}$ & $+1.4^{b}$ & +3 & 24 \\
\hline$(P, P)-(+)-20$ & 526 & 588 & 55 & $\mathrm{CH}_{2} \mathrm{Cl}_{2}$ & -8.5 & -8.5 & 25 \\
\hline$(P)-(+)-21 a$ & 456 & $\sim 480$ & 37 & THF & -4.8 & -2.4 & 26 \\
\hline$(P)-(+)-21 \mathbf{b}$ & 475 & $\sim 525$ & 22 & THF & -5.7 & -2.3 & 26 \\
\hline$(P)-(+)-22$ & 450 & 575 & 6 & $\mathrm{CH}_{2} \mathrm{Cl}_{2}$ & - & -9.45 & 27 \\
\hline$(P)-(+)-22 . H^{+}$ & 570 & 650 & 6 & $\mathrm{CH}_{2} \mathrm{Cl}_{2}$ & - & -5.92 & 27 \\
\hline$(P)-(-)-24 a$ & 366 & 445 & 12.8 & THF & -1.55 & -1.2 & 28 \\
\hline$(P)-(-)-24 \mathbf{b}$ & 366 & 457 & 19.2 & THF & -1.33 & -1.5 & 28 \\
\hline$(P)-(-)-24 c$ & 371 & 482 & 64.8 & THF & -1.35 & -0.8 & 28 \\
\hline$(P)-(-)-24 d$ & 387 & 556 & 40.3 & THF & -1.31 & -0.8 & 28 \\
\hline$(P)-(-)-24 \mathbf{e}$ & 415 & 617 & 7.4 & THF & -3.53 & -0.2 & 28 \\
\hline
\end{tabular}

${ }^{a}$ Lowest energy absorption band. ${ }^{b}$ Taken from reference 12. 


\subsection{Carbocationic azahelicenes}

Lacour, Vauthey and coworkers prepared functionalized carbocationic [4]helicene (25-30) and [6] helicene (31-33) derivatives and studied their photophysical and chiroptical properties (Figs. 9 and 10 and Table 3). ${ }^{29,30,31}$ Interestingly, these compounds exhibit fluorescence emissions in the red to near infrared region (with $\Phi_{\mathrm{F}}$ ranging from 0.01 to 0.445 ), which corresponds to an unusual spectral range for helicene-based chromophores, especially for fully organic ones. As a result, these helical derivatives may be interesting for chiral bioimaging. The same authors investigated different diaza[4]helicenium chiral dyes functionalized with different donor and acceptor groups in order to tune their chiroptical properties in terms of ECD and CPL responses (Fig. 9). ${ }^{31}$ These helical derivatives present ECD signatures up to $750 \mathrm{~nm}$ with moderate intensity in the visible-red region $\left(\Delta \varepsilon \sim 10 \mathrm{M}^{-1} \mathrm{~cm}^{-1}\right)$, resulting from partial charge-transfer transitions involving the nitrogen atoms and the central carbocation. Furthermore, CPL emissions were recorded between 650 and $700 \mathrm{~nm}$ and were characterized by a $g_{\text {lum }}$ of $\sim 10^{-4}-10^{-3}$. Such cationic chiral dyes were also used as pH-triggered ECD and CPL chiroptical switches when they possessed $\mathrm{pH}$-sensitive group such as carboxylic acid. For instance, zwitterionic [4]helicene $\mathbf{2 9}$ was reported in 2016 as a reversible pH-triggered ECD/CPL chiroptical switch (Fig. 10). ${ }^{29}$ Protonated $\mathbf{3 0}$ displayed $g_{\text {lum }}$ of around $5 \times 10^{-4}$ and of similar order as $g_{\text {abs }}\left(4 \times 10^{-4}\right)$, while the carboxylate derivative 29 displayed no CPL, probably due to very low emission. Overall it represented an on-off CPL switch. Similarly, longer O-containing and N-containing [6] helicenium derivatives 31-33 displayed CPL signals (with opposite signs compared to their optical rotation values) with $\left|g_{\text {lum }}\right|$ between $0.32 \times 10^{-3}$ and $2.1 \times 10^{-3}$ in the infrared region. ${ }^{30}$ 


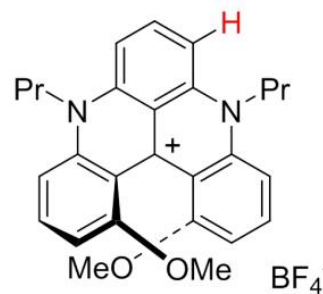

$(P)-25$

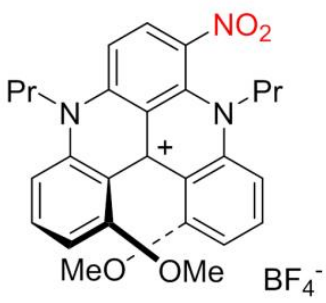

(P)-26

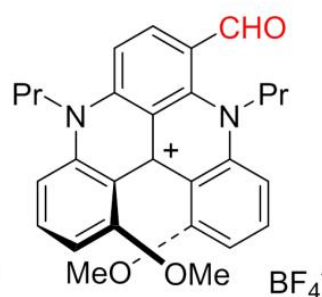

(P)-27

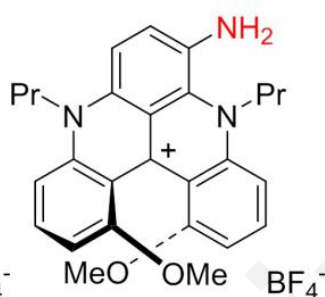

$(P)-28$

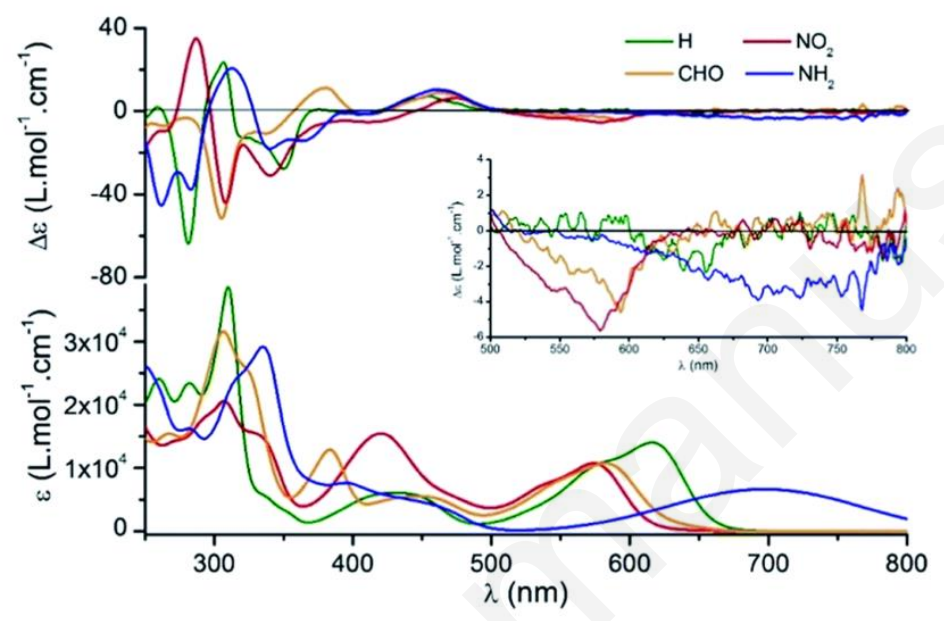

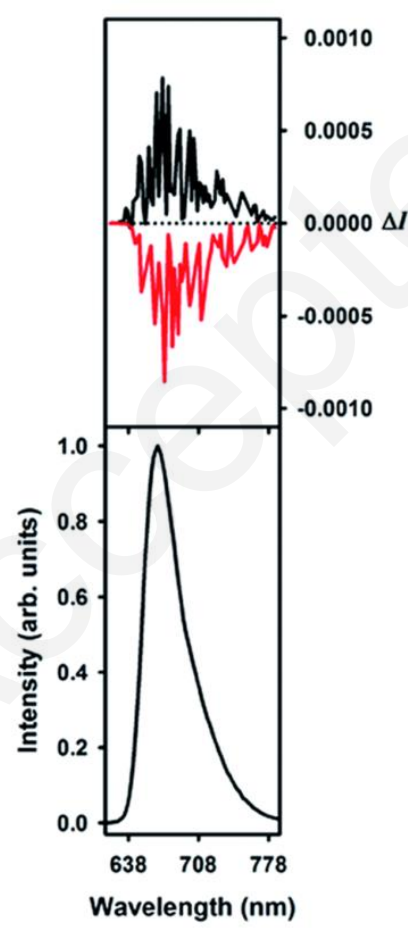

25

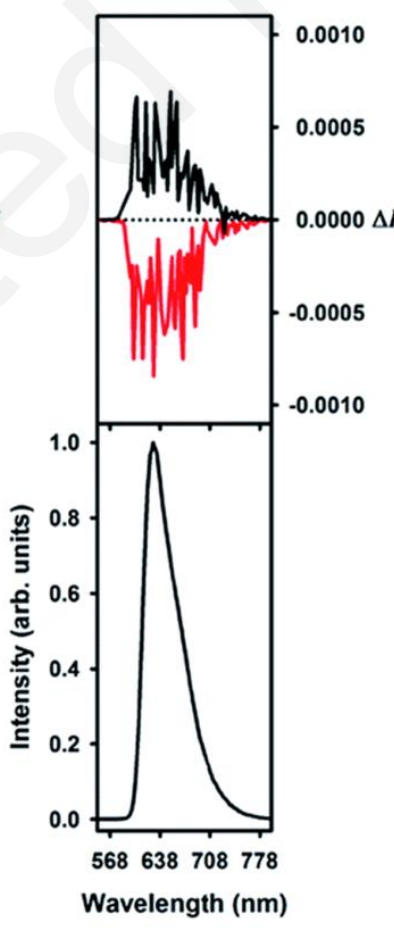

26

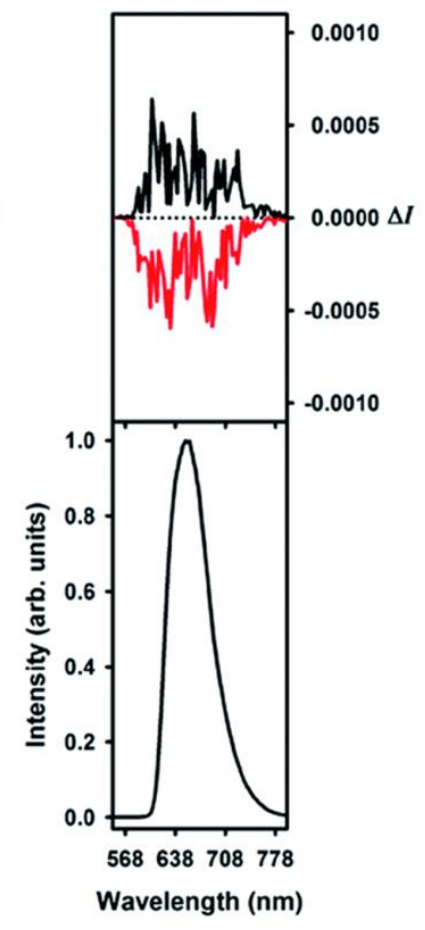

27

Fig. 9. Chemical structures of carbocationic diaza[4] helicenes 25-28 and their UV-vis, ECD and CPL activities. Adapted with permission. ${ }^{31}$ Copyright 2016, Royal Society of Chemistry. 


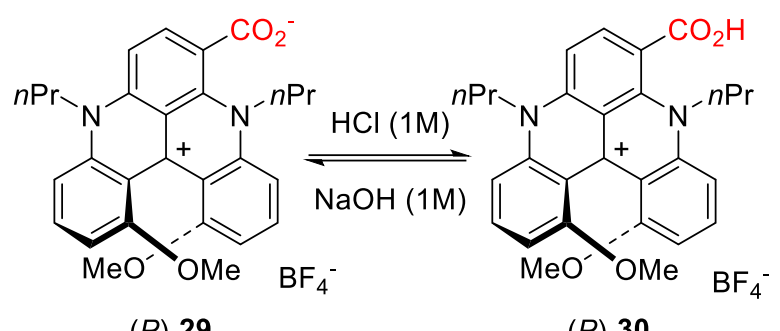

$(P)-29$

$(P)-30$<smiles></smiles>

$(P)-31$<smiles>CC(C)N1c2cccc3cccc(c23)[C@@H]1c1c(Oc2ccccc2)ccc2ccccc12</smiles>

$(P)-32$

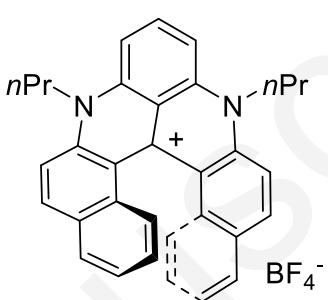

$(P)-\mathbf{3 3}$

Fig. 10. Chemical structures of carbocationic diaza[4] helicenes $29-30$ (pH-triggered switch) and $\mathrm{O}, \mathrm{N}$-containing carbocationic [6]helicenes. ${ }^{29,30}$

Table 3. Photophysical data of carbocationic azahelicenes.

\begin{tabular}{|c|c|c|c|c|c|c|c|}
\hline Compound & $\lambda_{\text {Abs }}{ }^{\max }(\mathrm{nm})$ & $\lambda_{\mathrm{Em}}(\mathrm{nm})$ & $\Phi_{F}(\%)$ & Solvent (CPL) & $10^{3} \mathrm{~g}_{\mathrm{abs}}$ & $10^{3} \mathrm{~g}_{\text {lum }}$ & Ref. \\
\hline$(P)-(+)-25$ & 616 & 667 & $13\left(\mathrm{CH}_{3} \mathrm{CN}\right)$ & $\mathrm{CH}_{2} \mathrm{Cl}_{2}$ & +0.15 & +1.3 & 31 \\
\hline$(P)-(+)-26$ & 575 & 624 & $35\left(\mathrm{CH}_{3} \mathrm{CN}\right)$ & $\mathrm{CH}_{2} \mathrm{Cl}_{2}$ & +0.45 & +1.6 & 31 \\
\hline$(P)-(+)-27$ & 582 & 640 & $37\left(\mathrm{CH}_{3} \mathrm{CN}\right)$ & $\mathrm{CH}_{2} \mathrm{Cl}_{2}$ & +0.36 & +0.9 & 31 \\
\hline$(P)-(+)-29$ & 626 & 709 & 1 & $\mathrm{CH}_{3} \mathrm{CN}$ & $\sim 0.4$ & 0 & 29 \\
\hline$(P)-(+)-30$ & 590 & 654 & 29 & $\mathrm{CH}_{3} \mathrm{CN}$ & 0.4 & 0.5 & 29 \\
\hline$(P)-(+)-31$ & 562 & 595 & 44.5 & $\mathrm{CH}_{2} \mathrm{Cl}_{2}$ & $-0.86^{b}$ & -0.32 & 30 \\
\hline$(P)-(+)-32$ & 562 & 614 & 28 & $\mathrm{CH}_{2} \mathrm{Cl}_{2}$ & $-1.3^{b}$ & -2.1 & 30 \\
\hline$(P)-(+)-33$ & 614 & 658 & 28.4 & $\mathrm{CH}_{2} \mathrm{Cl}_{2}$ & $-0.57^{b}$ & -1.2 & 30 \\
\hline
\end{tabular}

${ }^{a}$ Lowest energy absorption band. ${ }^{b}$ Taken from ref. 12.

\section{CPL-active oxygen-containing helicene derivatives}

In 2011, Tanaka, Takeuchi et al. reported a phthalhydrazide-functionalized [7]oxahelicene derivative 34 (Fig. 11), displaying a strong increase of $g_{\text {lum }}$, i.e. one order of magnitude, as compared to other helicenic derivatives. ${ }^{32}$ This strong CPL enhancement was attributed to the presence of multiple-hydrogen-bonding sites enabling the formation of a trimeric structure 
which further organizes into chiral fibers (Fig. 12). These chiral fibers were $200 \mathrm{~nm}$ wide and 3-4 $\mu \mathrm{m}$ long in chloroform solutions, as characterized by SEM and AFM images. While UVvis and ECD spectra seemed hardly sensitive to the formation of such aggregates, CPL measurements of $\mathbf{3 4}$ afforded $g_{\text {lum }}$ of -0.035 for the $(M)$ enantiomer in chloroform solutions, which was larger than in methanol solutions (-0.021). Similar systems, namely [7] oxahelicene 35 (71\% ee) and [9] oxahelicene derivative 36 (88\% ee) were reported in 2017. ${ }^{33}$ Comparison of the photophysical data of these 9-oxahelicene 36 compared to 35 shows a red-shift of both the absorption and luminescence spectra by $\sim 20-50 \mathrm{~nm}$, along with a decrease in fluorescence quantum yield (0.23 to 0.18). ECD and CPL spectra followed the same trend as for unpolarized UV-vis and fluorescence measurements, but with more intense ECD and CPL signals for 36. Here the $g_{\text {lum }}$ values around $10^{-3}$ in chloroform are classical for helicenic solutions (see Table 4). Similarly to $\mathbf{1 8}$ (see Fig. 7), Hiroto, Shinokubo and coworkers prepared $P-(+)$ and $M$-(-) enantiomers of 19 which displayed strong orange fluorescence $\left(\Phi_{\mathrm{F}}=0.66\right.$ in dichloromethane) and moderate CPL activity $\left( \pm 1.2 \times 10^{-3}\right){ }^{34}$ Note that different emission properties between racemic and pure enantiomers were obtained for this compound in the solid state but no CPL in the solid state was reported.

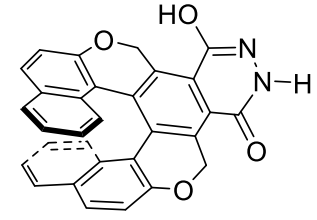

(P)-34

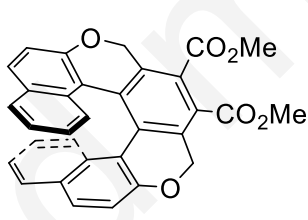

$(P)-(+)-35$

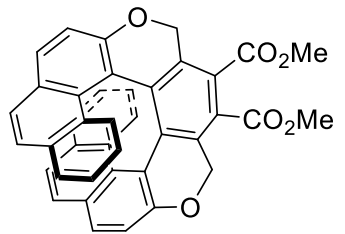

$(P)-(+)-36$

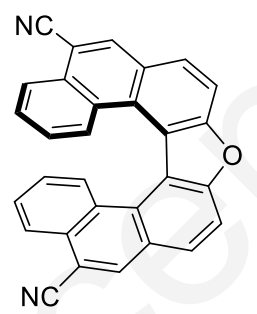

$(P)-(+)-37$

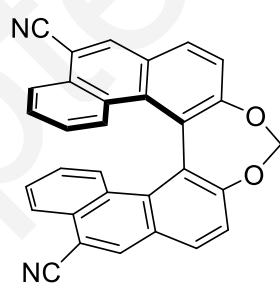

$(P)-(+)-38$

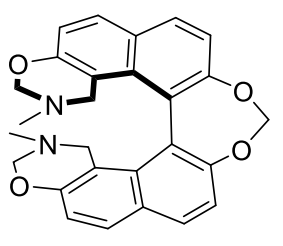

$(P)-(+)-39$

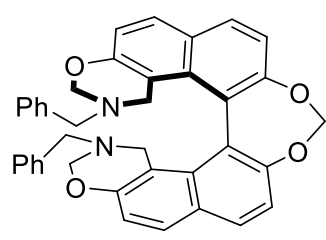

$(P)-(+)-40$

Fig. 11. Chemical structures of oxahelicenic derivatives. 

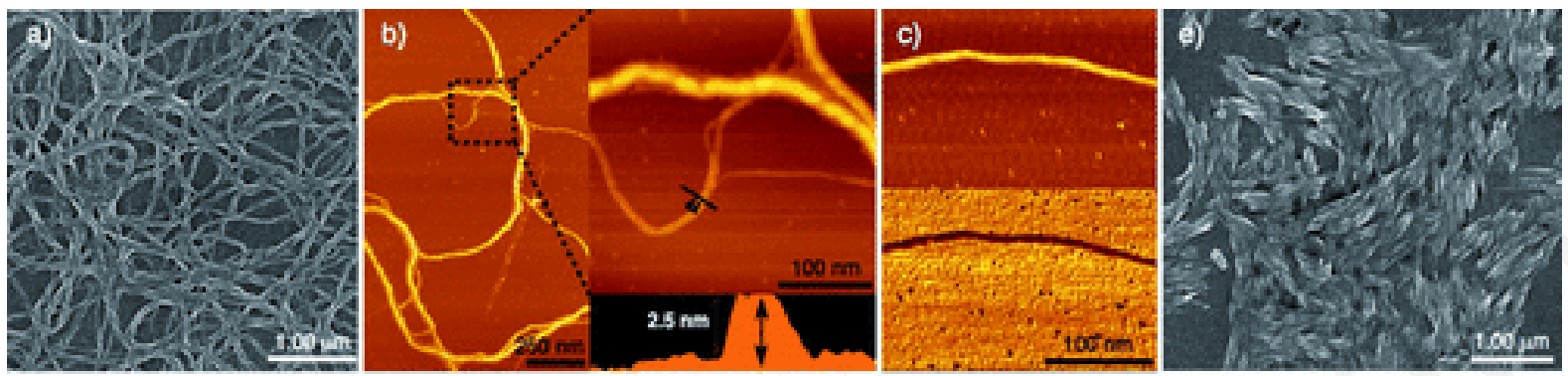

d)

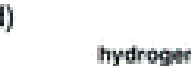

$(M)-1$
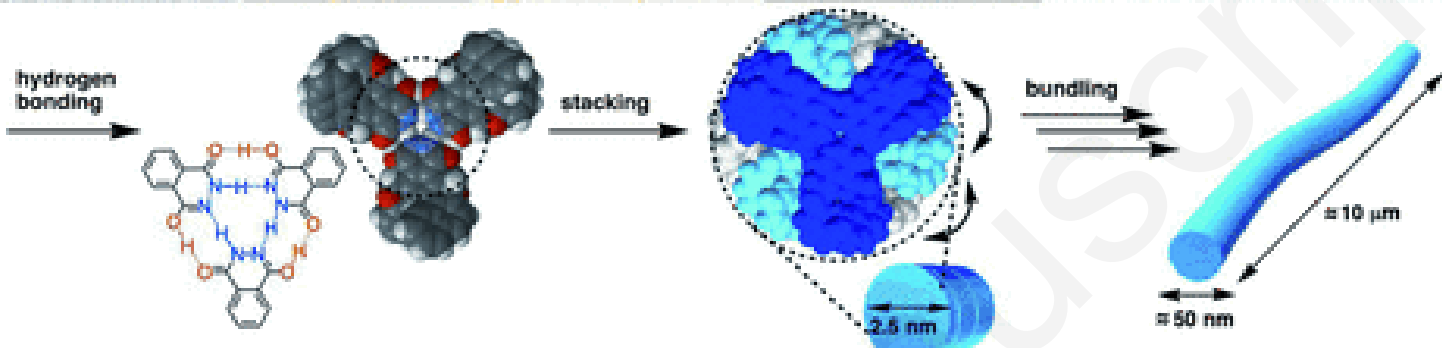

Fig. 12. AFM (b, c) and SEM images of (M)-34 (a) and (rac)-34 (e) prepared in toluene solutions. d) Postulated mechanism for the formation of supramolecular chiral aggregates from a trimeric association. Reproduced with permission. ${ }^{32}$ Copyright 2011, Wiley.

In 2018, Bedekar and coworkers reported the preparation of $(P)-(+)$ and $(M)-(-)$ enantiomers of two 5,13-dicyano-9-oxa[7]helicene derivatives $\mathbf{3 7}$ and $\mathbf{3 8}$ and reported their photophysical and chiroptical properties. ${ }^{35}$ These helical compounds are also active in CPL and mirror-like CPL spectra were measured with positive sign for $(P)$ enantiomers, and $g_{\text {lum }}$ values of 3-5 $\times 10^{-3}$ in DMSO solutions, i.e. falling within the classical range of helicene compounds. In 2014, Bedekar, Muller and coworkers also reported helicene-like bis-oxazines 39 and 40 from atropisomeric 7,7'-dihydroxy BINOL derivatives displaying good CPL activity, with $g_{\text {lum }}$ of $+0.0015 /-0.0009$ and $+0.0014 /-0.0013$ for $(P)-/(M)$-39 and $(P)-/(M)$-40, respectively. ${ }^{36}$

Table 4. Photophysical data of oxahelicenic derivatives.

\begin{tabular}{|c|c|c|c|c|c|c|c|}
\hline Compound & $\lambda_{\mathrm{Abs}} \max a(\mathrm{~nm})$ & $\lambda_{\mathrm{Em}}(\mathrm{nm})$ & $\Phi_{\mathrm{F}}(\%)$ & Solvent (CPL) & $10^{3} g_{\text {abs }}$ & $10^{3} \mathrm{~g}_{\text {lum }}$ & Ref. \\
\hline$(M)-34$ & 400 & 476 & - & $\mathrm{CHCl}_{3}$ & $-0.22^{b}$ & -35 & 32 \\
\hline & & & & $\mathrm{MeOH}$ & - & -2.1 & 32 \\
\hline$(P)-(+)-35$ & 380 & 479 & 23 & $\mathrm{CHCl}_{3}$ & $+0.56^{b}$ & +0.95 & 33 \\
\hline$(P)-(+)-36$ & 388 & 514 & 18 & $\mathrm{CHCl}_{3}$ & $+1.3^{b}$ & +1.1 & 33 \\
\hline$(P)-19$ & 500 & 550 & 66 & $\mathrm{CH}_{2} \mathrm{Cl}_{2}$ & $-1.1^{b}$ & -1.2 & 34 \\
\hline$(P)-(+)-37$ & 323 & 421 & - & DMSO & - & 3 & 35 \\
\hline$(P)-(+)-38$ & 310 & 439 & - & DMSO & - & 5 & 35 \\
\hline
\end{tabular}




\begin{tabular}{llcccccc}
\hline$(P)-(+)-39$ & $\sim 360$ & 430 & - & $\mathrm{CH}_{3} \mathrm{CN}$ & $\sim+1.2^{b}$ & +1.5 & \\
$(P)-(+)-40$ & $\sim 360$ & 430 & - & $\mathrm{CH}_{3} \mathrm{CN}$ & $\sim+1.2^{b}$ & $+1.4 \quad 36$ \\
\hline
\end{tabular}

${ }^{a}$ Lowest-energy absorption band. ${ }^{b}$ Taken form ref. 12.

\section{CPL-active sulfur-containing helicene derivatives}

There are few examples of CPL-active sulfur containing helicenes and helicenoids reported in the literature. First of all, it is worth to compare results obtained for $\mathbf{3 4}$ with those reported by Katz and coworkers in 2001 on thia[7]helicene-bisquinone derivative $\mathbf{4 1}$ decorated with four dodecyloxy groups. ${ }^{37}$ Indeed, enantiopure [7]helicene 41 aggregated into columnar structures depending on the solvent type. The aggregation occurred in dodecane and in pure materials, but not in chloroform. The specific rotation showed strong enhancement with increasing concentration, i.e. $[\alpha]_{D}=2800$ and 10400 at $2 \times 10^{-5} \mathrm{M}$ and $2 \times 10^{-2} \mathrm{M}$, respectively in dodecane. The same behaviour was observed by ECD spectroscopy showing significant change for concentrated solutions in dodecane and for films obtained by drop casting from nonane solutions. Interestingly, for a concentration higher than $2 \times 10^{-3} \mathrm{M}$, the solution was viscous and at $0.05 \mathrm{M}$ it became a gel. CPL measurement was carried out for a solution with $1 \times 10^{-3} \mathrm{M}$ in dodecane (Fig. 13). Emission from enantiomer aggregates between 600 and $700 \mathrm{~nm}$ was found to be mirror-image for enantiomeric systems. Interestingly, aggregation offered a strong dissymmetry factor $\left(g_{\text {lum }}=0.01\right.$ at around $\left.630 \mathrm{~nm}\right)$. Likewise, the $g_{\text {abs }}$ was large $\left(g_{\text {abs }}=0.01\right.$ between $500-550 \mathrm{~nm}$ ); thus, the good similarity suggests that the aggregates adopt the same chiral geometry in the ground and the excited states. However, the increased ordering of these aggregates also resulted in a large degree of linear polarization $(P=0.39)$ which can greatly affect the CPL measurement. ${ }^{38}$ 

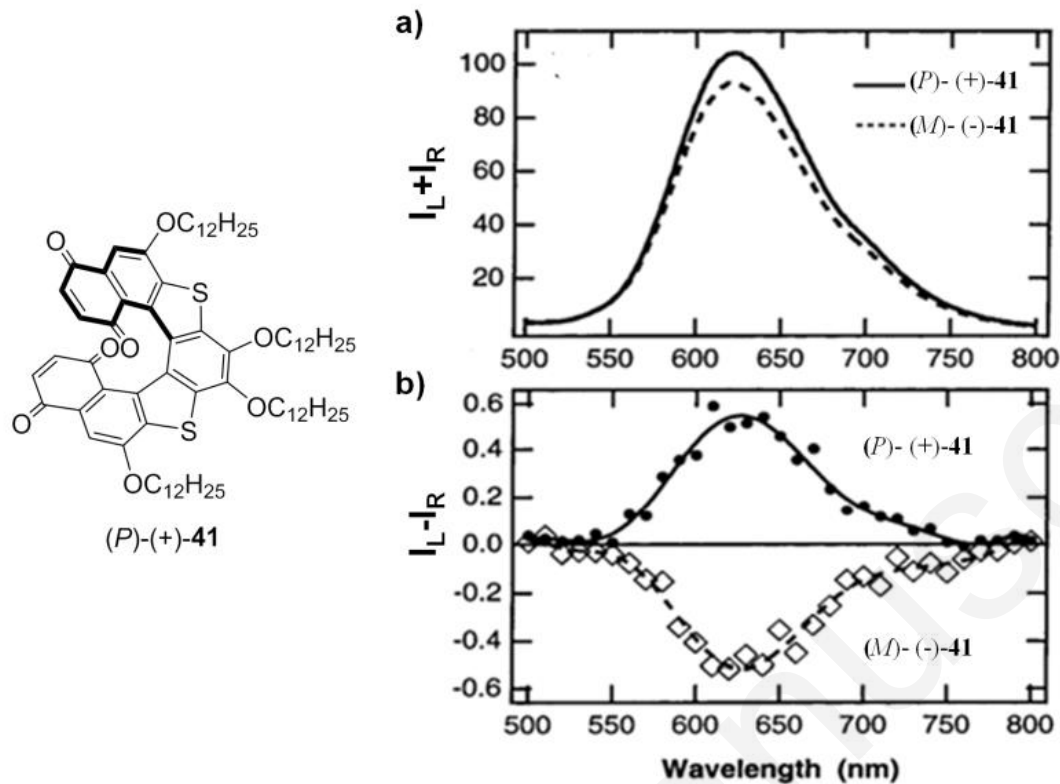

Fig. 13. Chemical structure of $(P)-41$. a) Total luminescence and b) CPL from solutions at $23^{\circ} \mathrm{C}$ of $(P)-(+)$ and $(M)-(-)-41$ in dodecane $\left(1 \times 10^{-3} \mathrm{M}\right)$ after excitation with unpolarized light $\left(\lambda_{\mathrm{ex}}=325 \mathrm{~nm}\right)$. Adapted with permission. ${ }^{37}$ Copyright 2001 , American Chemical Society.

In 2016, Yamamoto et al reported the synthesis of tetrasulfone[9]helicene via the oxidation of tetrathia[9] helicene. ${ }^{39}$ Remarkably, it was found that the quantum yield of fluorescence for sulfone[9] helicene $43\left(\Phi_{\mathrm{F}}=0.27\right)$ was ten times higher than tetrathia[9] helicene precursor $\mathbf{4 2}$ $\left(\Phi_{\mathrm{F}}=0.03\right)$. The author explain this strong enhancement by a significant increase of the energy gap between the lowest singlet $\left(\mathrm{S}_{1}\right)$ and the triplet $\left(\mathrm{T}_{1}\right)$ excited states $\Delta \mathrm{E}_{\mathrm{ST}}$ in the case of $\mathbf{4 3}$ $\left(\Delta \mathrm{E}_{\mathrm{ST}}=1.02 \mathrm{eV}\right)$ compared to $\left(\Delta \mathrm{E}_{\mathrm{ST}}=0.60 \mathrm{eV}\right)$ for 42 , which may efficiently decrease the intersystem crossing (ISC) rate. Additionally, ECD spectra for $\mathbf{4 3}$ were recorded and an anisotropy factor $g_{\mathrm{abs}}=-4.7 \times 10^{-3}$ was measured for the $(P)$ enantiomer. Likewise, plotting the fluorescence CPL mirror-image spectra $\mathbf{4 3}$ enantiomers gave an estimated anisotropy factor value of $g_{\text {lum }}=-8.3 \times 10^{-4}$ for the $(P)-\mathbf{4 3}$ (Fig. 14).

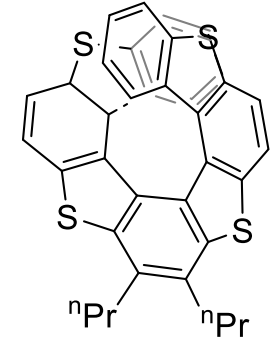

42

$$
\Phi_{\mathrm{F}}=0.03
$$

1) Sulfonation

2) HPLC separation

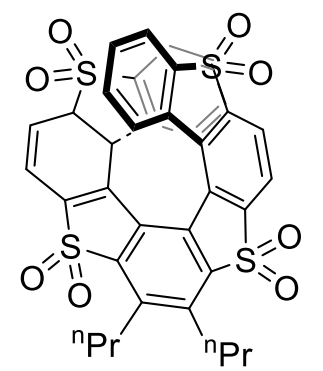

$(P)-43$

$$
\begin{aligned}
\Phi_{\mathrm{F}} & =0.27 \\
\left|g_{\text {lum }}\right| & =8.3 \times 10^{-4}
\end{aligned}
$$

Fig. 14. Chemical structures of $\mathbf{4 2}$ and $\mathbf{4 3}$ and their emission data. 
A series of fluorescent "push-pull" tetrathia[9]helicenes based on quinoxaline (acceptor) fused with tetrathia[9] helicene (donor) derivatives was synthesized for control of the excitedstate dynamics and circularly polarized luminescence (CPL) properties. ${ }^{40}$ Introduction of a quinoxaline onto the tetrathia[9] helicene skeleton induced a "push-pull" character, which was enhanced by further introduction of electron-releasing or electron-withdrawing groups onto the quinoxaline unit (Fig. 15). Significant enhancement in the fluorescence quantum yields $\left(\Phi_{\mathrm{F}}\right)$ was for instance obtained for 44: $\left(\Phi_{\mathrm{F}}=0.30\right.$, Table 5), which is more than 20 times larger than that of pristine tetrathia[9] helicene $\left(\Phi_{\mathrm{F}}=0.02\right)$. Good CPL properties, with an anisotropy factor $g_{\text {lum }}$ of $3.0 \times 10^{-3}$ were measured for 44. In 2017, Avarvari et al. reported the synthesis of $(P)$ and $(M)-\mathbf{4 5}$, corresponding to $\mathrm{Pt}$ (diimine)(dithiolene) connected with a [6]helicene unit. ${ }^{41}$ Interestingly, $(P)$ and $(M)-\mathbf{4 5}$ showed triplet state CPL activity at room temperature with low $g_{\text {lum }}$ values of $3 \times 10^{-4}$.

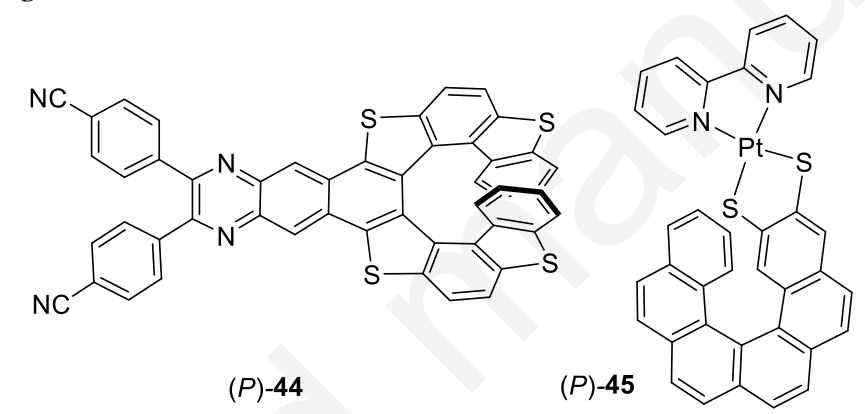

Fig. 15. Chemical structures of push-pull systems with improved luminescence and CPL emission and of a [6]helicene Pt(diimine)(dithiolene) complex.

Table 5. Photophysical data of thiahelicenic derivatives.

\begin{tabular}{|c|c|c|c|c|c|c|c|}
\hline Compound & $\lambda_{\mathrm{Abs}} \max a(\mathrm{~nm})$ & $\lambda_{\mathrm{Em}}(\mathrm{nm})$ & $\Phi_{\mathrm{F}}(\%)$ & Solvent (CPL) & $10^{3} g_{\mathrm{abs}}$ & $10^{3} g_{\text {lum }}$ & Ref. \\
\hline$(P)-(+)-41$ & 470 & 630 & - & dodecane & +10 & +10 & 32 \\
\hline$(P)-43$ & 390 & 450 & 27 & THF & -4.7 & -0.83 & 39 \\
\hline$(P)-44$ & 475 & 600 & 30 & THF & +6.8 & +3.0 & 40 \\
\hline$(P)-45$ & 562 & 715 & 15 & $\mathrm{CH}_{3} \mathrm{CN}$ & $\sim_{+0.91^{b}}$ & +0.3 & 41 \\
\hline
\end{tabular}

${ }^{a}$ Lowest-energy absorption band. ${ }^{b}$ Taken form ref. 12.

\section{CPL-active borahelicenes}

Due to the electron-accepting and Lewis acidic character of boron, introducing one or several boron atoms into carbohelicenes generally results in strongly blue emitting fluorophores. For chemical stability reasons, helicenes incorporating boron atoms are azaborahelicenes and 
oxaborahelicenes, i.e. also including $\mathrm{N}$ or $\mathrm{O}$ atoms. In 2017, our group prepared enantiopure azabora[n] helicenes 46a-d incorporating one or two boron atoms and with 6,8 or 10 orthofused rings $\left(n=6,8,10\right.$, Fig. 16). ${ }^{42}$ These compounds displayed strong absorption between $250-450 \mathrm{~nm}$ and blue fluorescence $\left(\lambda_{\mathrm{Em}} \sim 420-450 \mathrm{~nm}\right)$ with rather strong quantum yields (0.21-0.49) for azaborahexahelicenes 46a,c and more modest ones $(\sim 0.07)$ for the octa- and decahelicenes $46 \mathbf{b}, \mathbf{d}$. The introduction of one additional boron atom on $46 \mathbf{c}$ strongly increased the emission efficiency compared to 46a, but at the same time strongly decreased the configuration stability (enantiomerization barrier $\Delta G^{\neq}$of $27.5 \mathrm{kcal} \mathrm{mol}^{-1}$ at $78^{\circ} \mathrm{C}$, in ethanol) due to the presence of two azaborapentacycles. From the UV-vis spectra, the longer the helicene, the stronger were the absorption coefficients and the more red-shifted the absorption wavelengths. Similarly, the ECD spectra were more red-shifted and more intense for azaboraoctahelicene 46b and azaboradecahelicene 46d as compared to azaborahexahelicenes 46a,c. Note that, except for 46c, the overall ECD signature appeared typical of helicene derivatives and that the $(P)$-enantiomers display positive optical rotation values. Regarding the CPL respons-

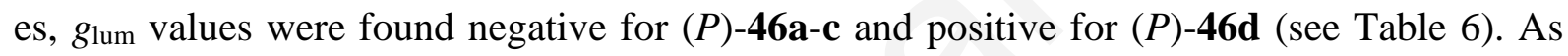
mentioned above, the sign of CPL greatly varies with the substituents grafted onto the helicenic core and generally follows the sign of the lower energy ECD-active band. The absolute values of $g_{\text {lum }}$ (between $7 \times 10^{-4}$ and $10^{-3}$ ) for 46a-d are typical of enantiopure organic helicenes.

Enantiopure azabora[5]helicenes 47-49 were also prepared; they displayed different charge transfer characters and fluorescence quantum yields ranging from 0.13 and 0.30 in toluene, governed by the electron-donor substitution ( $p$-MeO-phenyl, $p$ - $\mathrm{Me}_{2} \mathrm{~N}$-phenyl) at the helicene. ${ }^{43}$ The dimethylamino-substituted derivative emitted at the most red-shifted wavelength and showed the highest Stokes shift in toluene. These helicenes also showed CPL activity with dissymmetry factors $g_{\text {lum }}$ between $2.5 \times 10^{-4}$ and $3.5 \times 10^{-3}$. Their ECD spectra and optical rotation values of 47-49 were very different from azaborahelicenes 46a-d and it was shown that the sign of the ECD band corresponding to the first transition and the CPL spectrum depended on the electron-donor substitution.

Oxabora[6]helicene $\mathbf{5 0}$ was prepared in 2016 by Hatakeyama and coworkers and revealed deep and almost pure blue fluorescence with Commission Internationale de l'Eclairage coordinates of $(0.15,0.08) .{ }^{44}$ Its enantiomers showed CPL high fluorescence quantum yields of 0.65 at $436 \mathrm{~nm}$ activity with $g_{\text {lum }}$ of $1.7 \times 10^{-3}$. Achiral structural analogues of $\mathbf{5 0}$ have proven efficient B-containing PAH dopants in organic OLEDs and in field-effect transistors. ${ }^{45}$ These compounds are indeed known to display good carrier mobilities. Note also that such BN and BO aromatic compounds display increasing interest in the domain of thermally activated delayed fluorescence (TADF). ${ }^{46}$ 


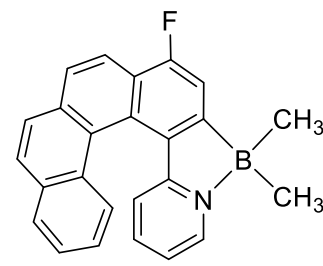

(rac)-46a

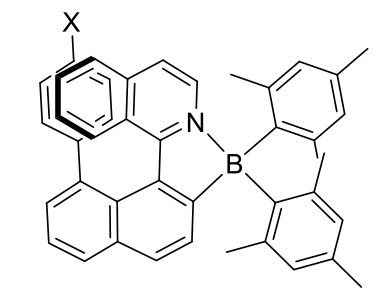

$X=H(47)$, OMe (48), $\mathrm{NMe}_{2}(49)$

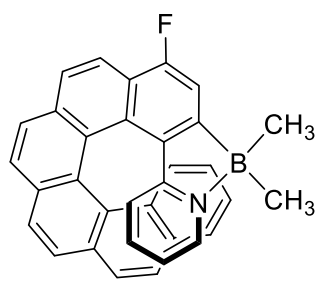

$(r a c)-46 b$

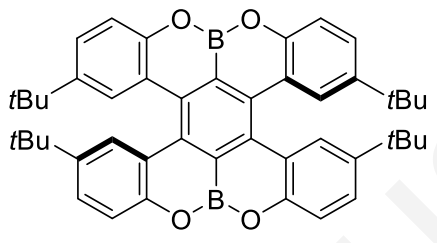

50

Fig. 16. Chemical structures of azabora[ $n]$ helicenes $46 a-d$ and 47-49 and oxaborahelicene 50.

Table 6. Photophysical data of borahelicenes.

\begin{tabular}{|c|c|c|c|c|c|c|c|}
\hline Compound & $\lambda_{\mathrm{Abs}} \max a(\mathrm{~nm})$ & $\lambda_{\mathrm{Em}}(\mathrm{nm})$ & $\Phi_{\mathrm{F}}(\%)$ & Solvent (CPL) & $10^{3} g_{\mathrm{abs}}$ & $10^{3} \mathrm{~g}_{\text {lum }}$ & Ref. \\
\hline$(P)-46 a$ & 398 & 404 & 21 & $\mathrm{CH}_{2} \mathrm{Cl}_{2}$ & $\sim-1.9^{b}$ & -0.9 & 42 \\
\hline$(P)-46 b$ & 429 & 435 & 6.9 & $\mathrm{CH}_{2} \mathrm{Cl}_{2}$ & $\sim-2.7^{b}$ & -0.7 & 42 \\
\hline$(P)-46 c$ & 391 & 427 & 49 & $\mathrm{CH}_{2} \mathrm{Cl}_{2}$ & $\sim-0.8^{b}$ & -2.3 & 42 \\
\hline$(P)-46 \mathrm{~d}$ & 440 & 471 & 7.4 & $\mathrm{CH}_{2} \mathrm{Cl}_{2}$ & $\sim+2.6^{b}$ & +1 & 42 \\
\hline$(P)-47$ & 414 & 495 & 29/toluene & $\mathrm{CHCl}_{3}$ & -0.7 & -0.25 & 43 \\
\hline$(P)-48$ & 420 & 502 & 30/toluene & $\mathrm{CHCl}_{3}$ & +1.1 & +0.95 & 43 \\
\hline$(P)-49$ & 433 & 586 & 13/toluene & $\mathrm{CHCl}_{3}$ & +2 & +3.5 & 43 \\
\hline$(P, P)-\mathbf{5 0}$ & 411 & 436 & $65 / \mathrm{CH}_{2} \mathrm{Cl}_{2}(26)^{c}$ & $\mathrm{CH}_{2} \mathrm{Cl}_{2}$ & $\sim-1.1^{b}$ & -1.7 & 44 \\
\hline
\end{tabular}

${ }^{a}$ Lowest-energy absorption band. ${ }^{b}$ Taken from ref. $12 .{ }^{c}$ Fluorescence quantum yield measured in the solid state.

\section{CPL-active silahelicenes}

Silylated $\pi$-conjugated molecules also display strong blue emission. In 2013, Nozaki and coworkers reported the synthesis of enantiopure sila[7]helicene 51, bearing a silole as the cen- 
tral cycle (Fig. 17). ${ }^{47}$ The UV-vis absorption spectrum of ( $\mathrm{rac}$ )-51 showed longest absorption at $412 \mathrm{~nm}$, that is much longer than pristine phenanthrene $(293 \mathrm{~nm})$ and dibenzosilole (286 $\mathrm{nm})$, due to extended delocalization of the $\pi$-electrons over the molecule, The absorption edge of (rac)-51 at $431 \mathrm{~nm}$ is similar to that of $\lambda^{5}$-phospha[7]helicene (432 nm) and red-shifted compared to the related aza- and oxa-[7]helicenes (425 nm for aza[7]helicene and $409 \mathrm{~nm}$ for oxa[7]helicene). Upon excitation at $320 \mathrm{~nm}$, compound ( $\mathrm{rac}$ )-51 exhibited a strong blue fluorescence with $\lambda_{\max }$ at $450 \mathrm{~nm}$ and good quantum yields in solution and in the solid state (see Fig. 17 and Table 7). The CPL spectra of enantiopure sila[7]helicene $(P)$ - and $(M)$-32, which are mirror-image, of positive and negative sign, respectively; dissymmetry factors of $3.5 \times 10^{-}$ ${ }^{4}$ at $470 \mathrm{~nm}$ were measured. The authors concluded that the $g_{\text {lum }}$ derives mainly from the helical biphenanthryl moiety while the heterole moiety plays essential roles in the luminescent properties. In 2015, Tanaka et al. prepared enantioenriched 1,1'-bis-triphenylene-based sila[7]helicenes $(P)-\mathbf{5 2}$ with $91 \%$ ee ${ }^{48}$ Compared to sila[7]helicene 51, $\mathbf{5 2}$ displayed red-shifted absorption and fluorescence responses explained by the presence of fused 1,1'bistriphenylenes resulting in more extended $\pi$-conjugation. Probably for the same reason, en-

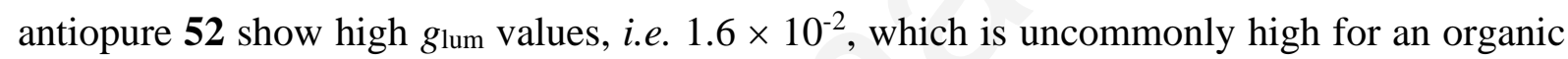
helicene. These values appear larger than that for the 3,3-biphenanthrene-based sila[7]helicene 51 ( $g_{\text {lum }}=-0.0035$ at $470 \mathrm{~nm}$ ) but smaller than that for the 1,1-bitriphenylene based carbo[7]helicene $\mathbf{6 1}\left(g_{\text {lum }}=-0.030\right.$ at $428 \mathrm{~nm}$ for the $(M)-(-)$ enantiomer, see paragraph $7.3)^{71}$

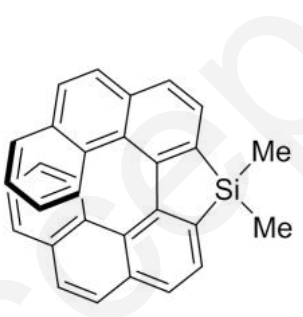

$(P)-51$
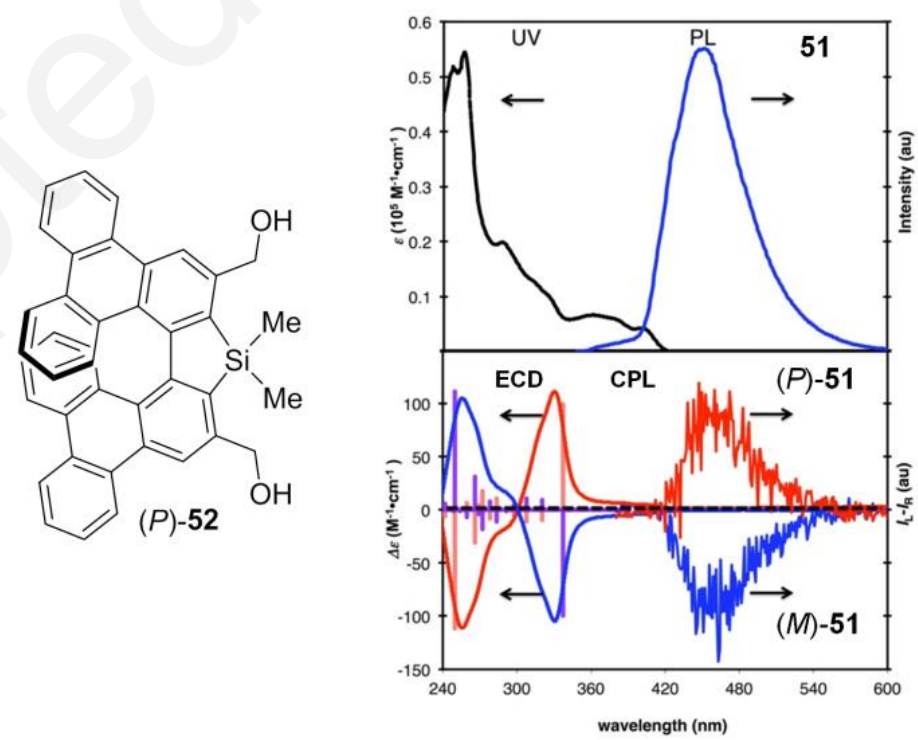

Fig. 17. Chemical structures of silahelicenes $(P)$-51 and $(P)$-52. UV-vis/fluorescence spectra and ECD/CPL spectra spectra of sila[7]helicene 51 in $\mathrm{CH}_{2} \mathrm{Cl}_{2}$. Blue lines in ECD and CPL spectra: $(M)$-isomer. Red lines: $(P)$-isomer. The blue and red bars show the calculated ECD spectra. Reproduced with permission. ${ }^{47}$ Copyright 2013, American Chemical Society. 
Table 7. Photophysical data of silahelicenes.

\begin{tabular}{llllllll}
\hline Compound & $\lambda_{\mathrm{Abs}} \max a$ & $\lambda_{\mathrm{Em}}$ & $\Phi_{\mathrm{F}}(\%)$ & Solvent $(\mathrm{CPL})$ & $10^{3} g_{\mathrm{abs}}$ & $10^{3} g_{\text {lum }}$ & Ref. \\
& $(\mathrm{nm})$ & $(\mathrm{nm})$ & & & & & \\
& 412 & 450 & $23 / \mathrm{CH}_{2} \mathrm{Cl}_{2}(26)^{b}$ & $\mathrm{CH}_{2} \mathrm{Cl}_{2}$ & $\sim 1.4^{c}$ & -3.5 & 47 \\
$(P)-51$ & 400 & 482 & 6.9 & $\mathrm{CHCl}_{3}$ & $\sim 4.2^{c}$ & +16 & 48 \\
$(P)-52$ & & & & & & & \\
\hline
\end{tabular}

${ }^{a}$ Lowest-energy absorption band. ${ }^{b}$ Fluorescence quantum yield measured in the solid state. ${ }^{c}$ Taken from ref. 12.

\section{CPL-active phosphahelicenes}

It is now well-recognized that phosphorus-containing $\pi$-conjugated small molecules, oligomers, polymers, and supramolecular assemblies are important classes of heteroatomic molecular materials for many applications in optoelectronics including OLEDs. ${ }^{49}$ P-containing building blocks can indeed lead to materials with unique properties (emission, charge transport, coordination, (anti)aromaticity, etc). So far, most phosphorus derivatives having helical chirality have displayed polyaromatic (or heteroaromatic) helical scaffolds with pendant phosphorus functions (phosphites, trivalent phosphines and phosphine oxides, helicenephospholes derivatives, ...) but a few classes of P-containing heterohelicenes have appeared in the literature in the last years. Although several phosphole and helicenes are known to exhibit efficient fluorescence properties, the only example of CPL-active phosphane-containing helicenes has been reported recently. ${ }^{50}$ Compounds 53a and 53b are benzooxophosphole derivatives that display a carbo[6]helicene unit that is meta-fused with one terminal oxophosphole ring containing a pendant phenyl ring at position 5 (Fig. 18). In both systems a $l$ menthyl group at the $\mathrm{P}$ atom is directed toward the inner groove of the helix (endo isomer). These epimeric compounds can be considered as pseudo-enantiomers since they demonstrate reverse stereochemistry of the helix $(P / M)$ and of the $\mathrm{P}$ atom $\left(R_{\mathrm{P}} / S_{\mathrm{P}}\right)$ but unchanged stereochemistry of the chiral $l$-menthyl group. The epimeric helicenes [6]- $(P)$-endo-53a and [6]$(M)$-endo-53b displayed almost identical UV/Vis spectra, blue fluorescence with moderate quantum yield (0.07-0.10), and mirror-image ECD spectra. Similarly, they exhibited mirrorimage CPL spectra with luminescence anisotropy factor $g_{\text {lum }}=+8 \times 10^{-4}$ and $-7 \times 10^{-4}$ at 452 $\mathrm{nm}$ (excitation at 404-416 $\mathrm{nm}$ ) for $(P)-53 \mathbf{a}$ and $(M)$-53b, respectively (Table 8 ). Note that the other phosphahelicenes tested underwent photodegradation under the conditions of the CPL measurement.

In 2018, Tanaka and coworkers reported the enantioselective synthesis of [7]- and [9]phosphahelicenes 53c and 53d (Fig. 18) by [2+2+2] cycloaddition. These heterohelicenes displayed modest quantum yields $(0.22$ and 0.085$)$ and $g_{\text {lum }}$ values $\left(+8.1 \times 10^{-4}\right.$ and $+3.8 \times 10^{-}$ $\left.{ }^{4}\right) .{ }^{51}$ 


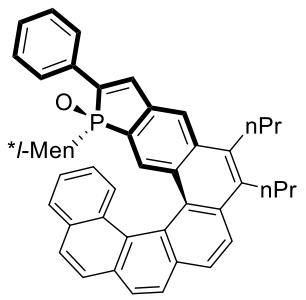

$[6]-(P)-e n d o-53 a$

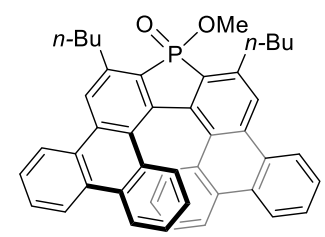

$(P)-53 c$

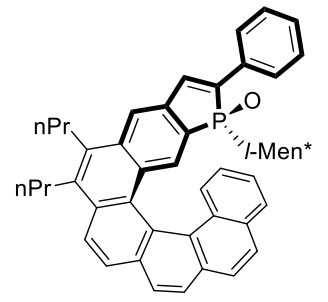

[6]-(M)-endo-53b

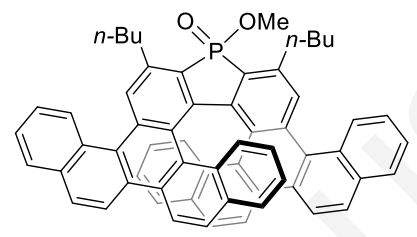

(P)-53d

Fig. 18. CPL-active phosphahelicenes.

Table 8. Photophysical data of phosphahelicenes.

\begin{tabular}{|c|c|c|c|c|c|c|c|}
\hline Compound & $\lambda_{\mathrm{Abs}} \operatorname{maxa}(\mathrm{nm})$ & $\lambda_{\mathrm{Em}}(\mathrm{nm})$ & $\Phi_{\mathrm{F}}(\%)$ & Solvent & $10^{3} g_{\mathrm{abs}}$ & $10^{3} \mathrm{~g}_{\text {lum }}$ & Ref. \\
\hline$(P)-(+)-53 a$ & 436 & 449 & 10 & $\mathrm{CH}_{2} \mathrm{Cl}_{2}$ & - & +0.8 & 50 \\
\hline$(M)-(-)-53 b$ & 438 & 455 & 7 & $\mathrm{CH}_{2} \mathrm{Cl}_{2}$ & - & -0.7 & 50 \\
\hline$(+)-53 c^{b}$ & 388 & 487 & 22 & $\mathrm{CHCl}_{3}$ & - & +8.81 & 51 \\
\hline$(+)-53 d^{b}$ & 315 & 502 & 8.5 & $\mathrm{CHCl}_{3}$ & - & +0.48 & 51 \\
\hline
\end{tabular}

${ }^{a}$ Lowest energy UV-vis band. ${ }^{b}$ Absolute configuration not determined.

\section{CPL-active carbohelicenic derivatives}

\subsection{Pentahelicenic structures}

In 2018, Mori and coworkers reported a combined experimental and theoretical study to elucidate the ECD and CPL behaviors of parent pentahelicene $(P)-\mathbf{2 3}$ and of $D_{3}$-symmetric triple pentahelicene $(P, P, P)-54 .^{52}$ They showed that the pentahelicene unit exhibits absorption and luminescence, with dissymmetry factors $g_{\text {abs }}$ and $g_{\text {lum }}$ that are intrinsically larger than those of higher homologues. Thus, $(P)-\mathbf{2 3}$ emitted strong CPL with $g_{\text {lum }}$ of $-2.7 \times 10^{-3}$ at low temperature (see Table 9 and Fig. 19), which is about a half value of the $g_{\text {abs. }}$ Due to its pho- 
tolabile nature, $\mathbf{2 3}$ is not suitable to be incorporated in chiroptical materials. However, such undesirable reactivities can be excluded by merging three pentahelicenic units into $\mathbf{5 4}$, for which the $g_{\text {lum }}$ and $g_{\text {abs }}$ factors were found to be as high as $-1.3 \times 10^{-3}$ and $-1.8 \times 10^{-3}$, respectively for the $(P)$ enantiomer, corresponding to a high $g_{\text {lum }} / g_{\text {abs }}$ ratio of 0.72 , indicating moderate excited-state relaxation. Theoretical calculations provided further insights into the improved chiroptical responses at the main band $\left({ }^{1} \mathrm{~B}_{\mathrm{b}}\right.$ transition) in the triple pentahelicene $\mathbf{2 3}$, which was ascribed to its symmetric nature.
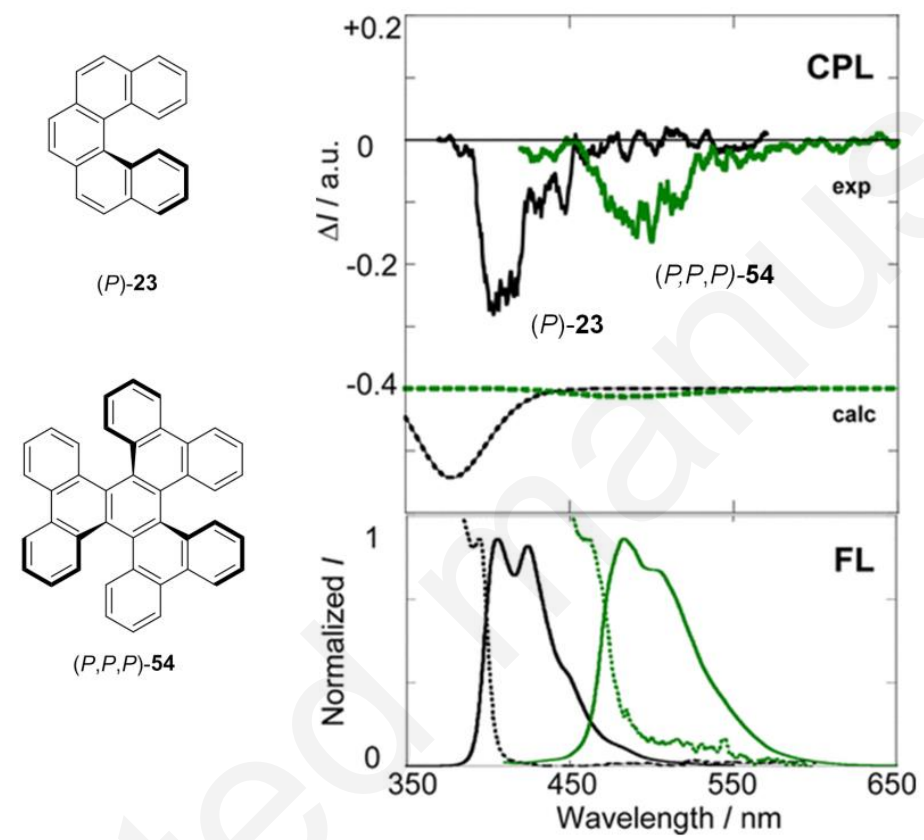

Fig. 19. Chemical structures, fluorescence and CPL activity of pentahelicenic $(P)-23$ and of $D_{3}$-symmetric triple pentahelicene $(P, P, P)-54$. Adapted with permission. ${ }^{52}$ Copyright 2018, American Chemical Society.

In 2017, Lu, Chen and coworkers prepared enantiopure tetrahydrocarbo[5]helicenic derivatives (Fig. 20) with high configurational stability thanks to the presence of phenyl groups placed in the inner groove of the helix. ${ }^{53}$ These compounds displayed strong blue fluorescence with quantum yield of up to 0.59 . Compounds $(P)-(+)-55 \mathbf{a}-\mathbf{e}, 56$ and $(M)-(-)-55 a-\mathbf{e}, 56$ also exhibited mirror-imaged ECD and CPL spectra in THF. Due to similar helical backbones, all systems showed similar Cotton effects with strong negative Cotton effects at $290 \mathrm{~nm}$ and positive ones at 315-320 $\mathrm{nm}$ for the $(P)-(+)-55 \mathbf{a}-\mathbf{e}, \mathbf{5 6}$ enantiomers. The $g_{\text {abs }}$ values were found within the range of $+2.63 \times 10^{-3}$ to $+4.77 \times 10^{-3}$ for the $(P)$ enantiomers, and $-3.40 \times 10^{-3}$ to $2.73 \times 10^{-3}$ for the $(M)$ enantiomers, respectively. These compounds also showed intense CPL signals, matching with the region of emission spectra and corresponding ECD signals at the longest wavelength $(305-400 \mathrm{~nm})$. The pure enantiomers all exhibited relatively high $g_{\text {lum }}$ with values between $+3.66 \times 10^{-3}$ and $+6.41 \times 10^{-3}$ for the $(P)$ configurations and $-3.40 \times 10^{-3}$ to $-6.59 \times 10^{-3}$ for the $(M)$ configurations (Table 9 ) thus showing that chirality existed in both the ground and excited states and could be attributed to their rigid helical structures. Interest- 
ingly, absorption dissymmetry factors $\left(g_{\text {abs }}\right)$ of $(P)-(+)-56$ and $(M)-(-)-56$ were found stronger $\left(+7.9 \times 10^{-3}\right.$ and $-7.7 \times 10^{-3}$, respectively $)$, as well as the emission dissymmetry factors $\left(g_{\text {lum }}\right)$ as large as $2.8 \times 10^{-2}$ and $-3.1 \times 10^{-2}$ at $466 \mathrm{~nm}$, respectively, considerably higher than values reported for other CPL-active single organic molecules. Similar tetrahydropentahelicenic structures, i.e. $(P)-(-)-57 \mathbf{a}-\mathbf{c}$ and $(M)-(+)-57 \mathbf{a}-\mathbf{c}$, were prepared in 2018 by Chen et al.. ${ }^{54}$ They exhibited mirror-image ECD and CPL spectra in dichloromethane, with $g_{\text {abs }}$ of $-4.7 \times 10^{-4}$ to $8.3 \times 10^{-4}$ for the $(P)$ configuration, and $+4.9 \times 10^{-4}$ to $+8.7 \times 10^{-4}$ for the $(M)$ configuration (Table 10, and ref. 54). As for fully conjugated derivative pentahelicene $(P)-(+)$ and $(\mathrm{M})-(-)-$ $\mathbf{5 7 d}$, they display $g_{\text {abs }}$ values of similar magnitude $\left(+3.28 \times 10^{-4}\right.$ and $-3.57 \times 10^{-4}$, respectively). Furthermore, the enantiomers of 57a-c showed CPL signals with $g_{\text {lum }}$ values between -2.5 $\times 10^{-4}$ and $-4.1 \times 10^{-4}$ for the $(P)$ enantiomers and $+2.6 \times 10^{-4}$ and $+4.2 \times 10^{-4}$ for the $(M)$ ones. $(P)-(+)$ and $(M)-(-)-57 d$ in dichloromethane exhibited stronger CPL activity, with $g_{\text {lum }}$ values of $-4.52 \times 10^{-3}$ and $+4.43 \times 10^{-3}$, respectively. In 2018 , Chen et al. also reported the one-pot oxidative aromatization and dearomatization (OADA) reactions of similar tetrahydro[5]helicene diols, with DDQ as the oxidant, which provided a new method for the synthesis of novel CPL-active chiral $\pi$-extended diones. ${ }^{55}$
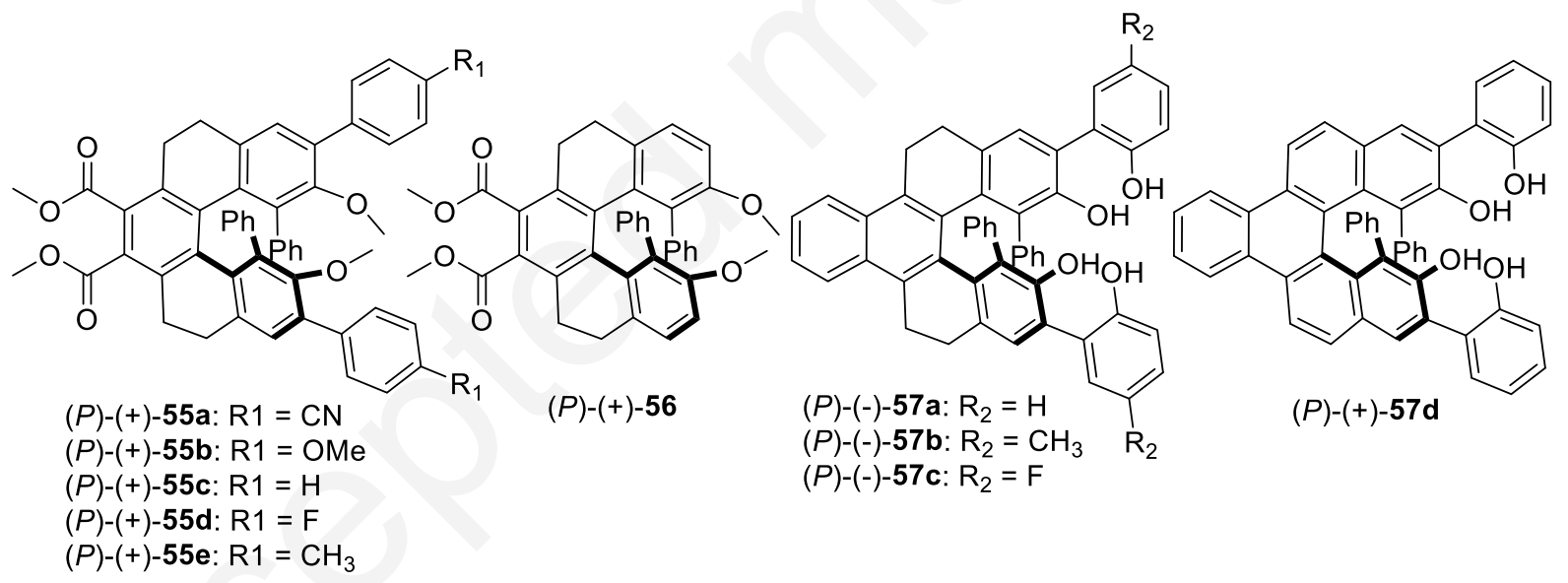

Fig. 20. Enantioenriched tetrahydrocarbo[5] helicenic derivatives prepared by Chen et al..

Table 9. Photophysical data of pentahelicenic derivatives.

\begin{tabular}{|c|c|c|c|c|c|c|c|}
\hline Compound & $\lambda_{\mathrm{Abs}} \max a(\mathrm{~nm})$ & $\lambda_{\mathrm{Em}}(\mathrm{nm})$ & $\Phi_{F}(\%)$ & Solvent (CPL) & $10^{3} g_{\text {abs }}$ & $10^{3} \mathrm{~g}_{\text {lum }}$ & Ref. \\
\hline$(P)-(+)-23$ & 398 & 406 & 5.7 & $\mathrm{CH}_{2} \mathrm{Cl}_{2}$ & -7.6 & -2.7 & 52 \\
\hline$(M)-(-)-54$ & 460 & 483 & 1.8 & $\mathrm{CH}_{2} \mathrm{Cl}_{2}$ & -1.8 & -1.3 & 52 \\
\hline$(P)-(+)-55 a$ & 347 & 440 & 48 & THF & 2.63 & 5.63 & 53 \\
\hline$(P)-(+)-55 b$ & 349 & 442 & 59 & THF & 3.55 & 3.66 & 53 \\
\hline
\end{tabular}




\begin{tabular}{lccccccc}
\hline$(P)-(+)-55 \mathbf{c}$ & 344 & 439 & 40 & THF & 4.34 & 6.32 & 53 \\
$(P)-(+)-55 d$ & 344 & 438 & 41 & THF & 3.82 & 6.41 & 53 \\
$(P)-(+)-55 \mathbf{e}$ & 345 & 440 & 42 & THF & 3.21 & 4.58 & 53 \\
$(P)-(+)-56$ & 338 & 465 & 3 & THF & 7.87 & 28.2 & 53 \\
$(P)-(-)-57 a$ & 305 & 424 & 32.6 & $\mathrm{CH}_{2} \mathrm{Cl}_{2}$ & -0.47 & -0.25 & 54 \\
$(P)-(-)-57 b$ & 310 & 425 & 41.0 & $\mathrm{CH}_{2} \mathrm{Cl}_{2}$ & -0.50 & -0.28 & 54 \\
$(P)-(-)-57 \mathrm{c}$ & 301 & 425 & 39.1 & $\mathrm{CH}_{2} \mathrm{Cl}_{2}$ & -0.83 & -0.41 & 54 \\
$(P)-(+)-57 d$ & 330 & 455 & 18.7 & $\mathrm{CH}_{2} \mathrm{Cl}_{2}$ & -0.328 & -4.52 & 54 \\
\hline
\end{tabular}

${ }^{a}$ Lowest energy UV-vis band. ${ }^{b}$ Taken from ref. 12.

\subsection{CPL-active hexahelicenic structures}

Hexahelicenic derivatives are prototypic helicenes exhibiting CPL activity. In 2018, our group showed that grafting diketopyrrolopyrrole (dpp) dyes onto a carbo[6]helicene structure through ethynyl bridges (see 58a-c in Fig. 21) leads to exciton coupling circular dichroism in the red region arising from the achiral red-absorbing DPP units in the helical environment. ${ }^{56}$ Furthermore, red to near-infrared circularly CPL was obtained. Indeed, the association of enantiopure [6]helicene and dpp units provided helical $\pi$-conjugated molecules with strong ECD signal in the visible region $(\sim 600 \mathrm{~nm})$, intense red and near-infrared fluorescence $\left(\phi_{\mathrm{F}} \sim 0.4\right)$ and CPL activity up to $650 \mathrm{~nm}$ with $g_{\text {lum }}$ found to increase from $1 \times 10^{-4}$ to $6 \times 10^{-4}$ then $9 \times 10^{-4}$ with the increase of exciton coupling (i.e. through the series $\mathbf{5 8 a} \rightarrow \mathbf{5 8 b} \rightarrow \mathbf{5 8 c}$ ). The $g_{\text {abs }}$ values were also found to follow the same increasing trend with the increasing exciton coupling. These results highlighted the synergy between the chiral hexahelicene structure and the organic dye. Thus, decorating carbohelicenes with dyes constitutes an appealing strategy of chemical engineering of a $\pi$-helical platform to further improve the chiroptical responses. 

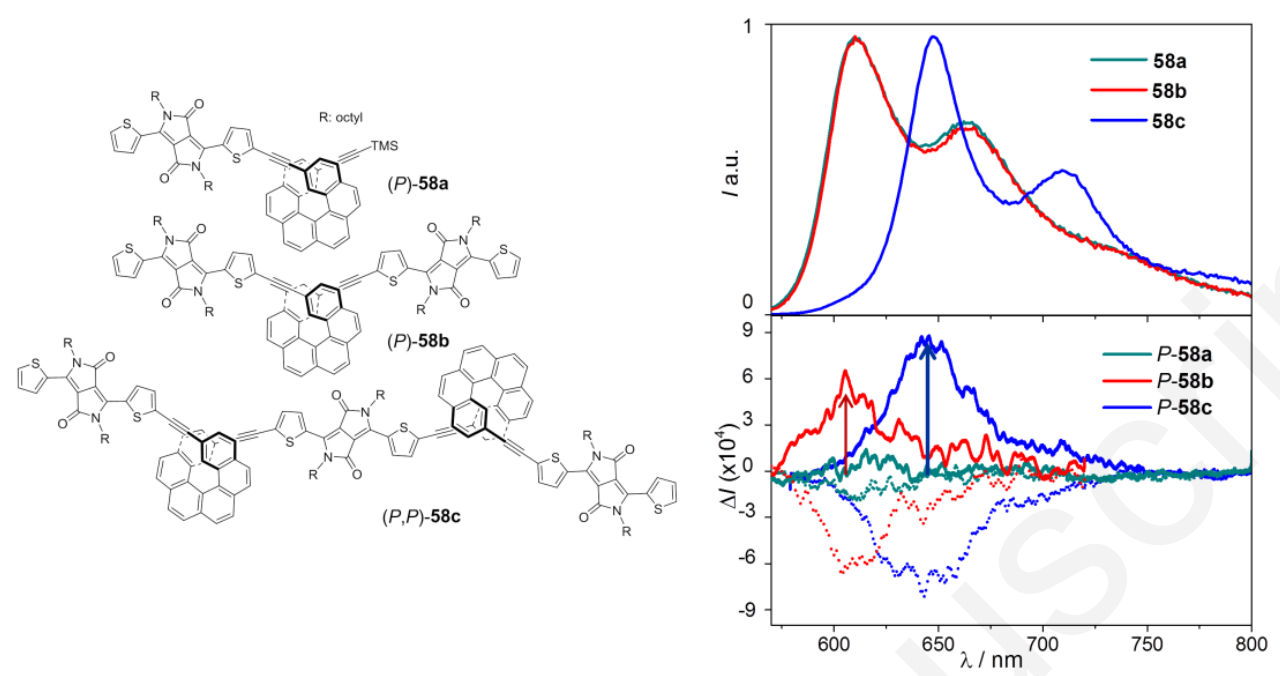

Fig. 21. Chemical structures, fluorescence and $\mathrm{CPL}$ spectra in $\mathrm{CH}_{2} \mathrm{Cl}_{2}$ of hexahelicene-dpp derivatives (P)-58a-c. Adapted with permission. ${ }^{56}$ Copyright 2018, Royal Society of Chemistry.

In 2018, Tanaka and coworkers reported the enantioselective synthesis of fully benzenoid single (59a,b) and double $(\mathbf{5 9 c}, \mathbf{d})$ carbo[6]helicenes via efficient gold-catalyzed intramolecular hydroarylation (Fig. 22) ${ }^{57}$ Similarly to the single (12-14) and double azahelicenes (15-16) described in part 2.3., the double carbo[6]helicenes 59c,d exhibited relatively large CPL activities (up to $2.7 \times 10^{-3}$, see Table 10), as compared to the single carbo[6]helicenes $\mathbf{5 9 a}, \mathbf{b}$ whose CPL was below the limit of the apparatus.

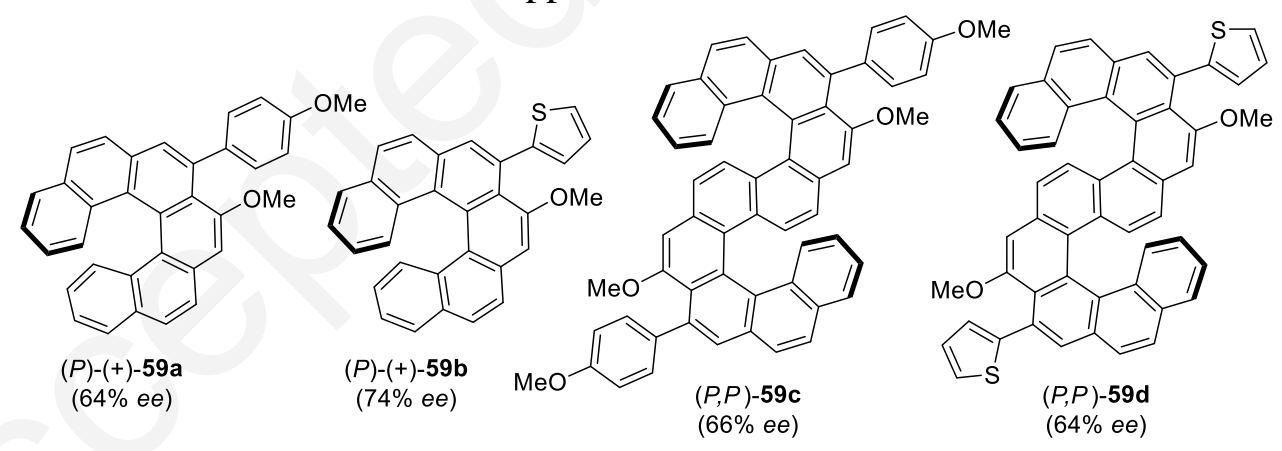

Fig. 22. Chemical structures of enantioenriched single carbo[6]helicenes $\mathbf{5 9 a , b}$ and S-shaped double carbo[6]helicenes $\mathbf{5 9 c , \mathbf { d }}{ }^{57}$

In 2018, X-shaped and S-shaped pristine double hexahelicenes (60 and 61, Fig. 23) were prepared and used as representative molecular models and a theory-guided, symmetry-based protocol was developed. ${ }^{22}$ Compound $\mathbf{6 0}$ and $\mathbf{6 1}$ exhibited a strong increase in intensity of ECD and CPL. The enhanced chiroptical responses were theoretically assigned to the electric $\left(\mu_{\mathrm{e}}\right)$ and magnetic $\left(\mu_{\mathrm{m}}\right)$ transition dipole moments of component hexahelicenes aligned in the correct symmetry. Indeed, $\mathbf{6 0}$ and 61, constructed by merging two hexahelicenes in $D_{2}$ and $C_{2}$ symmetry, respectively, showed absorption dissymmetry factors per benzene unit $\left(g_{\text {abs }} / \mathrm{n}\right)$ for the ${ }^{1} \mathrm{~B}_{\mathrm{b}}$ band that are larger by a factor of up to 1.5 than that of parent $\mathbf{1 0}$. This enhancement was well rationalized by $\mu_{\mathrm{e}}$ and $\mu_{\mathrm{m}}$ and their relative angle $(\theta)$ evaluated theoretically. In the 
double helicenes, $\mu_{\mathrm{e}}$ and $\mu_{\mathrm{m}}$ were parallel-aligned $(\theta=0)$ to maximize the orientation factor $(\cos \theta)$ up to unity, which was mere $0.24\left(\cos 76^{\circ}\right)$ in $\mathbf{1 0}$, while $\left|\mu_{\mathrm{e}}\right|$ and $\left|\mu_{\mathrm{m}}\right|$ were comparable or only slightly improved. Similarly, the luminescence dissymmetry factor per benzene unit ( $g_{\text {lum }} / \mathrm{n}$ ) was up to 1.7-fold larger for the double helicenes than for $\mathbf{1 0}$, for which the increased $\left|\mu_{\mathrm{e}}\right|$ and $\theta$ are responsible. The enhanced $g_{\text {abs }} / \mathrm{n}$ and $g_{\text {lum }} / \mathrm{n}$ values for double helicenes mean that merging two helicenes is $50-70 \%$ more resource-efficient than simply assembling them, in favor of the molecular, rather than supramolecular strategy for constructing advanced chiroptical devices.

a)

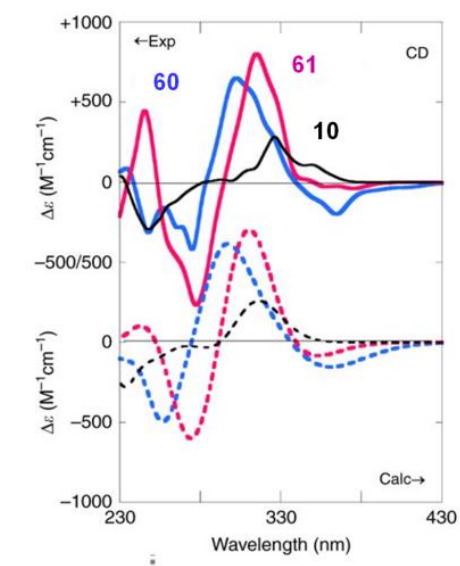

b)

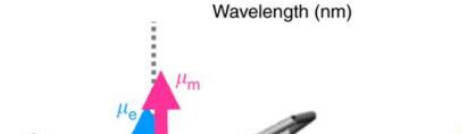

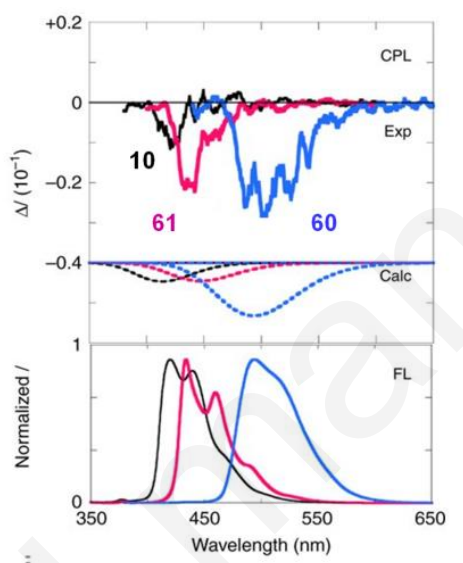

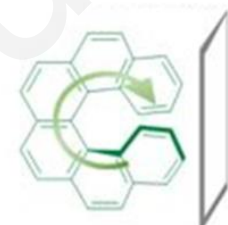

$(P)-10$

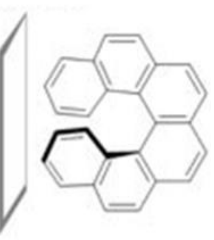

(M)-10

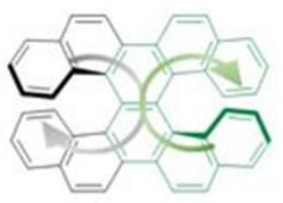

$(P, P)-60$

10

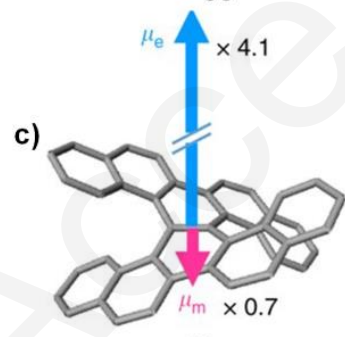

60

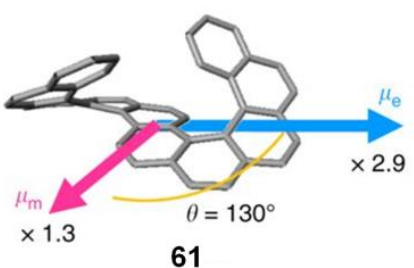

61

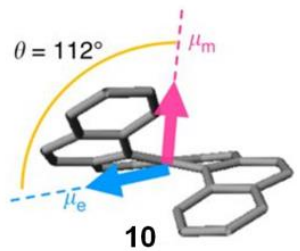

10

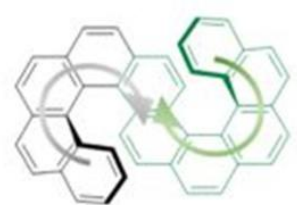

$(P, P)-61$

Fig. 23. a) Experimental and calculated ECD and CPL responses of 10, $\mathbf{6 0}$ and $\mathbf{6 1}((P)$ enantiomers). b) Transition dipole moments in the ground state. Schematic representations of electric $\left(\mu_{e}\right.$, blue) and magnetic $\left(\mu_{m}\right.$, red) transition dipole moments of the ${ }^{1} B_{b}$ band for X-shaped and S-shaped double hexahelicenes $\mathbf{6 0}$ and 61, with the magnitudes relative to parent helicene 10, calculated at the RI-CC2/def2-TZVPP level. Dashed arrows in double helicenes indicate the transition dipole moments of component helicene units. c) Transition dipole moments in the excited state. Schematic representations of the electric $\left(\mu_{\mathrm{e}}\right.$, blue) and magnetic $\left(\mu_{\mathrm{m}}\right.$, red) transition dipole moments of the ${ }^{1} \mathrm{~L}_{b}$ band of 60 and 61 in the excited states, with the magnitudes relative to those for parent helicene 10, calculated at the RI-CC2/def2-TZVPP level. Adapted with permission. ${ }^{22}$ Copyright 2018, Nature Publishers. 
Table 10. Photophysical data of carbon-based helicenes.

\begin{tabular}{|c|c|c|c|c|c|c|c|}
\hline Compound & $\lambda_{\mathrm{Abs}} \operatorname{maxa}(\mathrm{nm})$ & $\lambda_{\mathrm{Em}}(\mathrm{nm})$ & $\Phi(\%)$ & Solvent (CPL) & $10^{3} g_{\text {abs }}$ & $10^{3} \mathrm{~g}_{\mathrm{lum}}$ & Ref. \\
\hline$(P)-58 a$ & 582 & 610 & 39 & $\mathrm{CH}_{2} \mathrm{Cl}_{2}$ & +0.15 & +0.1 & 56 \\
\hline$(P)-\mathbf{5 8 b}$ & 582 & 610 & 41 & $\mathrm{CH}_{2} \mathrm{Cl}_{2}$ & +0.9 & +0.6 & 56 \\
\hline$(P, P)-\mathbf{5 8 c}$ & 622 & 650 & 35 & $\mathrm{CH}_{2} \mathrm{Cl}_{2}$ & +1.3 & +0.9 & 56 \\
\hline$(P)-(+)-59 a$ & 326 & 442 & 14 & $\mathrm{CHCl}_{3}$ & -0.56 & $\sim 0$ & 57 \\
\hline$(P)-(+)-\mathbf{5 9} \mathbf{b}$ & 327 & 452 & 29 & $\mathrm{CHCl}_{3}$ & -3.1 & $\sim 0$ & 57 \\
\hline$(P, P)-(+)-59 \mathrm{c}$ & 291 & 464 & 11 & $\mathrm{CHCl}_{3}$ & -0.68 & -2.7 & 57 \\
\hline$(P, P)-(+)-59 \mathbf{d}$ & 292 & 466 & 7.6 & $\mathrm{CHCl}_{3}$ & -4.5 & -1.5 & 57 \\
\hline$(P)-10$ & 410 & 413 & 14 & $\mathrm{CHCl}_{3}$ & $-1.2^{b}$ & -0.9 & 22 \\
\hline$(P)-11$ & 410 & 416 & 5 & $\mathrm{CHCl}_{3}$ & $-2.5^{b}$ & $-0.02^{b}$ & 16 \\
\hline$(P, P)-60$ & 471 & 494 & 1.8 & $\mathrm{CH}_{2} \mathrm{Cl}_{2}$ & -2.6 & -2.5 & 22 \\
\hline$(P, P)-61$ & 430 & 434 & 4.1 & $\mathrm{CH}_{2} \mathrm{Cl}_{2}$ & -2.8 & -2.1 & 22 \\
\hline
\end{tabular}

${ }^{a}$ Lowest energy UV-vis band. ${ }^{b}$ Taken from ref. 12.

\subsection{CPL-active heptahelicenic structures}

In 2012, Tanaka et al. reported the preparation of helically chiral 1,1'-bitriphenylenes displaying a central fluorenyl cycle. These compounds correspond to heptahelicenic structures and exhibit among the strongest CPL activity. ${ }^{58}$ Indeed, compounds 62 and 63 (Fig. 24) obtained with high enantiomeric excesses (93\% and $91 \%$ ee respectively) exhibited mirrorimages CPL spectra with particularly high fluorescence dissymmetry factors $\left(g_{\text {lum }}=-0.030\right.$ at $428 \mathrm{~nm}$ for $(M)-(-)-62$ and $g_{1 \mathrm{lu}}=-0.032$ at $449 \mathrm{~nm}$ for $(M)-(-)-63$ in chloroform, Table 11), which are comparable to phthalhydrazide-functionalized [7] helicene-like molecule $\mathbf{3 4}$ ( $g_{\text {lum }}=$ -0.035 at $476 \mathrm{~nm}$ for the assembly state and -0.021 for the molecularly dispersed state) and significantly larger than those for helically chiral molecules reported to date. However, the

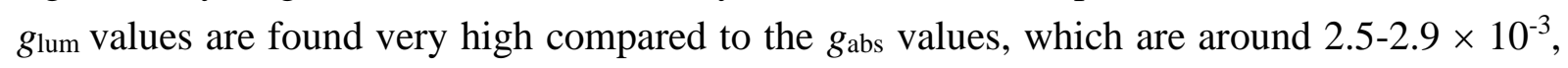
i.e. one order of magnitude lower. This is clearly seen in the ECD shape, which displays the typically large bands of $(P$ )-helicenes (a large positive band at $\sim 320 \mathrm{~nm}$, and two large nega- 
tive bands at $\sim 260$ and $285 \mathrm{~nm}$, Fig. 25) but small bands between 340-400 nm which correspond to the lowest energy transitions. Later on in 2016, Nozaki and coworkers reported the synthesis, and photophysical properties of enantiopure [7]helicene-like fluorenyl systems 64a,b. ${ }^{59}$ These compounds showed similar absorption spectra with the longest absorption maximum at $400 \mathrm{~nm}$ slightly blue-shifted compared to that of carbo[7]helicene, while they are significantly red-shifted compared to those of fluorene and phenanthrene. Indeed, the $\pi$ conjugation is well extended over the whole molecule despite their helically twisted structures. In addition, the longest absorption maximum is slightly red-shifted compared to that of compound 62 despite the fact that $\mathbf{6 2}$ possesses triphenylene units. ${ }^{58}$ This phenomenon may be attributed to a smaller twist of compounds 64 than compound $\mathbf{6 2}$, resulting in more effective $\pi$-conjugation along the helical structure. [7]Helicene-like compounds $\mathbf{6 4 a}, \mathbf{b}$ exhibited an emission maximum at around $420 \mathrm{~nm}$ with a very small Stokes shift and high fluorescence quantum yields (up to 40\%) among the highest reported helicenes and slightly higher than those of [7]helicene-like compounds. ${ }^{58}$ This makes helicenes incorporating a fluorene unit very appealing for highly emissive chiral molecular materials. ECD spectra of $\mathbf{6 4 a}, \mathbf{b}$ enantiomers display a similar shape as for $\mathbf{6 2}$ and $\mathbf{6 3}$ but their CPL activities were smaller, with dissymmetry factors of $3.0 \times 10^{-3}$ and $2.5 \times 10^{-3}$ respectively. These values are comparable to that of silole-fused compound $\mathbf{5 1}$ (vide supra). In 2015, Hasobe and coworkers reported a highly yellow fluorescent [7]carbohelicene fused by asymmetric 1,2-dialkyl-substituted quinoxaline (65). ${ }^{60}$ It displayed a fluorescence quantum yield of 0.25 at $550 \mathrm{~nm}$ emission wavelength which is more than 10 times larger than that of the pristine heptahelicene $\left(\Phi_{\mathrm{F}}=\right.$ 0.02). Such a large enhancement of fluorescence in $\mathbf{6 5}$ also provided good CPL activity, with

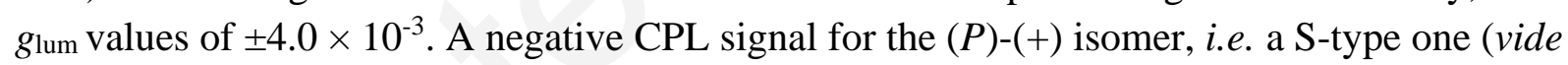
supra and refs. 16,17), corresponding to the small negative ECD signal at $435 \mathrm{~nm}$ with a $g_{\text {abs }}$ of $-1.3 \times 10^{-3}$. Note also that this compound was successfully used as an emitter in OLEDs but the authors did not report any CPL emission of the OLED.

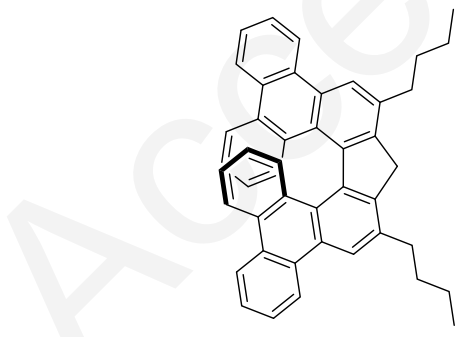

(M)-(-)-62 (93\% ee)

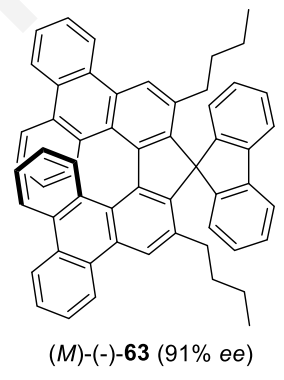

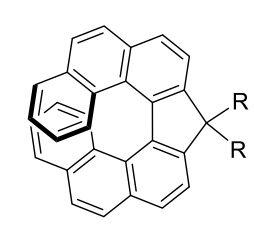

$(P)-(+)-64 \mathrm{a} \quad \mathrm{R}=\mathrm{H}$ $(P)-(+)-64 \mathrm{~b} \quad \mathrm{R}=\mathrm{Ph}$

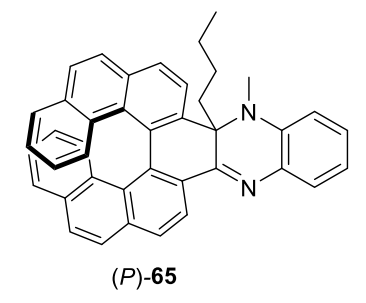

(P)-65

Fig. 24. Chemical structures of CPL-active heptahelicenic derivatives. 


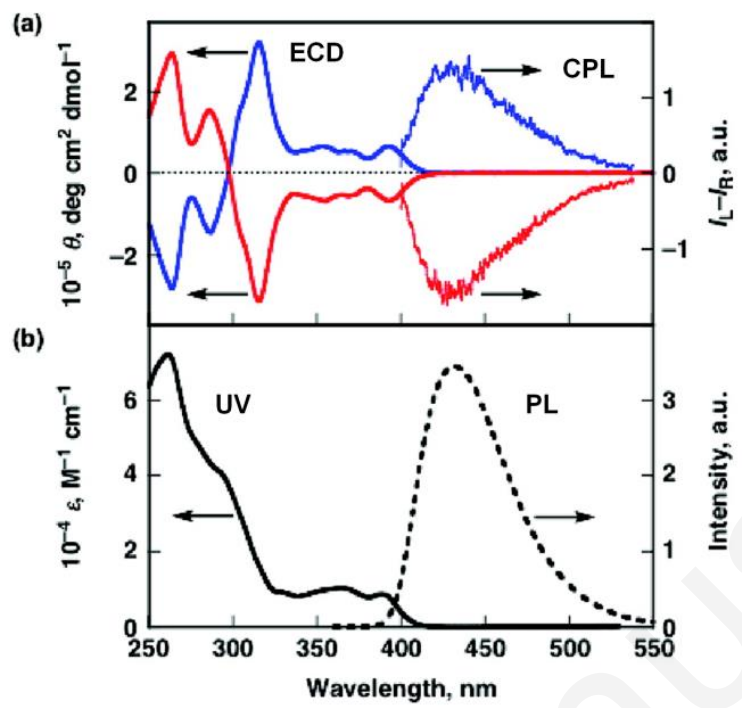

Fig. 25. UV-vis/fluorescence spectra and ECD/CPL spectra of heptahelicenic fluorene 63 in $\mathrm{CH}_{2} \mathrm{Cl}_{2}$. Blue lines in ECD and CPL spectra: $(P)$-isomer. Red lines: $(M)$-isomer. Reproduced with permission. ${ }^{58}$ Copyright 2012, American Chemical Society.

Table 11. Photophysical data of heptahelicenic derivatives.

\begin{tabular}{llllllll}
\hline Compound & $\lambda_{\text {Abs }}{ }^{\max }(\mathrm{nm})$ & $\lambda_{\mathrm{Em}}(\mathrm{nm})$ & $\Phi(\%)$ & Solvent $(\mathrm{CPL})$ & $10^{3} g_{\mathrm{abs}}$ & \multicolumn{1}{c}{$10^{3} g_{\text {lum }}$} & Ref. \\
\hline$(M)-(-)-62$ & 388 & 428 & 32 & $\mathrm{CHCl}_{3}$ & $-2.5^{\mathrm{b}}$ & -30 & 58 \\
$(M)-(-)-63$ & 400 & 449 & 29.6 & $\mathrm{CHCl}_{3}$ & $-2.9^{\mathrm{b}}$ & -32 & 58 \\
$(P)-(+)-64 \mathrm{a}$ & 400 & 417 & 39 & $\mathrm{CH}_{2} \mathrm{Cl}_{2}$ & $1.3^{\mathrm{b}}$ & 3 & 59 \\
$(P)-(+)-64 \mathrm{~b}$ & 408 & 421 & 40 & $\mathrm{CH}_{2} \mathrm{Cl}_{2}$ & - & 2.5 & 59 \\
$(P)-(+)-65$ & 435 & 550 & 25 & $\mathrm{THF}$ & -1.3 & -4 & 60 \\
\hline
\end{tabular}

${ }^{a}$ Lowest energy UV-vis band. ${ }^{b}$ Taken from ref. 12.

\section{CPL-active transition metal complexes of helicenes}

\subsection{Cycloplatinated helicenes}

Coordination chemistry offers a simple way to tune the optical and electronic properties of the $\pi$-ligands since both the coordination sphere geometry and the nature of the metal-ligand interaction can be readily modified by varying the metal center. This will produce a great impact on the properties of the molecule. ${ }^{61}$ Recent studies have demonstrated many potential applications of N-containing helicenes in coordination chemistry and in materials science. ${ }^{62} \mathrm{In}$ deed, their transition metal complexes may show interesting properties in harvesting (visible) 
light and re-emitting it at a wavelength that depends on the metallic ion used, thus allowing the development of light-emitting devices, chemosensors, photovoltaic dye-sensitized devices, etc. In 2010, our group prepared the first class of organometallic helicenes incorporating a metallic ion, i.e. Pt, within their helical backbone, named platinahelicenes. ${ }^{63,64}$ Enantiopure platina[6]helicene 66a, platina[8]helicene 66b, bisplatina[6]helicene 66c, and bisplatina[10]helicene 66d (Fig. 26), displayed absorption spectra that were strongly red-shifted compared to the starting ligands, with longer absorption wavelengths above $450 \mathrm{~nm}$. Furthermore, platinahelicenes 66a-d are efficient deep-red phosphors, with emission maxima between 630-700 nm, quantum yields around 0.05 in deoxygenated solution at room temperature and luminescence lifetimes of 10-20 $\mu$ s. Interestingly, platinahelicenes 66a-c displayed circularly polarized phosphorescence with dissymmetry factors as high as $10^{-2}$, which is one order of magnitude bigger than for most of organic helicenes. These $g_{\text {lum }}$ values appeared positive for the $(P)$ enantiomers and negative for the $(M)$, which was not always the case in azaborahelicenes analogues 46a-d. ${ }^{45}$ Note that bis-platina[10] helicene $66 \mathbf{d}$ also exhibited red phosphorescence at room temperature, but no CPL activity was detected. This can be explained by the weakly chiral environment around the two Pt centers and the high sensitivity to oxygen. Note also that the precursor 1-(2-pyridyl)-hexahelicene 67 displayed fluorescence emission and CPL activity (see Table 12). Recently, polyfluorinated platina[6]helicene 66e was prepared by Zheng, Zuo, et al.. ${ }^{65}$ It displayed similar molecular behavior as 66a-c namely CPL activity with a $g_{\text {lum }}$ of $-3.7 \times 10^{-3}$ in dichloromethane solution for the $(P)-(+)$ enantiomer. The same compound displayed a $g_{\text {lum }}$ of $-4.1 \times 10^{-3}$ when incorporated in a DCzppy film (DCzppy: 2,6-bis(3-(9H-carbazol-9-yl)phenyl)pyridine). Interestingly, compounds 66a and 66e were used as chiral dopants in OLED devices to conceive efficient circularly polarized OLEDs (CP-OLEDs, see paragraph 10).
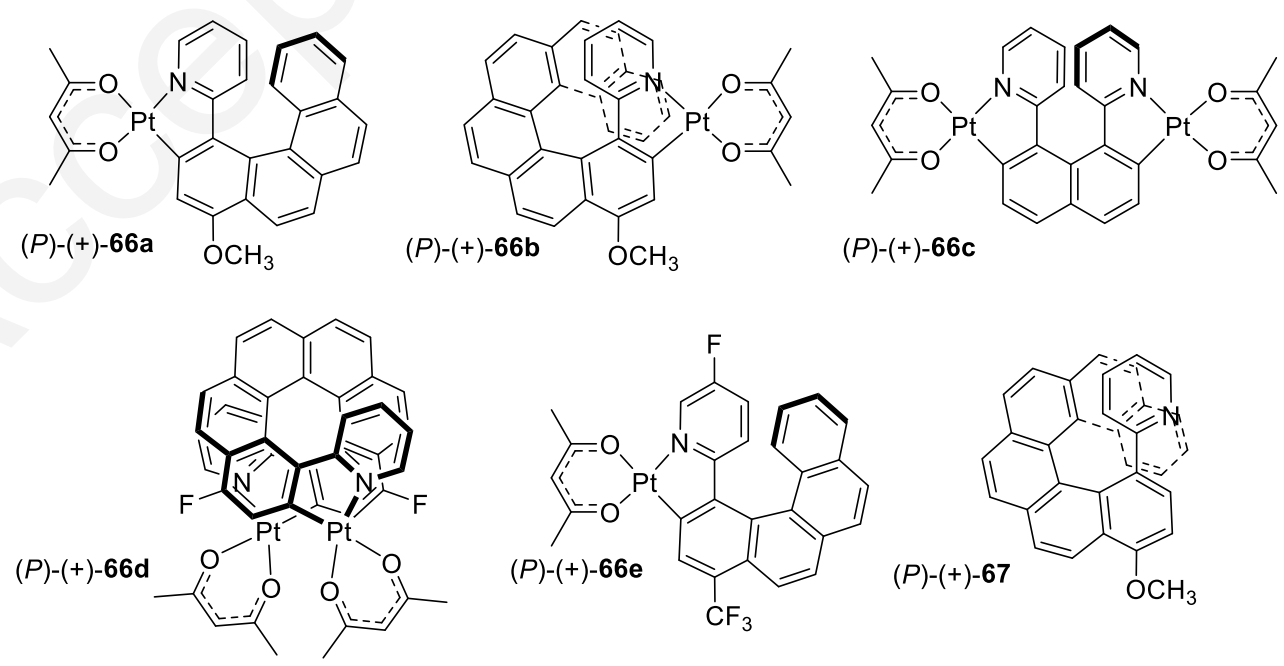

Fig. 26. Chemical structures of platinahelicenes $66 a-e$ and of precursor 67. 


\subsection{Coordination of helicene-bipyridine ligands}

Our group also prepared complexes bearing a helicene-bi-pyridine type ligand. Bipyridine ligands are classical $\mathrm{N}^{\wedge} \mathrm{N}$ chelate ligands but can also act as $\mathrm{C}^{\wedge} \mathrm{N}$ ones toward different transition metal ions such as platinum. In 2015, we reported the preparation of enantiopure helical cycloplatinated complexes $(P)$ - and $(M)$-69 from a [6]helicene-bipyridine-type ligand, namely 3-(2-pyridyl)-4-aza[6]helicene $\left((P)\right.$ - and $(M)$-68 in Fig. 27). ${ }^{66}$ Due to the presence of an additional $\mathrm{N}$ atom in organometallic species $(P)$ - and $(M)-69$, the acid-base triggering of UV-vis, ECD, phosphorescence and CPL were achieved, thus yielding the first acid-based CPL switch (see the increase of $g_{\text {lum }}$ upon protonation in Fig. 27). Furthermore, we showed that organic helicene ligand $(P)$ - and $(M)$-68 was also an efficient chiroptical switch since, after double protonation, it displayed a strong bathochromic shift in emission wavelength while keeping strong CPL fluorescence signal ( $g_{\text {lum }}= \pm 2 \times 10^{-3}$ in $\mathrm{CH}_{2} \mathrm{Cl}_{2}$ ). TDDFT calculations showed that, upon protonation, the HOMO-to-LUMO transition changed from a $\pi-\pi^{*}$-type to a charge transfer-type transition.

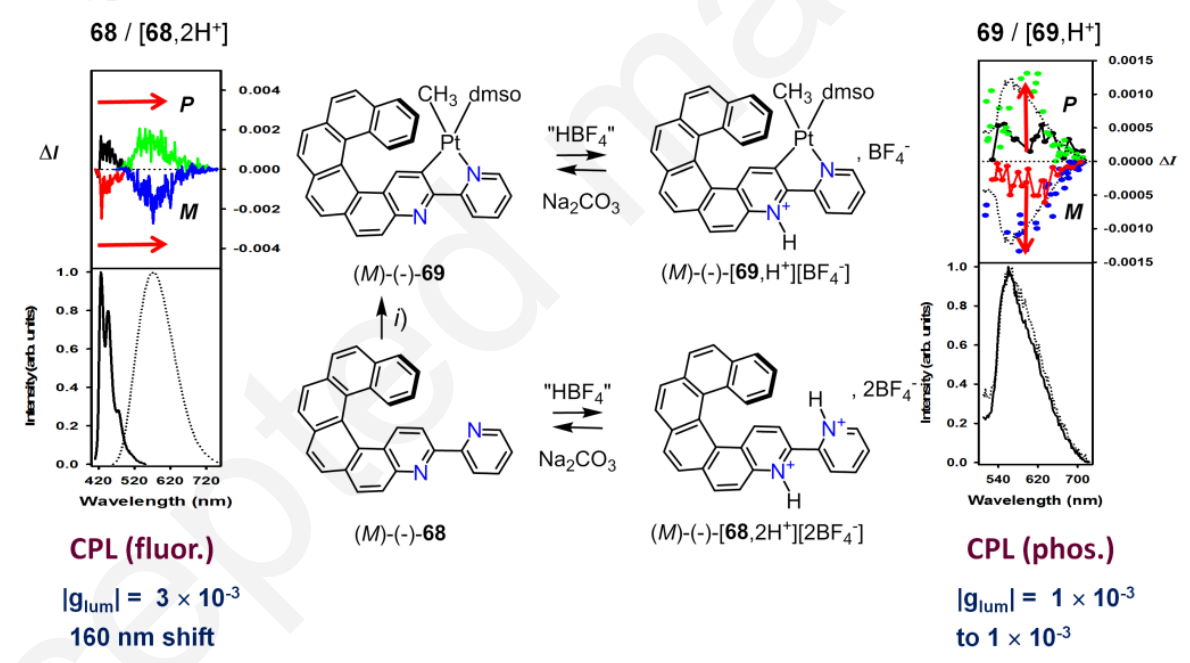

Fig. 27. Synthesis of cycloplatinated helicene $(M)-69$ from $(M)-68$ and reversible protonation and deprotonation process of organic and organometallic systems, observed by emission and $\mathrm{CPL}$ spectroscopies. i) $\mathrm{Pt}(\mathrm{dmso})_{2}\left(\mathrm{CH}_{3}\right)_{2}$, acetone, $50{ }^{\circ} \mathrm{C}, 5 \mathrm{hrs}, 90 \%$. Variation of emission and CPL responses upon protonation. ${ }^{66}$

Rhenium(I)-chloro-tricarbonyl complexes bearing a bipy ligand are known to display efficient luminescence, usually a ${ }^{3} \mathrm{CT}$ emission from an excited state based on the bis-imine ligand. In this context, organic helicene-bipy ligand $(P)$ - and $(M)-68$ was used as $\mathrm{N}^{\wedge} \mathrm{N}$ chelate to prepare enantio-enriched CPL-active helicene-bipyridine-rhenium complexes $\mathbf{7 0}$ (Fig. 28). ${ }^{67}$ Starting from $(M)-68$ ligand, two diastereomeric complexes, i.e. $\left(M, A_{\mathrm{Re}}\right)-\mathbf{7 0 a ^ { 1 }}$ and $\left(P, C_{\mathrm{Re}}\right)-$ $\mathbf{7 0 a}^{\mathbf{2}}$, were formed, since the $\operatorname{Re}(\mathrm{I})$ atom is also a stereogenic center. These stereoisomers were separated by regular silica gel column chromatography and their chiroptical and emissive properties were studied. They revealed strong ECD spectra in $\mathrm{CH}_{2} \mathrm{Cl}_{2}$ (whose intensity depends on the rhenium stereochemistry, see Fig. 28), accompanied by substantial phospho- 
rescence and CPL activity. Indeed $\left(M, A_{\mathrm{Re}}\right)-\mathbf{7 0 a}^{\mathbf{1}}$ and $\left(M, C_{\mathrm{Re}}\right)-\mathbf{7 0 \mathbf { a } ^ { 2 }}$ displayed phosphorescence emission $\left(\lambda_{\max }{ }^{\text {phos }}=673-680 \mathrm{~nm}, \phi=0.13-0.16 \%, \tau=27-33 \mathrm{~ns}\right)$ and good $g_{\text {lum }}$ values $\left(\left(M, C_{\mathrm{Re}}\right)-\mathbf{7 0 a}^{2}: \quad g_{\text {lum }} \sim-310^{-3}\right.$ around $\left.670 \mathrm{~nm}\right)$. Upon reaction with AgOTf and 2,6dimethylphenyl isocyanide in the presence of $\mathrm{NH}_{4} \mathrm{PF}_{6},\left(M, C_{\mathrm{Re}}\right)$ and $\left(P, A_{\mathrm{Re}}\right)-\mathbf{7 1} \mathbf{a}^{2}$ were trans-

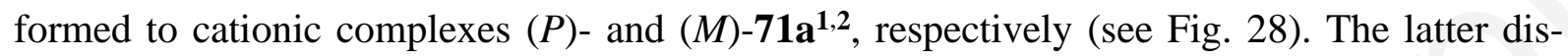
played stronger phosphorescence $\left(\lambda_{\max }{ }^{\text {phos }}=598 \mathrm{~nm}, \phi=6 \%, \tau=79 \mu \mathrm{s}\right)$ and still good CPL activity $\left(g_{\text {lum }} \sim \pm 1.510^{-3}\right)$. However, the stereochemical information at the $\operatorname{Re}(\mathrm{I})$ center was lost (epimerization to 50:50 mixture). Nevertheless, the ECD spectrum of $(P)-\mathbf{7 1}^{\mathbf{1}} \mathbf{1}^{\mathbf{2}}$ displayed an additional positive ECD-active band around $450 \mathrm{~nm}$ as compared to $\left(P, C_{\mathrm{Re}}\right)-\mathbf{1 1 4 \mathbf { a } ^ { \mathbf { 1 } }}$ and $\left(P, A_{\mathrm{Re}}\right)-\mathbf{7 0 \mathbf { a } ^ { 2 }}$. According to TDDFT calculations, this band does not involve the Re center but corresponds to the HOMO-to-LUMO transition with strong intra-ligand charge transfer from the $\pi$-helicene to the bipy moiety. ${ }^{67} \mathrm{We}$ have thus shown that the incorporation of a rhenium atom within an extended helical $\pi$-conjugated bi-pyridine system can impact the chiroptical and photophysical properties of the resulting neutral or cationic complexes, leading to the first rhenium-based circularly polarized phosphors.

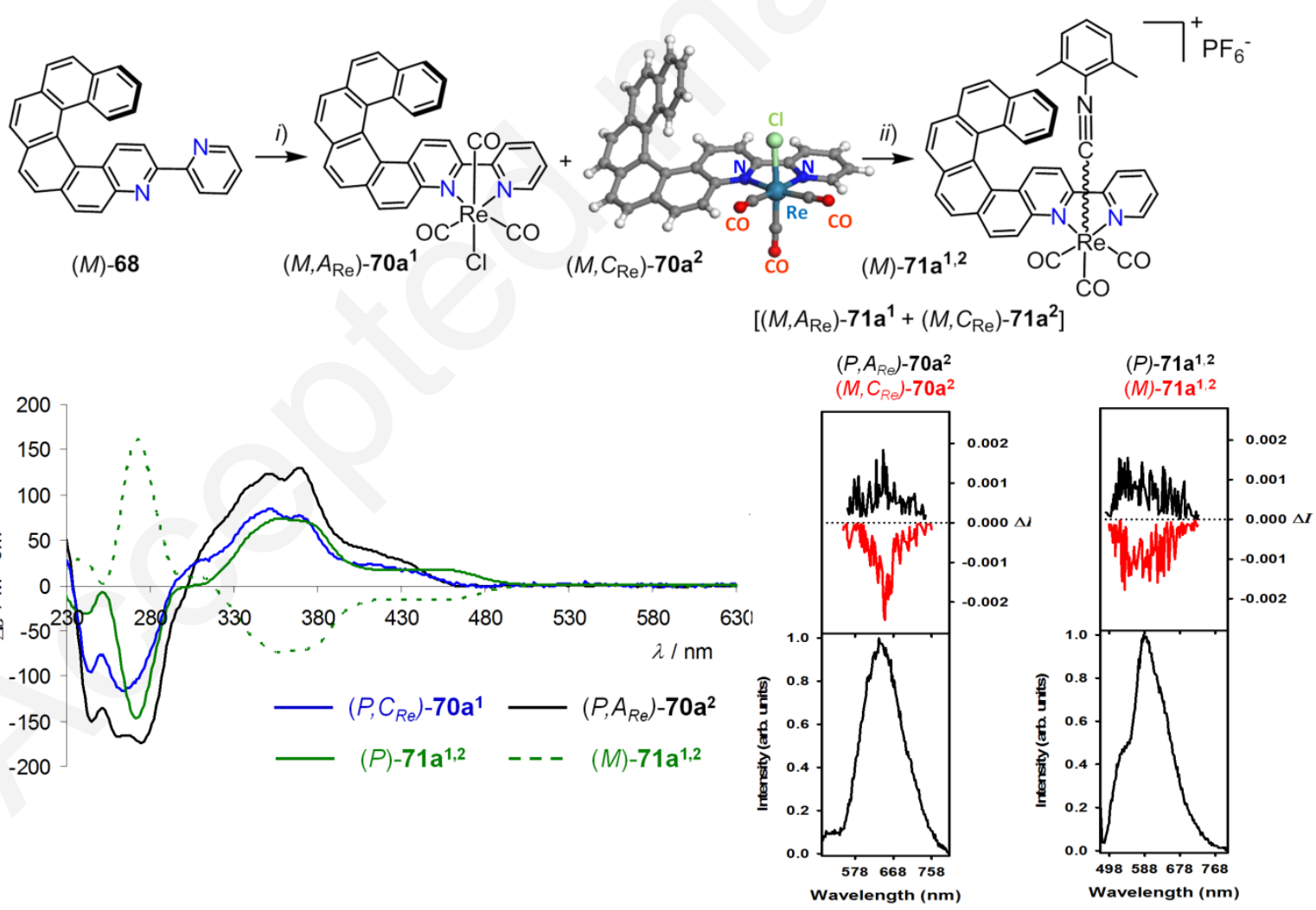

Fig. 28. Synthesis of enantioenriched rhenium complexes $\left(M, A_{R e}\right)-70 a^{1},\left(M, C_{R e}\right)-70 a^{2}$, and $(M)-71 a^{1,2}$ (mixture of two diastereomers). i) $\operatorname{Re}(\mathrm{CO})_{5} \mathrm{Cl}$, toluene, reflux; ii) $\mathrm{AgOTf}, \mathrm{EtOH} / \mathrm{THF}$, then 2,6-dimethylphenyl isocyanide, $\mathrm{THF}, \mathrm{NH}_{4} \mathrm{PF}_{6}$. X-ray crystallographic

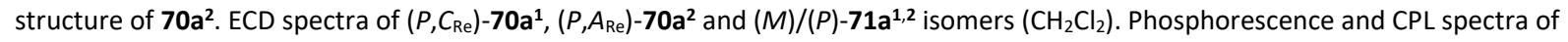
$\left(P, C_{\mathrm{Re}}\right)-\mathbf{7 0 a ^ { 1 }},\left(P, A_{\mathrm{Re}}\right)-\mathbf{7 0 a ^ { 2 }}$ and $(M) /(P)-\mathbf{7 1} \mathbf{a}^{\mathbf{1}, \mathbf{2}}$ isomers in $\mathrm{CH}_{2} \mathrm{Cl}_{2} \cdot{ }^{67}$ 
Table 12 . Photophysical data of platinahelicenes and helicene-bipy rhenium complexes.

\begin{tabular}{|c|c|c|c|c|c|c|c|}
\hline \multirow{2}{*}{$\begin{array}{l}\text { Compound } \\
(P)-(+)-66 a\end{array}$} & \multirow{2}{*}{$\begin{array}{l}\lambda_{\mathrm{Abs}} \max a(\mathrm{~nm}) \\
452\end{array}$} & \multirow{2}{*}{$\begin{array}{l}\lambda_{\mathrm{Em}}(\mathrm{nm}) \\
644\end{array}$} & \multirow{2}{*}{$\begin{array}{l}\Phi(\%) \\
10\end{array}$} & \multicolumn{2}{|c|}{ Solvent $(\mathrm{CPL}) 10^{3} \mathrm{~g}_{\mathrm{abs}}$} & \multirow{2}{*}{$\begin{array}{l}10^{3} g_{\mathrm{lum}} \\
+13\end{array}$} & \multirow{2}{*}{$\begin{array}{l}\operatorname{Re} \\
64\end{array}$} \\
\hline & & & & $\mathrm{CH}_{2} \mathrm{Cl}_{2}$ & $\sim 3.5^{b}$ & & \\
\hline$(P)-(+)-67$ & 422 & 430 & - & $\mathrm{CH}_{2} \mathrm{Cl}_{2}$ & $\sim 7.3^{b}$ & +0.8 & 64 \\
\hline$(P)-(+)-66 \mathbf{b}$ & 467 & 648 & 5.6 & $\mathrm{CH}_{2} \mathrm{Cl}_{2}$ & $\sim 12^{b}$ & +0.5 & 64 \\
\hline$(P)-(+)-66 c$ & 471 & 633 & 13 & $\mathrm{CH}_{2} \mathrm{Cl}_{2}$ & $\sim 3.2^{b}$ & +0.4 & 64 \\
\hline$(P)-(+)-66 \mathrm{~d}$ & 479 & 639 & 6.6 & $\mathrm{CH}_{2} \mathrm{Cl}_{2}$ & - & $\sim 0$ & 64 \\
\hline$(P)-(+)-66 \mathbf{e}$ & 463 & 612 & 27 & $\mathrm{CH}_{2} \mathrm{Cl}_{2}$ & - & $-3.7(-4.1)^{c}$ & 65 \\
\hline$(M)-(-)-68$ & 417 & 421 & 8.4 & $\mathrm{CH}_{2} \mathrm{Cl}_{2}$ & $\sim-4.1^{b}$ & -3.2 & 66 \\
\hline$(M)-(-)-68.2 \mathrm{H}^{+}$ & 418 & 590 & 8.2 & $\mathrm{CH}_{2} \mathrm{Cl}_{2}$ & $\sim-5.3^{b}$ & -2.9 & 66 \\
\hline$(M)-(-)-69$ & 430 & 547 & 0.38 & $\mathrm{CH}_{2} \mathrm{Cl}_{2}$ & $\sim-5.2$ & -1.1 & 66 \\
\hline$(M)-(-)-69 . \mathrm{H}^{+}$ & 450 & 555 & 2.7 & $\mathrm{CH}_{2} \mathrm{Cl}_{2}$ & $\sim-10$ & -2 & 66 \\
\hline$\left(\left(M, C_{\mathrm{Re}}\right)-70 \mathrm{a}^{2}\right.$ & 445 & 673 & 0.16 & $\mathrm{CH}_{2} \mathrm{Cl}_{2}$ & $\sim-2$ & -3 & 67 \\
\hline$(M)-71 a^{1,2}$ & 444 & 598 & 6 & $\mathrm{CH}_{2} \mathrm{Cl}_{2}$ & $\sim_{-0.4}$ & -1.5 & 67 \\
\hline
\end{tabular}

${ }^{a}$ Lowest energy UV-vis band. ${ }^{b}$ Taken from ref. $12 .{ }^{c}$ Fluorescence quantum yield measured in a DCzppy film.

\subsection{Coordination chemistry of bis-helicene-terpyridine and bis-helicene-bipy ligands}

In 2016, our group also prepared the bis-helical terpyridine (terpy) ligand $\mathbf{7 2}$ which acted as a chiroptical switch upon reversible coordination-decoordination to zinc(II). The strong conformational changes induced led to a multi-responsive chiroptical switch (Fig. 29). ${ }^{68}$ The interconversion between the ligand and zinc-complexed states was analyzed via firstprinciples calculations, which highlighted the change from $\pi-\pi *$ transitions in the organic ligand to charge transfer transitions in the $\mathrm{Zn}$ complex. Overall, this system behaved as a chiroptical switch offering multi-output read-out (UV-vis, ECD, luminescence and CPL). Furthermore, the switching process triggered conformational changes and molecular motion around the $\mathrm{Zn}$ centre, from a clear trans (W-shape) conformation in the free ligand to a cis (U-shape) one in the Zn-complex 73 (Fig. 29, Table 13). Recently, we have prepared a novel enantiopure bis-helicenic 2,2'-bipyridine system ligand, 74. ${ }^{69}$ Thanks to the bipyridine unit, the coordination to 75 with $\mathrm{Zn}^{\mathrm{II}}$ and protonation processes to $\mathbf{7 4 . 2 \mathrm { H } ^ { + }}$ were studied revealing efficient tuning of photophysical (UV/Visible and emission) and chiroptical properties (ECD and 
CPL) of the system (Fig. 29, Table 13). The coordination/decoordination and protonation/deprotonation processes appeared reversible thus constituting novel chiroptical switches.

a)

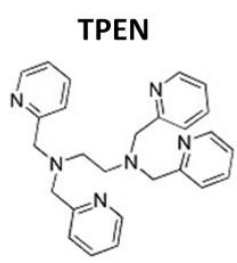

b)

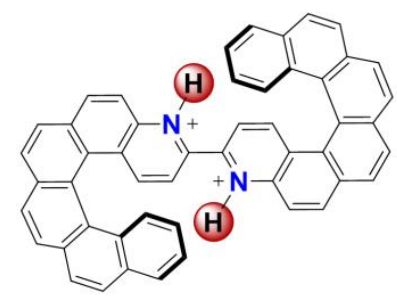

$(P, P)-74.2 \mathrm{H}^{+}$

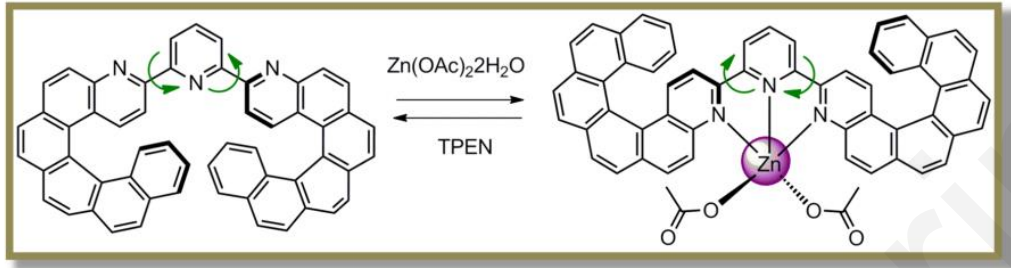

$(P, P)-72$
$(P, P)-73$

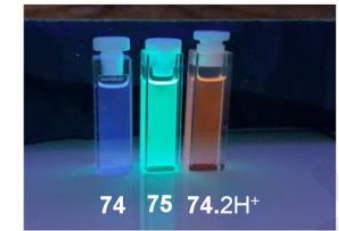

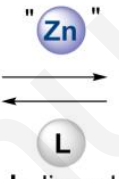

L: ligand
$(P, P)-74$

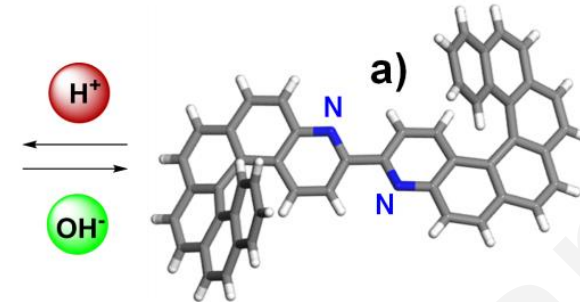

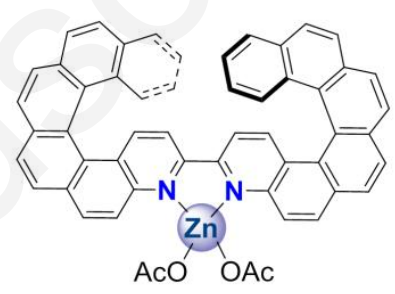

$(P, P)-75$

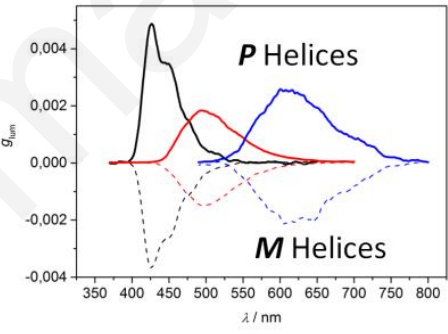

Fig. 29 a) Reversible $\mathrm{Zn}(I I)$ complexation-decomplexation process of $(P, P)-\mathbf{7 2}$ to $(P, P)-\mathbf{7 2}$ using $\mathrm{Zn}(\mathrm{OAC})_{2}$ and TPEN as the chemical stimuli. ${ }^{8} \mathrm{~b}$ ) Reversible $\mathrm{Zn}(\mathrm{II})$ complexation-decomplexation process of $(P, P)-\mathbf{7 4}$ to $(P, P)-75$ using $\mathrm{Zn}(\mathrm{OAc})_{2}$ and TPEN as the chemical stimuli and acid-base triggered switch between $(P, P)-74$ to $(P, P)-74.2 \mathrm{H}^{+}$. Emission colors and CPL activity of $\mathbf{7 2}$ (black), 75 (red) and $74.2 \mathrm{H}^{+}$(blue). Plain lines are for the $(P)$ helicenes and dotted lines for the $(M)$ ones. Adapted with permission. ${ }^{69}$ Copyright 2019, American Chemical Society.

Table 13. Photophysical data of helicene-bipy and terpy ligands together with heir $\mathrm{Zn}$ and proton complexes.

\begin{tabular}{lccccccc}
\hline Compound & $\lambda_{\mathrm{Abs}}^{\max a}(\mathrm{~nm})$ & $\lambda_{\mathrm{Em}}(\mathrm{nm})$ & $\Phi(\%)$ & Solvent $(\mathrm{CPL})$ & $10^{3} g_{\mathrm{abs}}$ & $10^{3} g_{\text {lum }}$ & Ref. \\
\hline$(P, P)-(+)-72$ & 416 & 421 & 8.4 & $\mathrm{CH}_{2} \mathrm{Cl}_{2}$ & $\sim 6.5^{b}$ & +8.6 & 68 \\
$(P, P)-(+)-73$ & 430 & 480 & 19 & $\mathrm{CH}_{2} \mathrm{Cl}_{2}$ & $\sim 4.3^{b}$ & +1.2 & 68 \\
$(P, P)-(+)-74$ & 420 & 421 & 22 & $\mathrm{CH}_{2} \mathrm{Cl}_{2}$ & - & +4.8 & 69 \\
$(P, P)-(+)-75$ & 453 & 520 & 44 & $\mathrm{CH}_{2} \mathrm{Cl}_{2}$ & - & +1.8 & 69 \\
$(P, P)-(+)-74.2 \mathrm{H}^{+}$ & 507 & 600 & 28 & $\mathrm{CH}_{2} \mathrm{Cl}_{2}$ & - & +2.5 & 69 \\
\hline
\end{tabular}

\footnotetext{
${ }^{a}$ Lowest energy UV-vis band. ${ }^{b}$ Taken from ref. 12.
} 


\subsection{CPL-active Iridium complexes from helicene-NHC ligands}

In the last two decades, octahedral cyclometalated iridium(III) complexes have attracted attention due to their appealing properties as phosphors in high-efficiency organic lightemitting devices (OLEDs). ${ }^{70}$ In 2017, the first fused $\pi$-helical NHC system was prepared and examined through its diastereoisomerically pure cyclometalated complexes $\operatorname{mer}-\left(P, \Lambda_{\mathrm{Ir}}\right)-\mathbf{7 7} \mathbf{a}^{\mathbf{1}}$ and $m e r-\left(P, \Delta_{\text {Ir }}\right)-\mathbf{7 7} \mathbf{a}^{2}$ from pentahelical imidazolium $\mathbf{7 6}$ (Fig. 30). ${ }^{71}$ These chiral organometallic species displayed light-green phosphorescence with $i$ ) circular polarization that depends on both the helical-NHC $(P) /(M)$ stereochemistry and the iridium $(\Delta) /(\Lambda)$ one (Fig. 30 and Table 14) and ii) unusually long lifetimes (up to $250 \mu$ s as compared to $530 \mathrm{~ns}$ for model mer-78). The unprecedented features of $\mathbf{7 7} \mathbf{a}^{\mathbf{1 , 2}}$ can be attributed to extended $\pi$-conjugation within helical carbenic ligand. A similar cycloiridiated complex, namely mer- $\left(\Delta_{\mathrm{Ir}} / \Lambda_{\mathrm{Ir}}\right)-\mathbf{7 8}$, bearing a NHC N-substituted with a carbo[4]helicene unit was recently obtained and also displayed long-lived mirror-image circularly polarized phosphorescence (Table 14). ${ }^{72}$

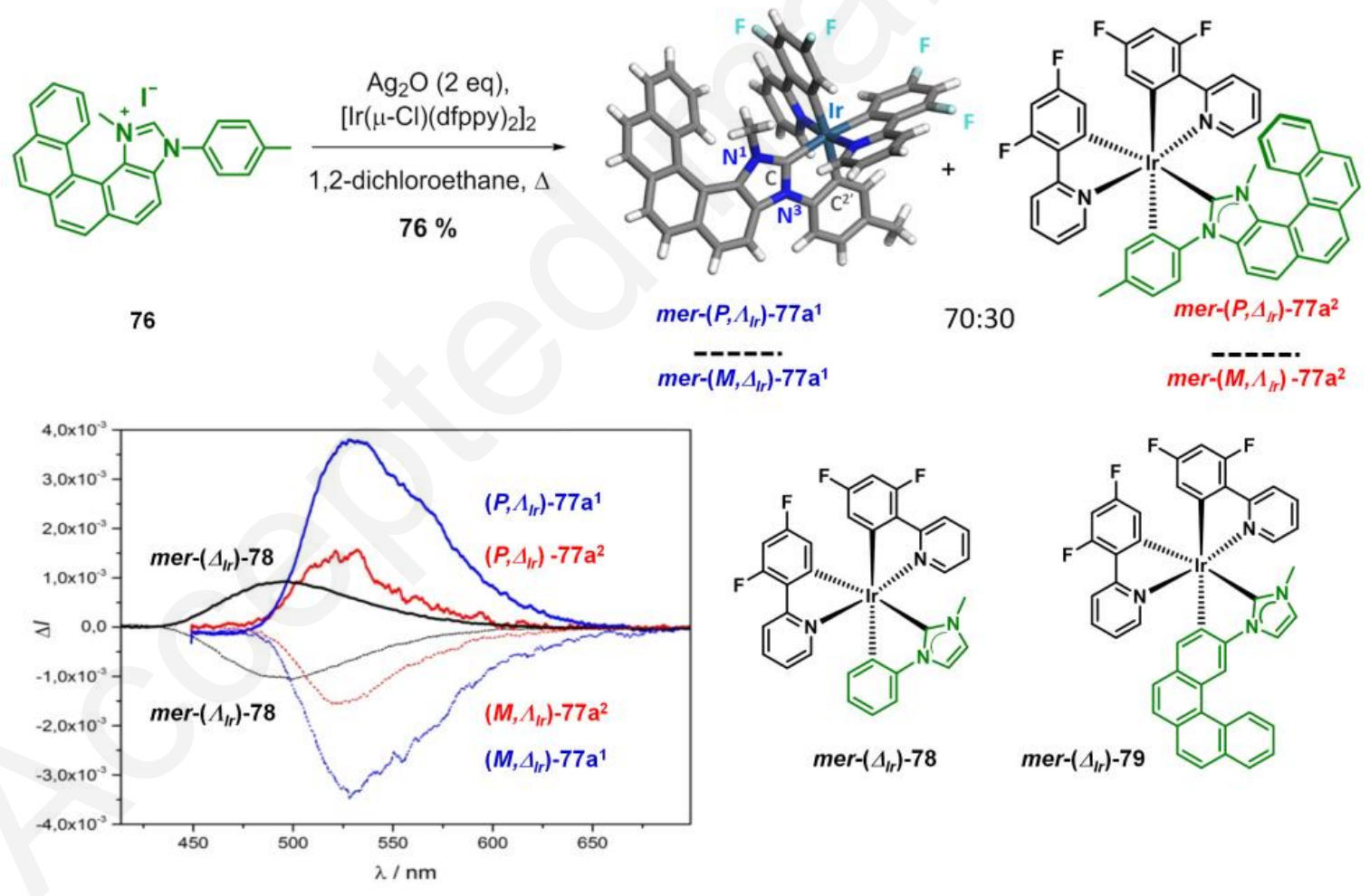

Fig. 30. Preparation of cycloiridiated complexes $77^{1,2}$. Chemical structures and CPL spectra of iridium(III) complexes $\left(P, \Lambda_{\mathrm{Ir}}\right)$ $\mathbf{7 7} \mathrm{a}^{1} /\left(M, \Delta_{\mathrm{lr}}\right)-\mathbf{7 7} \mathrm{a}^{\mathbf{1}},\left(P, \Delta_{\mathrm{r}}\right)-\mathbf{7 7} \mathrm{a}^{2} /\left(M, \Lambda_{\mathrm{rr}}\right)-\mathbf{7 7} \mathrm{a}^{2}$, and $\left(\Delta_{\mathrm{lr}}\right)-\mathbf{7 8} /\left(\Lambda_{\mathrm{lr}}\right)-\mathbf{7 8}$. Chemical structure of $\left(\Delta_{\mathrm{rr}}\right)-\mathbf{7 9}$. X-ray structure of stereoiso$\operatorname{mer}\left(P, \Lambda_{\mathrm{lr}}\right)-\mathbf{7 7} \mathbf{a}^{\mathbf{1}}$. All complexes have the mer geometry. ${ }^{71}$

Table 14. Photophysical data of helicene-NHC iridium complexes.

\begin{tabular}{llllll}
\hline Compound $\quad \lambda_{\mathrm{Abs}}{ }^{\max a}(\mathrm{~nm})$ & $\lambda_{\mathrm{Em}}(\mathrm{nm})$ & $\Phi(\%)$ & Solvent $(\mathrm{CPL})$ & $10^{3} g_{\text {lum }}$ & Ref.
\end{tabular}




\begin{tabular}{lcccccc}
\hline$\left(P, \Delta_{\mathrm{Ir}}\right)-(+)-77 \mathrm{a}^{1}$ & 402 & 525 & 9 & $\mathrm{CH}_{2} \mathrm{Cl}_{2}$ & +3.7 & 71 \\
$\left(P, \Lambda_{\mathrm{Ir}}\right)-(+)-77 \mathrm{a}^{2}$ & 403 & 526 & 13 & $\mathrm{CH}_{2} \mathrm{Cl}_{2}$ & +1.5 & 71 \\
$\left(\Delta_{\mathrm{lr}}\right)-(+)-78$ & 390 & 498 & 29 & $\mathrm{CH}_{2} \mathrm{Cl}_{2}$ & +0.9 & 71 \\
$\left(\Delta_{\mathrm{lr}}\right)-(+)-79$ & 394 & 510 & 5 & $\mathrm{CH}_{2} \mathrm{Cl}_{2}$ & +3.1 & 72 \\
\hline
\end{tabular}

${ }^{a}$ Lowest energy UV-vis band.

\section{Applications in optoelectronics}

There is an obvious interest to develop the use of helicenes and helicenoids as chiral molecular materials in chiral OLEDs, in chiral sensors, in chiral bioimaging agents, chiroptical switching activity, ${ }^{73,74}$ applications that directly take benefit from circularly polarized emission. For instance, there is a strong potential of CP light technologies in the development of OLEDs in which the electroluminescence is directly circularly polarized thus giving CPOLEDs. Indeed, antiglare filters commonly used for OLED displays exploit the physics of CP light to eliminate glare from external light sources (for example the sunlight). Unfortunately, this technology removes approximately $50 \%$ of the non polarized light emitted from the OLED pixels. If the non polarized OLEDs are replaced with CP-OLEDs (with a comparable device performance), an improved amount of CP light component of the correct handedness would pass through the antiglare filter with less loss, thus increasing the energy efficiency of the display in proportion to the increasing dissymmetry of the light. In addition, the use of CP-OLED will enable to simplify the architecture of the device by avoiding the use of extra filter components, which will directly impact the overall cost of the device.

In 2013, Fuchter, Campbell and coworkers, reported the use of 1-aza[6]helicene 9 as a chiral dopant in light-emitting polymer, i.e. poly[9,9-dioctylfluorene-co-benzothiadiazole] 80 (Fig. 31a). ${ }^{19}$ It was found that blends consisting of a small amount (7\%) of enantiopure 1aza[6]helicene dopant gave a strong CP-photoluminescence response of the $\mathbf{8 0}$ films. Increasing the 1-aza[6]helicene blending ratio resulted in improvements of the $g_{\text {PL factor, up to a sig- }}$ nificantly high value of 0.5 for the $53 \%$ helicene blend (while the starting azahelicene displayed only modest $g_{\text {lum }} \sim 10^{-4}-10^{-3}$ ). To explain this behavior, the authors suggested the formation of a chiroptical co-crystalline phase. The authors were then able to fabricate a single-layer polymer LED (PLED) device emitting circularly polarized light from the $\mathbf{8 0}$ blends containing $7 \%$ of either (-)-1-aza[6]helicene or (+)-1-aza[6]helicene with a dissymmetry factor of electroluminescence $\left(g_{\mathrm{EL}}\right)$ factor as high as 0.2. In 2016, Fuchter and Campbell succeeded in preparing a single layer CP-phosphorescent OLEDs (CP-PHOLEDs), using 66a as a chiral emissive dopant; these PHOLEDs displayed strong circularly polarized electrophosphorescence (CPEL), with $g_{\text {EL }}$ reaching -0.38 and +0.22 at $615 \mathrm{~nm}$ for (-)- and (+)-66a, respec- 
tively (see Fig. 31b). ${ }^{75}$ Although not yet clearly demonstrated, the increase of $g_{\text {EL }}$ as compared to the molecular $g_{\text {lum }}$ value $\left(10^{-2}\right)$ may be explained by a supramolecular organization of $\mathbf{6 6 a}$ in the solid state. Recently, by decorating the pyridyl-helicene ligands with $-\mathrm{CF}_{3}$ and $-\mathrm{F}$ groups, ${ }^{65}$ the platinahelicene enantiomers $\mathbf{6 6}$ e featured good configurational stability, as well as high sublimation yield ( $>90 \%$ ) and clear circularly polarized phosphorescence, with dissymmetry factors $\left(\left|g_{\mathrm{PL}}\right|\right)$ of approximately $3.7 \times 10^{-3}$ in solution and about $4.1 \times 10^{-3}$ in doped films. The CP-PHOLEDs with two enantiomers as emitters exhibited symmetric CPEL signals with $\left|g_{\mathrm{EL}}\right|$ of (1.1-1.6) $\times 10^{-3}$ and good device performances, achieving a maximum brightness of $11590 \mathrm{~cd} \mathrm{~m}^{-2}$, a maximum external quantum efficiency up to $18.81 \%$, which are the highest values among the reported devices based on chiral phosphorescent $\mathrm{Pt}^{\mathrm{II}}$ complexes. To suppress the effect of reverse CPEL signal from the cathode reflection, the further implementation of semi-transparent aluminum/silver cathode successfully boosted up the $\left|g_{\mathrm{EL}}\right|$ by over three times to $5.1 \times 10^{-3}$.

a)<smiles></smiles>

$(P)-9$

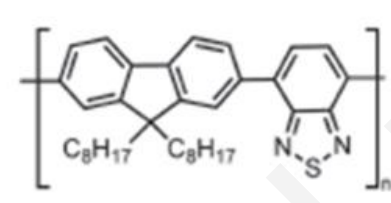

poly[9,9-dioctylfuorene-cobenzothiadiazole] (F8BT) b)

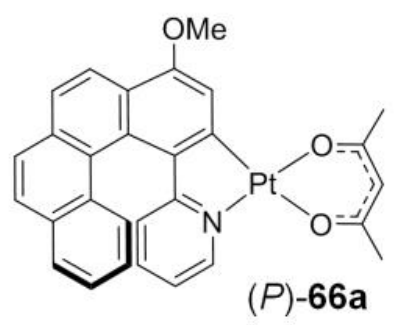

80
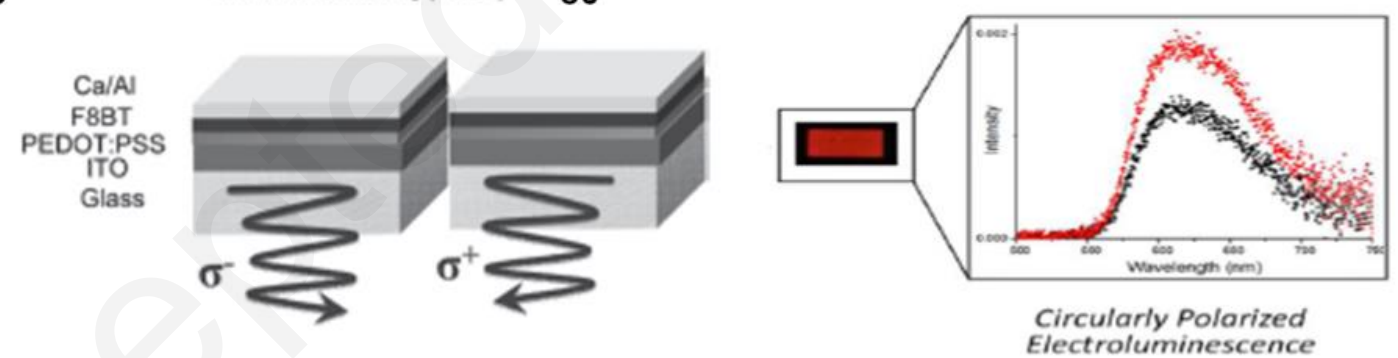

Fig. 31. a) CP-PLED based on blends between enantiopure 9 and 80 . Adapted with permission. ${ }^{19}$ Copyright 2013 , Wiley. b) CPPHOLED based on pure enantiopure cycloplatinahelicene 66a. Adapted with permission. ${ }^{75}$ Copyright 2016, American Chemical Society.

\section{Conclusion}

Since the first examples of helicenes displaying circularly polarized luminescence described in the literature, ${ }^{13,37}$ there has been a growing interest in CPL-active helicenes and helicenoids and the number of reported examples is growing very fast. This is concomitant to the development of helicenes chemistry and the creation of structural diversity of helical structures, either fully carbonated or containing main-group elements, and to the development of CPL instrumentations and CPL technology. However, a much higher degree of circular po- 
larization is still highly desirable for applications, for example in chiroptical devices. For this purpose, future work will be probably dedicated to the development of supramolecular architectures, sophisticated homogeneous/heterogeneous mixtures, Aggregation Induced Emission (AIE) materials, or chiral TADF systems, to obtain good CPL properties together with overall good quantum yield of photoluminescence. In these domains, there is still plenty of room for fundamental discoveries and for further applications. Finally, although not detailed in the present chapter, theoretical calculations of CPL activity may be of great help to anticipate highly efficient CPL-active systems. In this context, CPL-active helicenes are good models for testing and improving theoretical tools.

\section{Acknowledgements}

I thank the Ministère de l'Education Nationale, de la Recherche et de la Technologie, the Centre National de la Recherche Scientifique (CNRS), and the French National Agency (HEL-NHC, ANR-16-CE07-0019-01-HEL-NHC and HELPHOS, ANR-15-CE29-0012-03).

\section{References}

${ }^{1}$ Dekkers H P J M (2000) Circularly Polarized Luminescence: A Probe For Chirality in The Excited State. In: Berova N, Nakanishi K, Woody R W, editors. Circular dichroism: principles and applications. New York: Wiley-VCH; pp. 185-215.

${ }^{2}$ Riehl J P, Muller G (2012) Circularly polarized luminescence spectroscopy and emission-detected circular dichroism. In: Berova N, Polavarapu P L, Nakanishi K, Woody R W, editors. Comprehensive chiroptical spectroscopy. Vol. 1. Hoboken, NJ: Wiley.

${ }^{3}$ Maeda H, Bando Y (2013) Recent Progress in Research on Stimuli Responsive Circularly Polarized Luminescence Based On $\pi$ Conjugated Molecules. Pure Appl Chem 85: 1967-1978.

${ }^{4}$ Kumar J, Nakashima T, Kawai (2015) Circularly Polarized Luminescence in Chiral Molecules ad Supramolecular Assemblies. J Phys Chem Lett 6: 3445-3452.

${ }^{5}$ Sánchez-Carnerero E M, Agarrabeitia A R, Moreno F, Maroto B L, Muller G, Ortiz M J, de la Moya, S (2015) Circularly Polarized Luminescence from Simple Organic Molecules. Chem Eur J 21: 13488-13500.

${ }^{6}$ Chen N, Yan B (2018) Recent Theoretical and Experimental Progress in Molecules Circularly Polarized Luminescence of Small Organic Molecules, Molecules 23: 3376.

${ }^{7}$ Shen Y, Chen C -F (2012) Helicenes: Synthesis and Applications. Chem Rev 112: 1463-1535.

${ }^{8}$ Chen C -F, Shen Y (2017) Helicene Chemistry: From Synthesis to Applications; Springer Berlin Heidelberg: Berlin, Heidelberg.

${ }^{9}$ Gingras M (2012) One Hundred Years of Helicene Chemistry. Part 3: Applications And Properties Of Carbohelicenes, Chem Soc Rev 42: 1051-1095.

${ }^{10}$ Newman M S, Lednicer D (1956) The Synthesis and Resolution of Hexahelicene. J Am Chem Soc 78: 4765-4770.

${ }^{11}$ Zinna F, Di Bari L (2015) Lanthanide Circularly Polarized Luminescence: Bases and Applications. Chirality 27:1-13.

${ }^{12}$ Tanaka H, Inoue Y, Mori T (2018) Circularly Polarized Luminescence and Circular Dichroisms in Small Organic Molecules: Correlation Between Excitation and Emission Dissymmetry Factors. ChemPhotoChem 2: 386-402.

${ }^{13}$ Field J E, Muller G, Riehl J P, Venkataraman D (2003) Circularly Polarized Luminescence from Bridged Triarylamine Helicenes. J Am Chem Soc 125: 11808-11809.

${ }^{14}$ Longhi G, Castiglioni E, Villani C, Sabia R, Menichetti S, Viglianisi C, Devlin F, Abbate S (2016) Chiroptical Properties of The Ground and Excited States of Two Thia-Bridged Triarylamine Heterohelicenes. J Photochem. Photobiol A 331: 138-145.

${ }^{15}$ Nishimura H, Tanaka K, Morisaki Y, Chujo Y, Wakamiya A, Murata Y (2017) Oxygen-Bridged Diphenylnaphthylamine as a Scaffold for Full-Color Circularly Polarized Luminescent Materials. J Org Chem 82: 5242-5249.

${ }^{16}$ Abbate S, Longhi G, Lebon F, Castiglioni E, Superchi S, Pisani L, Fontana F, Torricelli F, Caronna T, Villani C, Sabia R, Tommasini M, Lucotti A, Mendola D, Mele A, Lightner D A (2014) Helical Sense-Responsive and Substituent-Sensitive Features in Vibrational and Electronic Circular Dichroism, in Circularly Polarized Luminescence, and in Raman Spectra of Some Simple Optically Active Hexahelicenes. J Phys Chem C 118: 1682-1695. 
${ }^{17}$ Nakai Y, Mori T, Sato K, Inoue Y (2013) Theoretical and Experimental Studies of Circular Dichroism of Mono and Diazonia[6]helicenes. J Phys Chem A 117: 5082-5092.

18 Liu Y, Cerezo J, Mazzeo G, Lin N, Zhao X, Longhi G, Abbate S, Santoro F (2016) Vibronic Coupling Explains the Different Shape of Electronic Circular Dichroism and of Circularly Polarized Luminescence Spectra of Hexahelicenes. J Chem Theory Comput 12: 2799-2819.

${ }^{19}$ Yang Y, da Costa R C, Smilgies D -M, Campbell A J, Fuchter M J (2013) Induction of Circularly Polarized Electroluminescence from an Achiral Light-Emitting Polymer via a Chiral Small-Molecule Dopant. Adv Mater 25: 2624-2628.

${ }^{20}$ Nakamura K, Furumi S, Takeuchi M, Shibuya T, Tanaka K (2014) Enantioselective Synthesis and Enhanced Circularly Polarized Luminescence of S-Shaped Double Azahelicenes. J Am Chem Soc 136: 5555-5558.

${ }^{21}$ Tanaka M, Shibata Y, Nakamura K, Teraoka K, Uekusa H, Nakazono K, Takata T, Tanaka K (2016) Gold- Catalyzed Enantioselective Synthesis, Crystal Structure, and Photophysical/Chiroptical Properties of Aza[10]helicenes, Chem Eur J 22: 9537-9541.

${ }^{22}$ Tanaka H, Ikenosako M, Kato Y, Fujiki M, Inoue Y, Mori T (2018) Symmetry-Based Rational Design for Boosting Chiroptical Responses, Commun. Chem. 1: 38.

${ }^{23}$ Otani T, Tsuyuki A, Iwachi T, Someya S, Tateno K, Kawai H, Saito T, Kanyiva K S, Shibata T (2017) Facile Two-Step Synthesis of 1,10-Phenanthroline-Derived Polyaza[7]helicenes with High Fluorescence and CPL Efficiency. Angew Chem Int Ed 56, 3906-3910.

${ }^{24}$ Goto K, Yamaguchi R, Hiroto S, Ueno H, Kawai T, Shinokubo H (2012) Intermolecular Oxidative Annulation of 2-Aminoanthracenes to Diazaacenes and Aza[7]helicenes. Angew Chem Int Ed 51: 10333-10336.

${ }^{25}$ Ushiyama A, Hiroto S, Yuasa J, Kawai T, Shinokubo H (2017) Synthesis of A Figure-Eight Azahelicene Dimer with High Emission and CPL Properties. Org Chem Front 4: 664-667.

${ }^{26}$ Sakai H, Kubota T, Yuasa J, Araki Y, Sakanoue T, Takenobu T, Wada T, Kawai T, Hasobe, T (2016) Synthetic Control of Photophysical Process and Circularly Polarized Luminescence of [5]Carbohelicene Derivatives Substituted by Maleimide Units. J. Phys. Chem. C 120: 7860-7869.

${ }^{27}$ Sakai H, Kubota T, Yuasa J, Araki Y, Sakanoue T, Takenobu T, Wada T, Kawai T, Hasobe T (2016) Protonation-Induced RedColoured Circularly Polarized Luminescence of [5]Carbohelicene Fused By Benzimidazole. Org Biomol Chem 14: 6738-6743.

${ }^{28}$ Li M, Lu H -Y, Zhang C, Shi L, Tang Z, Chen C -F (2016) Helical Aromatic Imide Based Enantiomers With Full Color Circularly Polarized Luminescence Chem. Comm. 52: 9921-9924.

${ }_{29}$ Pascal S, Besnard C, Zinna F, Di Bari L, Le Guennic B, Jacquemin D, Lacour J (2016) Zwitterionic [4]Helicene: A Water-Soluble and Reversible PH-Triggered ECD/CPL Chiroptical Switch in the UV and Red Spectral Regions. Org Biomol Chem 14: 4590-4594.

${ }^{30}$ Bosson J, Labrador G M, Pascal S, Miannay F A, Yushchenko O, Li H, Bouffier L, Sojic N, Tovar R C, Muller G, Jacquemin D, Laurent A D, Le Guennic B, Vauthey E, Lacour J (2016) Physicochemical and Electronic Properties of Cationic [6] Helicenes: from Chemical and Electrochemical Stabilities to Far-Red (Polarized) Luminescence. Chem Eur J 22: 18394-18403.

${ }^{31}$ Delgado I H, Pascal S, Wallabregue A, Duwald R, Besnard C, Guenee L, Nancoz C, Vauthey E, Tovar R C, Lunkley J L, Muller G, Lacour J (2016) Functionalized Cationic [4]Helicenes with Unique Tuning of Absorption, Fluorescence and Chiroptical Properties up to the Far-Red Range. Chem Sci 7: 4685-4693.

32 Kaseyama T, Furumi S, Zhang X, Tanaka K, Takeuchi M (2011) Hierarchical Assembly of a Phthalhydrazide-Functionalized Helicene. Angew Chem Int Ed 50: 3684-3687.

33 Yamano R, Hara J, Murayama K, Sugiyama H, Teraoka K, Uekusa H, Kawauchi S, Shibata Y, Tanaka K (2017) Rh-Mediated Enantioselective Synthesis, Crystal Structures, and Photophysical/Chiroptical Properties of Phenanthrenol-Based[9]Helicene-like Molecules. Org Lett 19: 42-45.

${ }^{34}$ Matsuno T, Koyama Y, Hiroto S, Kumar J, Kawai T, Shinokubo H (2015) Chem Commun 51: 4607-4610.

${ }^{35}$ Gupta R, Cabreros T A, Muller G, Bedekar A V (2018) Enantiomerically Pure 5,13-Dicyano-9-oxa[7]helicene: Synthesis and Study. Eur J Org Chem 5397-5405.

${ }^{36}$ Sundar M S, Talele H R, Mande H M, Bedekar A V, Tovar R C, Muller G (2014) Synthesis of Enantiomerically Pure Helicene Like Bis-Oxazines from Atropisomeric 7,7'-Dihydroxy BINOL: Preliminary Measurements of the Circularly Polarized Luminescence. Tetrahedron Letters 55: 1760-1764.

${ }^{37}$ Phillips K E S, Katz T J, Jockusch S, Lovinger A J, Turro N J (2001) Synthesis and Properties of an Aggregating Heterocyclic Helicene. J Am Chem Soc 123: 11899-11907.

${ }^{38}$ Riehl J P, Richardson F S (1986) Circularly Polarized Luminescence Spectroscopy. Chem Rev 86:1-16.

${ }^{39}$ Yamamoto Y, Sakai H, Yuasa J, Araki Y, Wada T, Sakanoue T, Takenobu T, Kawai T, Hasobe T (2016) Controlled Excited-State Dynamics and Enhanced Fluorescence Property of Tetrasulfone[9] helicene by a Simple Synthetic Process. J Phys Chem C 120: 7421-7427.

${ }^{40}$ Yamamoto Y, Sakai H, Yuasa J, Araki Y, Wada T, Sakanoue T, Takenobu T, Kawai T, Hasobe T (2016) Synthetic Control of the Excited-State Dynamics and Circularly Polarized Luminescence of Fluorescent "Push-Pull" Tetrathia[9] helicenes. Chem Eur J 22: 4263-4273.

${ }^{41}$ Biet T, Cauchy T, Sun Q, Ding J, Hauser A, Oulevey P, Bürgi T, Jacquemin D, Vanthuyne N, Crassous J, Avarvari N (2017) Luminescent Helicene-Dithiolene Platinum Diimine Complexes. Chem Comm 53: 9210-9213. 
${ }^{42}$ Shen C, Srebro-Hooper M, Jean, M, Vanthuyne N, Toupet L, Williams J A G, Torres A R, Riives A J, Muller G, Autschbach J, Crassous J (2017) Synthesis and Chiroptical Properties of Hexa-, Octa-, and Decaazaborahelicenes: Influence of Helicene Size and of the Number of Boron Atoms. Chem Eur J 23: 407-418.

${ }^{43}$ Dominguez Z, Lopez-Rodriguez R, Alvarez E, Abbate S, Longhi G, Pischel U, Ros A (2018) Azabora[5]helicene Charge-Transfer Dyes Show Efficient and Spectrally Variable Circularly Polarized Luminescence. Chem Eur J 24: 12660-12668.

${ }^{44}$ Katayama T, Nakatsuka S, Hirai H, Yasuda N, Kumar J, Kawai T, Hatakeyama T (2016) Two-Step Synthesis of Boron-Fused Double Helicenes. J Am Chem Soc 138: 5210-5213.

${ }^{45}$ Miyamoto F, Nakatsuka S, Yamada K, Nakayama K, Hatakeyama T (2015) Synthesis of Boron-Doped Polycyclic Aromatic Hydrocarbons by Tandem Intramolecular Electrophilic Arene Borylation. Org Lett 17: 6158-6161.

${ }^{46}$ Hatakeyama T, Shiren K, Nakajima K, Nomura S, Nakatsuka S, Kinoshita K, Ni J, Ono Y, Ikuta T (2016) Ultrapure Blue Thermally Activated Delayed Fluorescence Molecules: Efficient HOMO-LUMO Separation by the Multiple Resonance Effect. Adv Mater 28: 2777-2781.

${ }^{47}$ Oyama H, Nakano K, Harada T, Kuroda R, Naito M, Nobusawa K, Nozaki K (2013) Facile Synthetic Route to Highly Luminescent Sila[7]helicene, Org Lett 15: 2104-2107.

${ }^{48}$ Murayama K, Oike Y, Furumi S, Takeuchi M, Noguchi K, Tanaka K (2015) Enantioselective Synthesis, Crystal Structure, and Photophysical Properties of a 1,1'-Bitriphenylene-Based Sila[7]helicene. Eur J Org Chem: 1409-1414.

${ }^{49}$ Duffy M P, Delaunay W, Bouit P -A, Hissler M (2016) $\pi$-Conjugated Phospholes and their Incorporation Into Devices: Components with a Great Deal of Potential. Chem Soc Rev 45: 5296-5310.

${ }^{50}$ Yavari K, Delaunay W, De Rycke N, Reynaldo T, Aillard P, Srebro-Hooper M, Chang V Y, Muller G, Tondelier D, Geffroy B, Voituriez A, Marinetti A, Hissler M, Crassous J (2019) Phosphahelicenes: from Chiroptical and Photophysical Properties to OLED Applications. Chem Eur J 25: 5303-5310.

${ }^{51}$ Nishigaki S, Murayama K, Shibata Y, Tanaka K (2018) Rhodium-Mediated Enantioselective Synthesis of a Benzopicene-Based Phospha[9]Helicene: The Structure-Property Relationship of Triphenylene- and Benzopicene-Based Carbo- and Phosphahelicenes. Mater Chem Front 2: 585-590.

52 Tanaka H, Kato Y, Fujiki M, Inoue Y, Mori T (2018) Combined Experimental and Theoretical Study on Circular Dichroism and Circularly Polarized Luminescence of Configurationally Robust $D_{3}$-Symmetric Triple Pentahelicene. J Phys Chem A 122: 7378-7384.

${ }^{53}$ He D - Q, Lu H -Y, Li M, Chen C -F (2017) Intense Blue Circularly Polarized Luminescence From Helical Aromatic Esters. Chem Comm 53: 6093-6096.

${ }^{54}$ Fang L, Li M, Lin W -B, Chen C -F (2018) Enantiopure (P)-And (M)-3,14-Bis(O-Hydroxyaryl)Tetrahydrobenzo[5]Helicenediols and their Helicene Analogues: Synthesis, Amplified Circularly Polarized Luminescence and Catalytic Activity in Asymmetric HeteroDiels-Alder Reactions. Tetrahedron 74: 7164-7172.

55 Fang L., Li M., Lin W.-B., Shen Y., Chen C.-F. (2019) One-Pot Oxidative Aromatization and Dearomatization of Tetrahydro[5]helicene Diols: Synthesis, Structure, Photophysical and Chiroptical Properties of Chiral $\pi$-Extended Diones. Asian J OrgChem doi:10.1002/ajoc.201800541.

${ }^{56}$ Dhbaibi K, Favereau L, Srebro-Hooper M, Jean M, Vanthuyne N, Zinna F, Jamoussi B, Di Bari L, Autschbach J, Crassous J (2018) Exciton Coupling in Diketopyrrolopyrrole-Helicene Derivatives Leads to Red And Near-Infrared Circularly Polarized Luminescence. Chem Sci 9: 735-742.

${ }^{57}$ Satoh M, Shibata Y, Tanaka K (2018) Enantioselective Synthesis of Fully Benzenoid Single and Double Carbohelicenes via GoldCatalyzed Intramolecular Hydroarylation, Chem Eur J 24: 5434-5438.

${ }^{58}$ Sawada Y, Furumi S, Takai A, Takeuchi M, Noguchi K, Tanaka K (2012) Rhodium-Catalyzed Enantioselective Synthesis, Crystal Structures, and Photophysical Properties of Helically Chiral 1,1-Bitriphenylenes. J Am Chem Soc 134: 4080-4083.

${ }^{59}$ Oyama H, Akiyama M, Nakano K, Naito M, Nobusawa K, Nozaki K (2016) Synthesis and Properties of [7]Helicene-like Compounds Fused with a Fluorene Unit. Org Lett 18: 3654-3657.

${ }^{60}$ Sakai H, Shinto S, Kumar J, Araki Y, Sakanoue T, Takenobu T, Wada T, Kawai T, Hasobe T (2015) Highly Fluorescent [7]Carbohelicene Fused by Asymmetric 1,2-Dialkyl-Substituted Quinoxaline for Circularly Polarized Luminescence and Electroluminescence J Phys Chem C 119: 13937-13947.

${ }^{61}$ Saleh N, Shen C, Crassous J (2014) Helicene-Based Transition Metal Complexes: Synthesis, Properties and Applications. Chem Sci 5: 3680-3694.

${ }^{62}$ Ou-Yang J -K, Crassous J (2018) Chiral Multifunctional Molecules Based on Organometallic Helicenes: Recent Advances Coord Chem Rev 376: 533-547.

${ }^{63}$ Norel L, Rudolph M, Vanthuyne N, Williams J A G, Lescop C, Roussel C, Autschbach J, Crassous J, Réau R (2010) Metallahelicenes: Easily Accessible Helicene Derivatives with Large and Tunable Chiroptical Properties. Angew Chem Int Ed 49: 99-102.

${ }^{64}$ Shen C, Anger E, Srebro M, Vanthuyne N, Deol K K, Jefferson T D, Muller G, Williams J A G, Toupet L, Roussel C, Autschbach J, Réau R, Crassous J (2014) Straightforward Access to Mono- and Bis- Cycloplatinated Helicenes Displaying Circularly Polarized Phosphorescence by Using Crystallization Resolution Methods, Chem Sci 5: 1915-1927.

${ }^{65}$ Yan Z -P, Luo X -F, Liu W -Q, Wu Z -G, Liang X, Liao K, Wang Y, Zheng Y - X, Zhou L, Zuo J -L, Pan Y, Zhang H (2019) Configurationally Stable Platinahelicene Enantiomers for Efficient Circularly Polarized Phosphorescent Organic Light-Emitting Diodes. Chem Eur J 25: 5672-5676. 
${ }^{66}$ Saleh N, Moore B, Srebro M, Vanthuyne N, Toupet L, Williams J A G, Roussel C, Deol K K, Muller G, Autschbach J, Crassous J (2015) Acid/Base-Triggered Switching of Circularly Polarized Luminescence and Electronic Circular Dichroism in Organic and Organometallic Helicenes. Chem Eur J 21: 1673-1681.

${ }^{67}$ Saleh N, Srebro M, Reynaldo T, Vanthuyne N, Toupet L, Chang V Y, Muller G, Williams J A G, Roussel C, Autschbach J, Crassous J (2015) Enantio-Enriched CPL-Active Helicene-Bipyridine-Rhenium Complexes. Chem Comm 51: 3754-3757.

68 Isla H, Srebro-Hooper M, Jean M, Vanthuyne N, Roisnel T, Lunkley J L, Muller G, Williams J A G, Autschbach J, Crassous J (2016) Conformational Changes and Chiroptical Switching of Enantiopure Bis-Helicenic Terpyridine Upon $\mathrm{Zn}^{2+}$ Binding. Chem Comm 52: 5932-5935.

${ }^{69}$ Isla H, Saleh N, Ou-Yang J -K, Dhbaibi K, Jean M, Dziurka M, Favereau L, Vanthuyne N, Toupet L, Jamoussi B, Srebro-Hooper M, Crassous J (2019) Bis-4-aza[6] helicene: a bis-helicenic 2,2'-bipyridine with chemically-triggered chiroptical switching activity. J Org Chem 84: 5383-5393.

70 Lee J., Chen H.-F., Batagoda T., Coburn C., Djurovich P. I., Thompson M. E., Forrest, S. R. (2016) Deep Blue Phosphorescent Organic Light-Emitting Diodes with Very High Brightness and Efficiency. Nat Mater 15: 92-98.

${ }^{71}$ Hellou N, Srebro-Hooper M, Favereau L, Zinna F, Caytan E, Toupet L, Dorcet V, Jean M, Vanthuyne N, Williams J A G, Di Bari L, Autschbach J, Crassous J (2017) Enantiopure Cycloiridiated Complexes Bearing a Pentahelicenic N-Heterocyclic Carbene and Displaying Long-Lived Circularly-Polarized Phosphorescence. Angew Chem Int Ed 56: 8236-8239.

72 Macé A, Hellou N, Hammoud J, Martin C, Gauthier E S, Favereau L, Roisnel T, Caytan E, Nasser G, Vanthuyne N, Williams J A G, Berrée F, Carboni B, Crassous J (2019) An Enantiopure Cyclometallated Iridium Complex Displaying Long-Lived Phosphorescence Both in Solution and in The Solid State. Helv Chim Acta 102: e1900044.

${ }_{73}$ Isla H, Crassous J (2016)Helicene-Based Chiroptical Switches, C R Chimie 19: 39-49.

${ }^{74}$ Brandt J R, Salerno F, Fuchter M J (2017) The Added Value of Small-Molecule Chirality in Technological Applications. Nature Rev Chem 1: 0045.

${ }^{75}$ Brandt J R, Wang X, Yang Y, Campbell A J, Fuchter M J (2016) Circularly Polarized Phosphorescent Electroluminescence with a High Dissymmetry Factor from PHOLEDs Based on a Platinahelicene. J Am Chem Soc 138: 9743-9746. 